NATIONAL LABORATORY

MANAGED BY UT-BATTELLE

FOR THE DEPARTMENT OF ENERGY

\title{
Criticality Safety Validation of SCALE 6.1
}

\author{
November 2011 \\ January 2013 (revised)
}

\author{
Prepared by \\ W. J. Marshall \\ B. T. Rearden
}

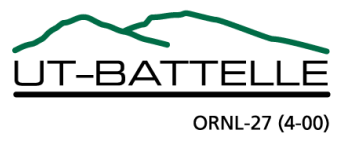




\section{DOCUMENT AVAILABILITY}

Reports produced after January 1, 1996, are generally available free via the U.S. Department of Energy (DOE) Information Bridge.

Web site http://www.osti.gov/bridge

Reports produced before January 1, 1996, may be purchased by members of the public from the following source.

National Technical Information Service

5285 Port Royal Road

Springfield, VA 22161

Telephone 703-605-6000 (1-800-553-6847)

TDD 703-487-4639

Fax 703-605-6900

E-mail info@ntis.gov

Web site http://www.ntis.gov/support/ordernowabout.htm

Reports are available to DOE employees, DOE contractors, Energy Technology Data Exchange (ETDE) representatives, and International Nuclear Information System (INIS) representatives from the following source.

Office of Scientific and Technical Information

P.O. Box 62

Oak Ridge, TN 37831

Telephone 865-576-8401

Fax 865-576-5728

E-mail reports@osti.gov

Web site http://www.osti.gov/contact.html

This report was prepared as an account of work sponsored by an agency of the United States Government. Neither the United States Government nor any agency thereof, nor any of their employees, makes any warranty, express or implied, or assumes any legal liability or responsibility for the accuracy, completeness, or usefulness of any information, apparatus, product, or process disclosed, or represents that its use would not infringe privately owned rights. Reference herein to any specific commercial product, process, or service by trade name, trademark, manufacturer, or otherwise, does not necessarily constitute or imply its endorsement, recommendation, or favoring by the United States Government or any agency thereof. The views and opinions of authors expressed herein do not necessarily state or reflect those of the United States Government or any agency thereof. 
Reactor and Nuclear Systems Division

\title{
Criticality Safety Validation of SCALE 6.1
}

\author{
W. J. Marshall and B. T. Rearden
}

Date Published: November 2011

January 2013 (revised)

\author{
Prepared by \\ OAK RIDGE NATIONAL LABORATORY \\ P.O. Box 2008 \\ Oak Ridge, Tennessee 37831-6285 \\ managed by \\ UT-BATTELLE, LLC \\ for the \\ U.S. DEPARTMENT OF ENERGY \\ under contract DE-AC05-00OR22725
}





\section{CONTENTS}

\begin{tabular}{|c|c|c|}
\hline & & Page \\
\hline LIST OF & FIGUI & \\
\hline IST C & 1 ADD & \\
\hline ACRON & YMS. & \\
\hline ACKNO & WLEDG & MENTS . \\
\hline ABSTR & ACT. & .xiii \\
\hline 1. INTI & RODUC & CION... \\
\hline 2. BEN & TCHMAF & K EXPERIMENTS \\
\hline 3. $\mathrm{COD}$ & ES, DA & ГA, AND METHODS.. \\
\hline 3.1 & Codes.. & 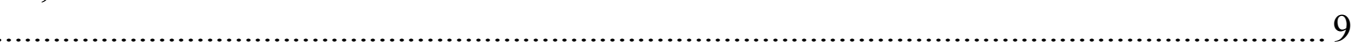 \\
\hline & 3.1 .1 & 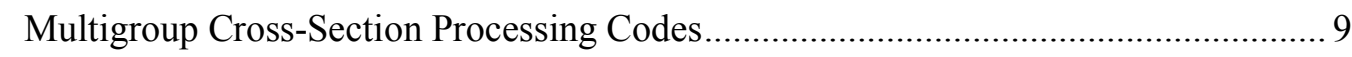 \\
\hline & 3.1 .2 & KENO V.a._. \\
\hline & 3.1 .3 & KENO-VI........... \\
\hline & 3.1 .4 & TSUNAMI-3D ... \\
\hline 3.2 & Nuclear & Data........................ \\
\hline & 3.2 .1 & 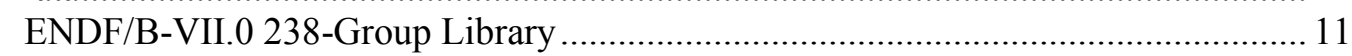 \\
\hline & 3.2 .2 & 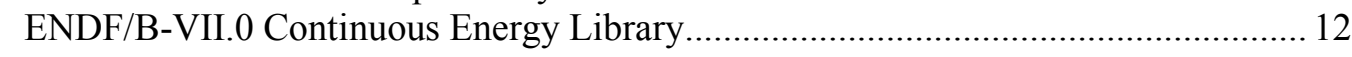 \\
\hline & 3.2 .3 & 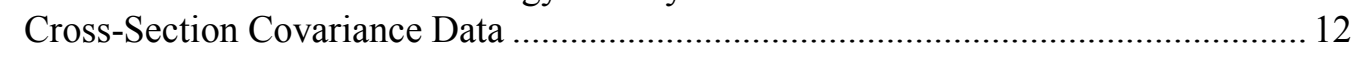 \\
\hline 3.3 & Valid L & 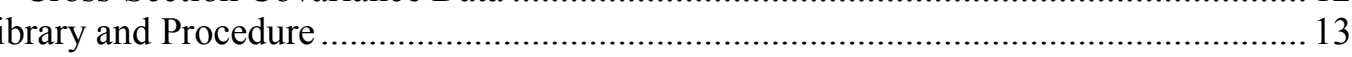 \\
\hline 3.4 & Validat & on Methods .................... \\
\hline 4. RES & ULTS... & 17 \\
\hline 4.1 & KENO & V.a... \\
\hline & 4.1 .1 & HMF Systems..... \\
\hline & 4.1 .2 & HST Systems....... \\
\hline & 4.1 .3 & IMF Systems ................... \\
\hline & 4.1.4 & LCT Systems.................. \\
\hline & 4.1 .5 & LST Systems ............. \\
\hline & 4.1 .6 & 27 \\
\hline & 4.1 .7 & PMF Systems .................. \\
\hline & 4.1.8 & PST Systems ........ \\
\hline & 4.1 .9 & Pooled Results............ \\
\hline & 4.1 .10 & 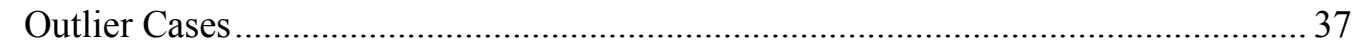 \\
\hline & 4.1 .11 & Normality Testing ............ \\
\hline 4.2 & KENO- & VI \\
\hline & 4.2 .1 & 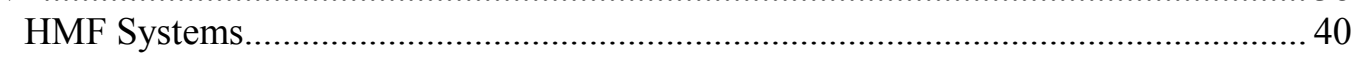 \\
\hline & 4.2 .2 & . \\
\hline & 4.2 .3 & 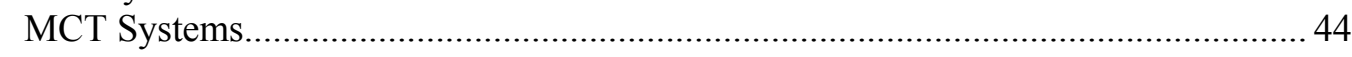 \\
\hline & 4.2 .4 & 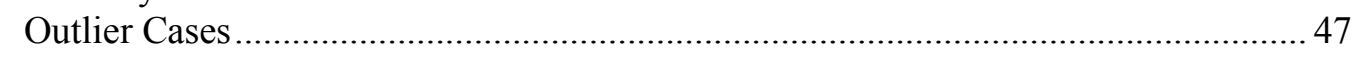 \\
\hline & 4.2 .5 & Normality Testing ............................... \\
\hline 5. SUN & IMARY & AND CONCLUSIONS ............................. \\
\hline 6. REC & OMMEI & JDATIONS FOR FUTURE WORK ............... \\
\hline 7. REF & ERENCI & $\mathrm{S}$ \\
\hline APPENL & SIX A : & DETAILED RESULTS FOR KENO V.a .. \\
\hline APPENL & IX B : & DETAILED RESULTS FOR KENO-VI.. \\
\hline
\end{tabular}





\section{LIST OF FIGURES}

Page

Fig. 1. Difference from unity of average C/E value by category for KENO V.a $\left(\Delta k_{e f f}\right) \ldots \ldots \ldots \ldots \ldots \ldots . . . . .18$

Fig. 2. Deviation from unity of average C/E value by category for KENO V.a................................ 19

Fig. 3. Detailed results for HMF systems, KENO V.a............................................................. 20

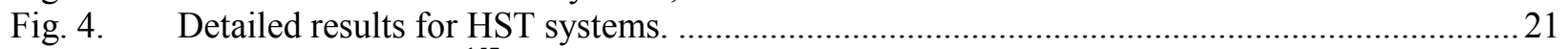

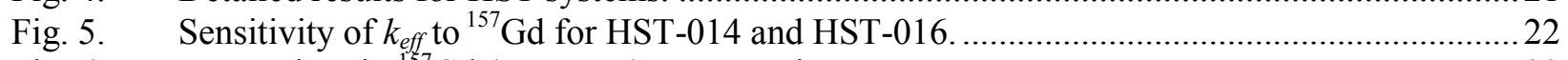

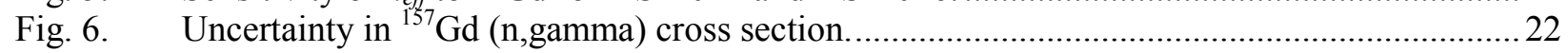

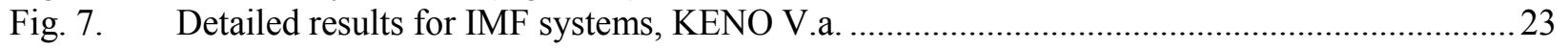

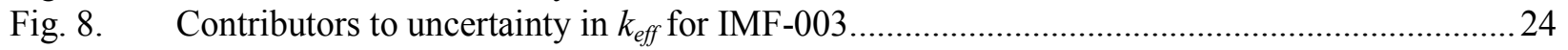

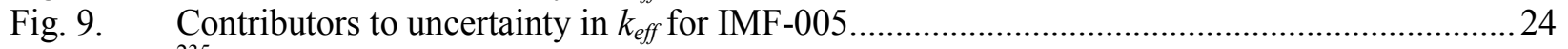

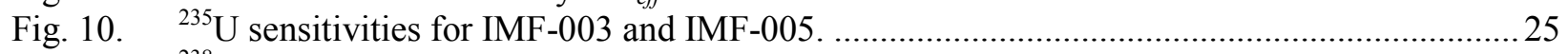

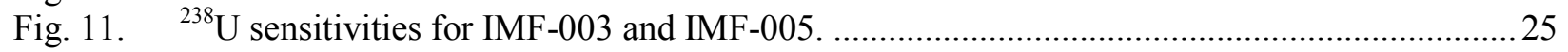

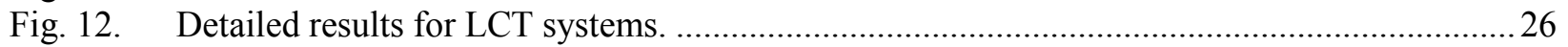

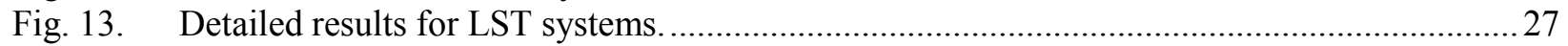

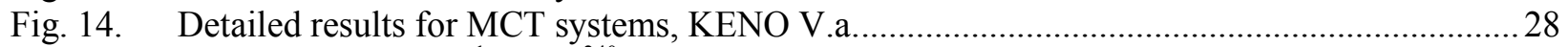

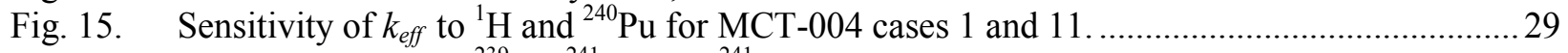

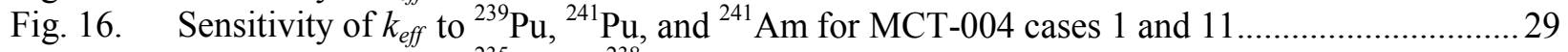

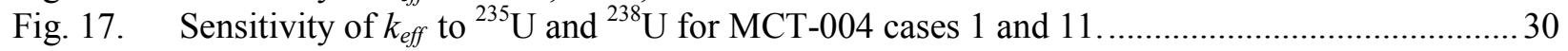

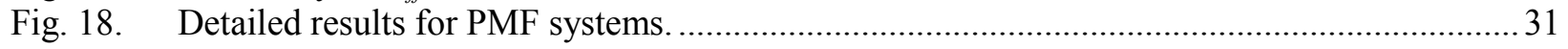

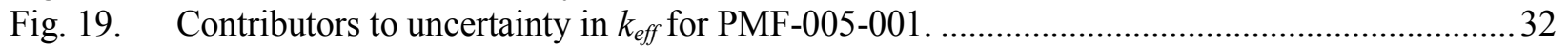

Fig. 20. Sensitivity of $k_{\text {eff }}$ to $\mathrm{W}$ elastic scattering cross sections for PMF-005-001........................... 32

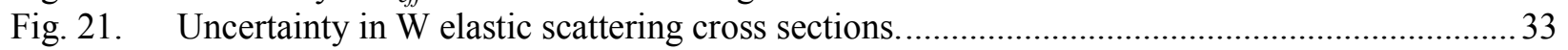

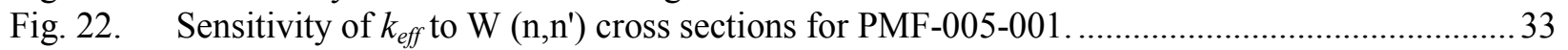

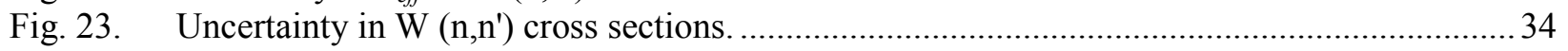

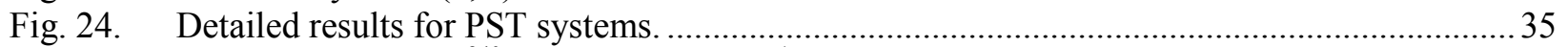

Fig. 25. Sensitivity of $k_{\text {eff }}$ to ${ }^{240} \mathrm{Pu}$ (n,gamma) and ${ }^{1} \mathrm{H}$ elastic scattering for PST-001 case 1 and

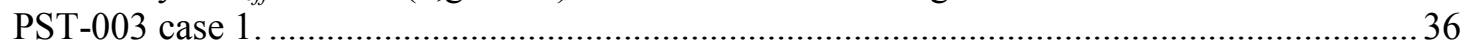

Fig. 26. Difference from unity of average C/E value by category for KENO-VI $\left(\Delta k_{\text {eff }}\right) \ldots \ldots \ldots \ldots \ldots \ldots \ldots . \ldots \ldots$

Fig. 27. Deviation from unity of average $\mathrm{C} / \mathrm{E}$ value by category for KENO-VI (standard

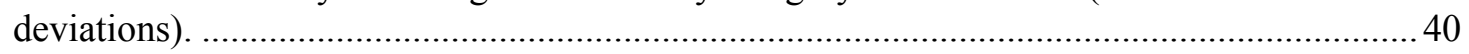

Fig. 28. Detailed results for HMF systems, KENO-VI.................................................................. 41

Fig. 29. Sensitivity of $k_{\text {eff }}$ to the bound cross section for beryllium for HMF-005 .......................... 41

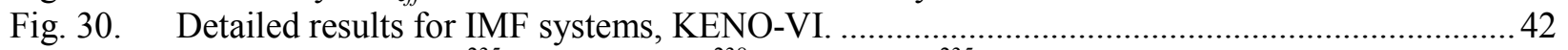

Fig. 31. Sensitivity of $k_{\text {eff }}$ to ${ }^{235} U$ (n,gamma), ${ }^{238} U$ (n,n'), and ${ }^{235} U$ fission cross sections for

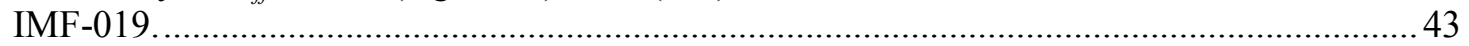

Fig. 32. Uncertainty i ${ }^{235} \mathrm{U}\left(\mathrm{n}\right.$,gamma) ${ }^{238} \mathrm{U}\left(\mathrm{n}, \mathrm{n}^{\prime}\right)$, and ${ }^{235} \mathrm{U}$ fission cross sections............................ 43

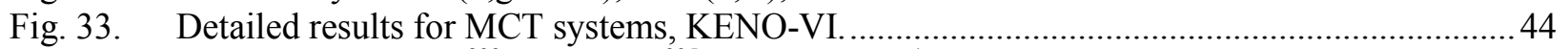

Fig. 34. Sensitivity of $k_{\text {eff }}$ to ${ }^{239} \mathrm{Pu}$ fission, ${ }^{235} \mathrm{U}$ fission, and ${ }^{1} \mathrm{H}$ total for MCT-008 Cases 8 and $12 \ldots \ldots .45$

Fig. 35. Sensitivity of $k_{\text {eff }}$ to ${ }^{177} \mathrm{Hf}$ and ${ }^{178} \mathrm{Hf}$ (n, gamma) for MCT-008 Cases 8 and 12.....................46

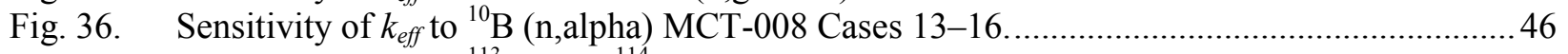

Fig. 37. Sensitivity of $k_{\text {eff }}$ to ${ }^{113} \mathrm{Cd}$ and ${ }^{114} \mathrm{Cd}$ (n,gamma) for MCT-008 Cases 17 and 28................... 47 



\section{LIST OF TABLES}

Page

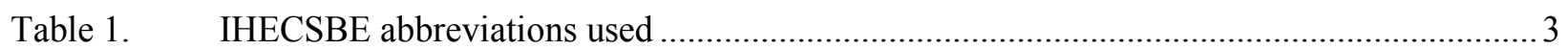

Table 2. Critical benchmark experiments available in VALID library .......................................... 4

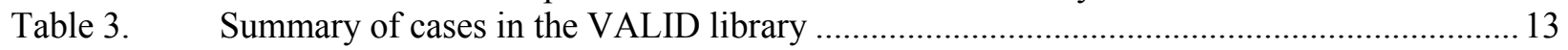

Table 4. Results by category for KENO V.a calculations........................................................ 17

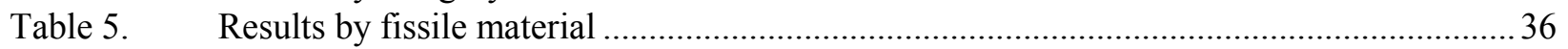

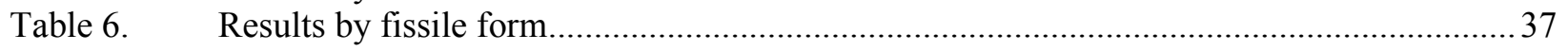

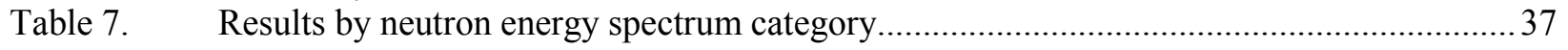

Table 8. Maximum individual case absolute differences for KENO V.a........................................37

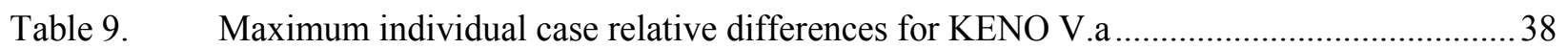

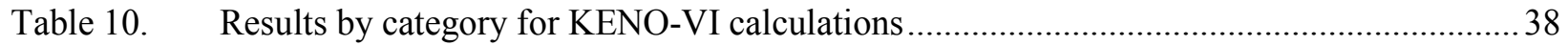

Table 11. Maximum individual case absolute differences for KENO-VI........................................47

Table 12. Maximum individual case relative differences for KENO-VI ......................................... 48

Table A.1. Detailed multigroup results for KENO V.a HMF systems …........................................

Table A.2. Detailed continuous energy results for KENO V.a HMF systems .....................................

Table A.3. Detailed multigroup results for KENO V.a HST systems...............................................

Table A.4. Detailed continuous energy results for KENO V.a HST systems .......................................

Table A.5. Detailed multigroup results for KENO V.a IMF systems ................................................

Table A.6. Detailed continuous energy results for KENO V.a IMF systems ....................................

Table A.7. Detailed multigroup results for KENO V.a LCT systems ................................................

Table A.8. Detailed continuous energy results for KENO V.a LCT systems ....................................7

Table A.9. Detailed multigroup results for KENO V.a LST systems ............................................. A-9

Table A.10. Detailed continuous energy results for KENO V.a LST systems .................................A-10

Table A.11. Detailed multigroup results for KENO V.a MCT systems ..........................................

Table A.12. Detailed continuous energy results for KENO V.a MCT systems .................................A-11

Table A.13. Detailed multigroup results for KENO V.a PMF systems ............................................11

Table A.14. Detailed continuous energy results for KENO V.a PMF systems ..................................

Table A.15. Detailed multigroup results for KENO V.a PST systems .............................................A-12

Table A.16. Detailed continuous energy results for KENO V.a PST systems.................................... A-14

Table B.1. Detailed multigroup results for KENO-VI HMF systems ................................................. B-1

Table B.2. Detailed continuous energy results for KENO-VI HMF systems ..................................... B-1

Table B.3. Detailed multigroup results for KENO-VI IMF systems .............................................. B-1

Table B.4. Detailed continuous energy results for KENO-VI IMF systems ...................................

Table B.5. Detailed multigroup results for KENO-VI MCT systems.............................................. B-2

Table B.6. Detailed continuous energy results for KENO-VI MCT systems .................................... B-3 



\section{ACRONYMS}

ANS

ANSI

$\mathrm{C} / \mathrm{E}$

COMP

CSAS

$\mathrm{eV}$

FAST

HEU

ICSBEP

IEU

IHECSBE

$\mathrm{keV}$

LEU

MET

$\mathrm{MeV}$

MIX

PU

SDF

SOL

THERM

TSUNAMI

VALID
American Nuclear Society

American National Standards Institute

calculated-to-expected ratio

compound system (e.g., lattice in water)

SCALE Criticality Safety Analysis Sequences

electron volt

fast neutron spectrum system, $\geq 50 \%$ of fissions above $100 \mathrm{keV}$

high enriched uranium $\left({ }^{235} \mathrm{U} \geq 60 \mathrm{wt} \%\right)$

International Criticality Safety Benchmark Experiment Program

intermediate enriched uranium ( $\left.10 \mathrm{wt} \%<{ }^{235} \mathrm{U}<60 \mathrm{wt} \%\right)$

International Handbook of Evaluated Criticality Safety Benchmark Experiments

kiloelectron volt

low enriched uranium $\left({ }^{235} \mathrm{U} \leq 10 \mathrm{wt} \%\right)$

metal

megaelectron volt

mixed uranium and plutonium

plutonium

sensitivity data file

solution

thermal neutron spectrum system, $(\geq 50 \%$ of fissions below $0.625 \mathrm{eV}$ )

SCALE Tools for Sensitivity and Uncertainty Analysis Methodology Implementation

verified, archived library of inputs and data 



\section{ACKNOWLEDGMENTS}

The authors wish to acknowledge the U.S. Department of Energy Nuclear Criticality Safety Program for their support of this work. The careful reviews of D. E. Mueller, D. A. Wiarda, and J. B. Clarity and the editorial assistance of A. Harkey, D. P. Stevens, and D. J. Weaver are gratefully acknowledged. 



\begin{abstract}
The computational bias of criticality safety computer codes must be established through the validation of the codes to critical experiments. A large collection of suitable experiments has been vetted by the International Criticality Safety Benchmark Experiment Program (ICSBEP) and made available in the International Handbook of Evaluated Criticality Safety Benchmark Experiments (IHECSBE). A total of more than 350 cases from this reference have been prepared and reviewed within the Verified, Archived Library of Inputs and Data (VALID) maintained by the Reactor and Nuclear Systems Division at Oak Ridge National Laboratory. The performance of the KENO V.a and KENO-VI Monte Carlo codes within the SCALE 6.1 code system with ENDF/B-VII.0 cross-section data in 238-group and continuous energy is assessed using the VALID models of benchmark experiments. The TSUNAMI tools for sensitivity and uncertainty analysis are utilized to examine some systems further in an attempt to identify potential causes of unexpected results.
\end{abstract}

The critical experiments available for validation of the KENO V.a code cover eight different broad categories of systems. These systems use a range of fissile materials including a range of uranium enrichments, various plutonium isotopic vectors, and mixed uranium/plutonium oxides. The physical form of the fissile material also varies and is represented as metal, solutions, or arrays of rods or plates in a water moderator. The neutron energy spectra of the systems also vary and cover both fast and thermal spectra. Over 300 of the total cases used utilize the KENO V.a code.

The critical experiments available for the validation of the KENO-VI code cover three broad categories of systems. The fissile materials in the systems vary and include high- and intermediate-enrichment uranium and mixed uranium/plutonium oxides. The physical form of the fissile material is either metal or rod arrays in water. As with KENO V.a, both fast and thermal neutron energy spectra are represented in the systems considered.

The results indicate generally good performance of both the KENO V.a and KENO-VI codes across the range of systems analyzed. The bias of calculated $k_{\text {eff }}$ from expected values is less than $0.9 \% \Delta \mathrm{k}$ in all cases. All eight categories of experiments show biases of less than $0.5 \% \Delta \mathrm{k}$ in KENO V.a with the exception of intermediate enrichment metal systems using the 238-group library. The continuous energy library generally manifests lower biases than the multigroup data. The KENO-VI results show slightly larger biases, though this may primarily be the result of modeling systems with more geometric complexity, which are more difficult to describe accurately, even with a generalized geometry code like KENO-VI.

Several additional conclusions can be drawn from the results of this validation effort. These conclusions include that the TSUNAMI tools can be used successfully to explain the cause of aberrant results, that some evaluations in the IHECSBE should be updated to provide more rigorous expected $k_{\text {eff }}$ values and uncertainties, and that potential cross-section errors can be identified by detailed review of the results of this validation. It also appears that the overall cross-section uncertainty as quantified through the SCALE covariance library is overestimated. Overall, the KENO V.a and KENO-VI codes are shown to provide consistent, low-bias results for a wide range of physical systems of potential interest in criticality safety applications. 



\section{INTRODUCTION}

This report documents the performance of the SCALE 6.1 code system ${ }^{1}$ using ENDF/B-VII.0 crosssection data ${ }^{2}$ with benchmark-quality criticality experiments and high-quality input models for a wide variety of fuel types with differing energy spectra of interest to criticality safety practitioners. The validation is performed using the KENO V.a and KENO-VI Monte Carlo neutron transport codes in both multigroup and continuous energy modes. Additionally, results from the KENO-based TSUNAMI-3D sensitivity and uncertainty analysis sequence establish the uncertainty in the benchmark calculations due to uncertainties in the cross-section data as tabulated in the SCALE covariance data library.

To predict or bound the computational bias for a design system of interest, the American National Standards for Nuclear Criticality Safety in Operations with Fissionable Material Outside Reactors, ANSI/ANS-8.1-1998; ${ }^{3}$ the Criticality Safety Criteria for the Handling, Storage, and Transportation of LWR Fuel Outside Reactors, ANSI/ANS-8.17-2004 (R2009); ${ }^{4}$ and the American National Standard for Validation of Neutron Transport Methods for Nuclear Criticality Safety Calculations, ANSI/ANS-8.24$2007,{ }^{5}$ allow the use of calculations in the determination of subcritical limits for the design of fissionable material systems. The standards require validation of the analytical methods and data used in nuclear criticality safety calculations to quantify any computational bias and the uncertainty in the bias. The validation procedure must be conducted through comparison of the computed results with experimental data, and the design system for which the subcritical limit is established must fall within the area of applicability of the experiments chosen for validation. The ANS-8.1 standard defines the area (or areas) of applicability as "the limiting ranges of material compositions, geometric arrangements, neutron-energy spectra, and other relevant parameters (e.g., heterogeneity, leakage, interaction, absorption, etc.) within which the bias of a computational method is established." Any analytical methods used to demonstrate the subcriticality of a system must be reliable to provide confidence that adequate safety margins exist. It is also desirable that the validation methods and codes used are not unnecessarily conservative so that operations are not unduly restricted.

The benchmark critical experiment models used in this validation were generated according to the procedure for the Verified, Archived Library of Inputs and Data (VALID) maintained within the Reactor and Nuclear Systems Division at Oak Ridge National Laboratory. ${ }^{6}$ More information about the VALID library and the process used to generate models for inclusion in the library is provided in Section 3.3. All cases that have been entered in the library using SCALE 6.0 are used in this validation effort, which includes a total of over 300 individual critical configurations. The systems analyzed as part of the validation include a range of uranium enrichments, plutonium, and mixed uranium and plutonium oxides as primary fissile components. A range of physical forms is also covered, though not for each fissile component, that includes metal, solution, and rod array systems.

The validation data presented here includes a wide range of systems and is intended to demonstrate the general applicability of the KENO V.a and KENO-VI Monte Carlo transport codes used in the SCALE

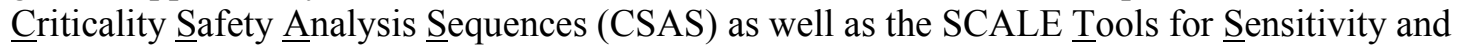
$\underline{\text { Uncertainty }}$ Analysis Methodology Implementation (TSUNAMI). However, the results documented here should not be used directly in any safety basis work without further site-specific quality assurance certification. 



\section{BENCHMARK EXPERIMENTS}

The benchmark experiments used for this validation effort are taken from the International Handbook of Evaluated Criticality Safety Benchmark Experiments (IHECSBE). ${ }^{7}$ All cases available in the VALID library are included in this effort. More information is available about the VALID library in Section 3.3. A list of standard IHECSBE abbreviations is provided in Table 1 along with a listing of the different experiment classes included in the VALID library and their abbreviations.

A wide range of physical systems is included in the suite of benchmark experiments presented. The physical form of the fissile material is varied and includes solutions, metal, and oxides of uranium, plutonium, or both. A range of enrichments from $2 \mathrm{wt} \%$ to over $90 \mathrm{wt} \%{ }^{235} \mathrm{U}$ is included in uranium systems, and plutonium systems include a wide range of plutonium isotopic vectors. Light water is the primary moderator used, and reflectors include light water as well as graphite, beryllium, molybdenum, and other materials. A brief description of the experiments is provided in Table 2.

The first column of Table 2 includes the report designation from the IHECSBE. ${ }^{7}$ These designations include a terse categorization of the benchmark experiment using a specific format. The first group of two to three characters indicates the primary fissile material in the system. The second group of three to four characters describes the physical form of the fissile material. The third set of four or five characters describes the spectrum of the system, and the final group of three characters is an integer counter for each experiment in the category.

Table 1. IHECSBE abbreviations used

\begin{tabular}{ll}
\hline Abbreviation & \multicolumn{1}{c}{ Missile material } \\
\hline HEU & \multicolumn{1}{c}{ High enriched uranium $\left({ }^{235} \mathrm{U} \geq 60 \mathrm{wt} \%\right)$} \\
IEU & $\begin{array}{l}\text { Intermediate or mixed enrichment uranium } \\
\left(60 \mathrm{wt} \%>{ }^{235} \mathrm{U}>10 \mathrm{wt} \%\right)\end{array}$ \\
LEU & Low enriched, natural, or depleted uranium \\
& $\left({ }^{235} \mathrm{U} \leq 10 \mathrm{wt} \%\right)$ \\
PU & Plutonium \\
MIX & Mixed uranium and plutonium \\
\hline & \multicolumn{1}{c}{ Physical form of fissile material } \\
\hline MET & Metal \\
SOL & Solution \\
COMP & Compound system (e.g., lattice in water $)$ \\
\hline & \multicolumn{1}{c}{ Spectrum } \\
\hline FAST & Fast system ( $\geq 50 \%$ of fissions above $100 \mathrm{keV})$ \\
THERM & Thermal system $(\geq 50 \%$ of fissions below $0.625 \mathrm{eV})$ \\
\hline & Experiment Class Abbreviations \\
\hline HMF & HEU-MET-FAST \\
HST & HEU-SOL-THERM \\
IMF & IEU-MET-FAST \\
LCT & LEU-COMP-THERM \\
LST & LEU-SOL-THERM \\
MCT & MIX-COMP-THERM \\
PMF & PU-MET-FAST \\
PST & PU-SOL-THERM
\end{tabular}


Table 2. Critical benchmark experiments available in VALID library

\begin{tabular}{|c|c|c|c|c|}
\hline Evaluation & Cases & Fissile material & Moderator & Experiment description \\
\hline HEU-MET-FAST-005 & 6 & $90 \%$ enriched $\mathrm{U}$ metal & None & $\begin{array}{l}\text { Beryllium- and Molybdenum-Reflected Cylinders of Highly } \\
\text { Enriched Uranium }\end{array}$ \\
\hline HEU-MET-FAST-008 & 1 & $90 \%$ enriched $U$ metal & None & Bare Sphere of Highly Enriched Uranium \\
\hline HEU-MET-FAST-009 & 2 & $90 \%$ enriched $\mathrm{U}$ metal & None & $\begin{array}{l}\text { Spheres of Highly Enriched Uranium Reflected by Beryllium } \\
\text { or Beryllium Oxide }\end{array}$ \\
\hline HEU-MET-FAST-010 & 2 & $90 \%$ enriched $U$ metal & None & $\begin{array}{l}\text { Spheres of Highly Enriched Uranium Reflected by } \\
\text { Boron+Beryllium or Boron+Beryllium Oxide }\end{array}$ \\
\hline HEU-MET-FAST-011 & 1 & $90 \%$ enriched $U$ metal & None & $\begin{array}{l}\text { Sphere of Highly Enriched Uranium Reflected by } \\
\text { Polyethylene }\end{array}$ \\
\hline HEU-MET-FAST-013 & 1 & $90 \%$ enriched $\mathrm{U}$ metal & None & Sphere of Highly Enriched Uranium Reflected by Steel \\
\hline HEU-MET-FAST-015 & 1 & $96 \%$ enriched U metal & None & Unreflected Cylinder of Highly Enriched Uranium \\
\hline HEU-MET-FAST-016 & 2 & $96 \%$ enriched U metal & None & $\begin{array}{l}\text { Beryllium-Reflected and Beryllium Oxide-Reflected Cylinders } \\
\text { of Highly Enriched Uranium }\end{array}$ \\
\hline HEU-MET-FAST-017 & 1 & $96 \%$ enriched $U$ metal & Beryllium & $\begin{array}{l}\text { Beryllium-Moderated and -Reflected Cylinder of Highly } \\
\text { Enriched Uranium }\end{array}$ \\
\hline HEU-MET-FAST-018 ${ }^{a}$ & 1 & $90 \%$ enriched $\mathrm{U}$ metal & None & Bare Spherical Assembly of ${ }^{235} \mathrm{U}(90 \%)$ \\
\hline HEU-MET-FAST-019 ${ }^{a}$ & 1 & $90 \%$ enriched $\mathrm{U}$ metal & None & Graphite-Reflected Spherical Assembly of ${ }^{235} \mathrm{U}(90 \%)$ \\
\hline HEU-MET-FAST- $020^{a}$ & 1 & $90 \%$ enriched $U$ metal & None & Polyethylene-Reflected Spherical Assembly of ${ }^{235} \mathrm{U}(90 \%)$ \\
\hline HEU-MET-FAST-02 $1^{a}$ & 1 & $90 \%$ enriched $U$ metal & None & Steel-Reflected Spherical Assembly of ${ }^{235} \mathrm{U}(90 \%)$ \\
\hline HEU-MET-FAST-024 & 1 & $90 \%$ enriched $U$ metal & None & $\begin{array}{l}\text { Sphere of Highly Enriched Uranium Reflected by Steel and } \\
\text { Polyethylene }\end{array}$ \\
\hline HEU-MET-FAST-025 & 5 & $96 \%$ enriched $\mathrm{U}$ metal & None & Five Vanadium-Reflected Highly Enriched Uranium Cylinders \\
\hline HEU-MET-FAST-030 & 1 & $96 \%$ enriched $U$ metal & Beryllium & $\begin{array}{l}\text { Heterogeneous Cylinder of Highly Enriched Uranium with } \\
\text { Beryllium Moderator and Depleted-Uranium Reflector }\end{array}$ \\
\hline HEU-MET-FAST-038 & 2 & $96 \%$ enriched $U$ metal & $\begin{array}{l}\text { Beryllium, } \\
\text { Beryllium oxide }\end{array}$ & $\begin{array}{l}\text { Two Heterogeneous Cylinders of Highly Enriched Uranium } \\
\text { with Beryllium and Beryllium Oxide Moderators and } \\
\text { Depleted-Uranium Reflector }\end{array}$ \\
\hline HEU-MET-FAST-040 & 1 & $96 \%$ enriched U metal & None & $\begin{array}{l}\text { Heterogeneous Vanadium-Diluted Highly Enriched Uranium } \\
\text { Cylinder }\end{array}$ \\
\hline HEU-MET-FAST-065 & 1 & $96 \%$ enriched U metal & None & $\begin{array}{l}\text { Unreflected Cylinder of Highly Enriched Uranium-Second } \\
\text { Configuration }\end{array}$ \\
\hline HEU-MET-FAST-080 & 1 & $93 \%$ enriched U metal & None & Bare, Highly Enriched Uranium Fast Burst Reactor CALIBAN \\
\hline HEU-SOL-THERM-001 & 10 & $93 \%$ enriched uranyl nitrate & Light water & $\begin{array}{l}\text { Minimally Reflected Cylinders of Highly Enriched Solutions } \\
\text { of Uranyl Nitrate }\end{array}$ \\
\hline HEU-SOL-THERM-013 & 4 & $93 \%$ enriched uranyl nitrate & Light water & $\begin{array}{l}\text { Unreflected 174-Liter Spheres of Enriched Uranium Nitrate } \\
\text { Solutions }\end{array}$ \\
\hline HEU-SOL-THERM-014 & 3 & $89 \%$ enriched uranyl nitrate & Light water & Uranium Nitrate Solution ( $70 \mathrm{~g} \mathrm{U} / \mathrm{L}$ ) with Gadolinium \\
\hline
\end{tabular}


Table 2. Critical benchmark experiments available in VALID library (continued)

\begin{tabular}{|c|c|c|c|c|}
\hline Evaluation & Cases & Fissile material & Moderator & Experiment description \\
\hline HEU-SOL-THERM-016 & 3 & $89 \%$ enriched uranyl nitrate & Light water & Uranium Nitrate Solution (150 g U/L) with Gadolinium \\
\hline HEU-SOL-THERM-028 & 18 & $89 \%$ enriched uranyl nitrate & Light water & $\begin{array}{l}\text { Uranium }\left(89 \%{ }^{235} \mathrm{U}\right) \text { Nitrate Solutions with Central Boron } \\
\text { Carbide Absorber Rod }\end{array}$ \\
\hline HEU-SOL-THERM-029 & 7 & $89 \%$ enriched uranyl nitrate & Light water & $\begin{array}{l}\text { Uranium }\left(89 \%{ }^{235} \mathrm{U}\right) \text { Nitrate Solutions with Cluster of Seven } \\
\text { Boron Carbide Absorber Rods }\end{array}$ \\
\hline HEU-SOL-THERM-030 & 7 & $89 \%$ enriched uranyl nitrate & Light Water & $\begin{array}{l}\text { Uranium }\left(89 \%{ }^{235} \mathrm{U}\right) \text { Nitrate Solutions with Cluster of Several } \\
\text { Boron Carbide Absorber Rods }\end{array}$ \\
\hline IEU-MET-FAST-002 & 1 & $16 \%$ enriched $U$ metal & None & $\begin{array}{l}\text { Natural Uranium-Reflected Assembly of Enriched and Natural } \\
\text { Uranium Plates }\end{array}$ \\
\hline IEU-MET-FAST-003 ${ }^{a}$ & 1 & $37 \%$ enriched U metal & None & Bare Spherical Assembly of ${ }^{235} U(36 \%)$ \\
\hline IEU-MET-FAST-004 ${ }^{a}$ & 1 & $37 \%$ enriched U metal & None & Graphite-Reflected Spherical Assembly of ${ }^{235} \mathrm{U}(36 \%)$ \\
\hline IEU-MET-FAST- $005^{a}$ & 1 & $37 \%$ enriched U metal & None & Steel-Reflected Spherical Assembly of ${ }^{235} U(36 \%)$ \\
\hline IEU-MET-FAST-006 & 1 & $37 \%$ enriched $U$ metal & None & Duralumin-Reflected Spherical Assembly of ${ }^{235} U(36 \%)$ \\
\hline IEU-MET-FAST-007 & 1 & $10 \%$ enriched $U$ metal & None & $\begin{array}{l}\text { BIG TEN: A Large, Mixed-Uranium-Metal Cylindrical Core } \\
\text { with } 10 \% \text { Average }{ }^{235} \text { U Enrichment, Surrounded by a Thick } \\
{ }^{238} \text { U Reflector }\end{array}$ \\
\hline IEU-MET-FAST-008 & 1 & $36 \%$ enriched $U$ metal & None & $\begin{array}{l}\text { Depleted Uranium-Reflected Spherical Assembly of } \\
{ }^{235} \mathrm{U}(36 \%)\end{array}$ \\
\hline IEU-MET-FAST-009 & 1 & $36 \%$ enriched $U$ metal & None & $\begin{array}{l}\text { Spherical Assembly of }{ }^{235} \mathrm{U}(36 \%) \text { with a } 5.75 \mathrm{~cm} \\
\text { Polyethylene Reflector }\end{array}$ \\
\hline IEU-MET-FAST-019 & 2 & $45 \%$ enriched $U$ metal & None & $45.5 \%{ }^{235}$ U Pseudo-cylindrical Metal Slabs: Bare Assemblies \\
\hline MIX-COMP-THERM-001 & 4 & $\mathrm{Pu}$ and natural $\mathrm{U}$ oxides & Light Water & $\begin{array}{l}\text { Water-Reflected Mixed Plutonium-Uranium Oxide (20 wt \% } \\
\text { Plutonium) Pins }\end{array}$ \\
\hline MIX-COMP-THERM-002 ${ }^{b}$ & 6 & $\mathrm{Pu}$ and natural $\mathrm{U}$ oxides & Light Water & $\begin{array}{l}\text { Rectangular Arrays of Water-Moderated } \mathrm{UO}_{2}-2 \mathrm{wt} \% \mathrm{PuO}_{2} \\
\left(8 \%{ }^{240} \mathrm{Pu}\right) \text { Fuel Rods }\end{array}$ \\
\hline MIX-COMP-THERM-004 & 11 & $\mathrm{Pu}$ and natural $\mathrm{U}$ oxides & Light Water & $\begin{array}{l}\text { Critical Arrays of Mixed Plutonium-Uranium Fuel Rods with } \\
\text { Water-to-Fuel Volume Ratios Ranging from } 2.4 \text { to } 5.6\end{array}$ \\
\hline MIX-COMP-THERM-008 & 28 & $\mathrm{Pu}$ and natural $\mathrm{U}$ oxides & Light Water & $\begin{array}{l}\text { Hexagonal Lattices of Mixed Oxide Fuel Pins } \mathrm{UO}_{2}-2 \text { wt \% } \\
\mathrm{PuO}_{2}, 24 \%{ }^{240} \mathrm{Pu} \text { Natural Uranium }\end{array}$ \\
\hline LEU-COMP-THERM-001 & 8 & $2 \%$ enriched $\mathrm{UO}_{2}$ & Light water & $\begin{array}{l}\text { Water-Moderated U(2.35) } \mathrm{O}_{2} \text { Fuel Rods in } 2.032 \mathrm{~cm} \text { Square- } \\
\text { Pitched Arrays }\end{array}$ \\
\hline LEU-COMP-THERM-002 & 5 & $4 \%$ enriched $\mathrm{UO}_{2}$ & Light water & $\begin{array}{l}\text { Water-Moderated U(4.31) } \mathrm{O}_{2} \text { Fuel Rods in } 2.54 \mathrm{~cm} \text { Square- } \\
\text { Pitched Arrays }\end{array}$ \\
\hline LEU-COMP-THERM-010 & 30 & $4 \%$ enriched $\mathrm{UO}_{2}$ & Light water & $\begin{array}{l}\text { Water-Moderated U(4.31) } \mathrm{O}_{2} \text { Fuel Rods Reflected by Two } \\
\text { Lead, Uranium, or Steel Walls }\end{array}$ \\
\hline LEU-COMP-THERM-017 & 29 & $2 \%$ enriched $\mathrm{UO}_{2}$ & Light water & $\begin{array}{l}\text { Water-Moderated U(2.35) } \mathrm{O}_{2} \text { Fuel Rods Reflected by Two } \\
\text { Lead, Uranium, or Steel Walls }\end{array}$ \\
\hline
\end{tabular}


Table 2. Critical benchmark experiments available in VALID library (continued)

\begin{tabular}{|c|c|c|c|c|}
\hline Evaluation & Cases & Fissile material & Moderator & Experiment description \\
\hline LEU-COMP-THERM-042 & 7 & $2 \%$ enriched $\mathrm{UO}_{2}$ & Light water & $\begin{array}{l}\text { Water-Moderated Rectangular Clusters of } \mathrm{U}(2.35) \mathrm{O}_{2} \text { Fuel } \\
\text { Rods (1.684 cm Pitch) Separated by Steel, Boral, Boraflex, } \\
\text { Cadmium, or Copper Plates with Steel Reflecting Walls }\end{array}$ \\
\hline LEU-COMP-THERM-050 & 18 & $5 \%$ enriched $\mathrm{UO}_{2}$ & Light water & $\begin{array}{l}{ }^{149} \text { Sm Solution Tank in the Middle of Water-Moderated } \\
4.738 \text { wt \% Enriched Uranium Dioxide Rod Arrays }\end{array}$ \\
\hline LEU-SOL-THERM-002 & 3 & $5 \%$ enriched uranyl fluoride & Light water & $\begin{array}{l}174 \text { Liter Spheres of Low Enriched (4.9\%) Uranium } \\
\text { Oxyfluoride Solutions }\end{array}$ \\
\hline LEU-SOL-THERM-003 & 9 & $10 \%$ enriched uranyl nitrate & Light water & $\begin{array}{l}\text { Full and Truncated Bare Spheres of 10\% Enriched Uranyl } \\
\text { Nitrate Water Solutions }\end{array}$ \\
\hline LEU-SOL-THERM-004 & 7 & $10 \%$ enriched uranyl nitrate & Light water & $\begin{array}{l}\text { STACY: Water-Reflected } 10 \% \text { Enriched Uranyl Nitrate } \\
\text { Solution in a } 60 \mathrm{~cm} \text { Diameter Cylindrical Tank }\end{array}$ \\
\hline PU-MET-FAST-001 & 1 & $95 \%{ }^{239} \mathrm{Pu}$ metal & None & $\begin{array}{l}\text { Bare Sphere of Plutonium-239 Metal }\left(4.5 \text { at } \%{ }^{240} \mathrm{Pu} \text {, }\right. \\
1.02 \mathrm{wt} \% \mathrm{Ga})\end{array}$ \\
\hline PU-MET-FAST-002 & 1 & $76 \%{ }^{239} \mathrm{Pu}$ metal & None & $\begin{array}{l}{ }^{240} \mathrm{Pu} \text { JEZEBEL: Bare Sphere of Plutonium-239 Metal } \\
\left(20.1 \text { at } \%{ }^{240} \mathrm{Pu}, 1.01 \mathrm{wt} \% \mathrm{Ga}\right)\end{array}$ \\
\hline PU-MET-FAST-005 & 1 & $95 \%{ }^{239} \mathrm{Pu}$ metal & None & $\begin{array}{l}\text { Benchmark Critical Experiment of a Plutonium Sphere } \\
\text { Reflected by Tungsten }\end{array}$ \\
\hline PU-MET-FAST-006 & 1 & $95 \%{ }^{239} \mathrm{Pu}$ metal & None & $\begin{array}{l}\text { Plutonium Sphere Reflected by Normal Uranium Using } \\
\text { FLATTOP }\end{array}$ \\
\hline PU-MET-FAST-008 & 1 & $95 \%{ }^{239} \mathrm{Pu}$ metal & None & $\begin{array}{l}\text { Benchmark Critical Experiment of a Thorium Reflected } \\
\text { Plutonium Sphere }\end{array}$ \\
\hline PU-MET-FAST-010 & 1 & $95 \%{ }^{239} \mathrm{Pu}$ metal & None & $\begin{array}{l}\text { Benchmark Critical Experiment of a Delta-Phase Plutonium } \\
\text { Sphere Reflected by Normal Uranium }\end{array}$ \\
\hline PU-MET-FAST-018 & 1 & $95 \%{ }^{239} \mathrm{Pu}$ metal & None & $\begin{array}{l}\text { Benchmark Critical Experiment of a Delta-Phase Plutonium } \\
\text { Sphere Reflected by Beryllium }\end{array}$ \\
\hline PU-MET-FAST-022 & 1 & $98 \%{ }^{239} \mathrm{Pu}$ metal & None & Bare Spherical Assembly of ${ }^{239} \mathrm{Pu}(\delta, 98 \%)$ \\
\hline PU-MET-FAST-023 & 1 & $98 \%{ }^{239} \mathrm{Pu}$ metal & None & Graphite Reflected Spherical Assembly of ${ }^{239} \mathrm{Pu}(\delta, 98 \%)$ \\
\hline PU-MET-FAST-024 & 1 & $98 \%{ }^{239} \mathrm{Pu}$ metal & None & Polyethylene Reflected Spherical Assembly of ${ }^{239} \mathrm{Pu}(\delta, 98 \%)$ \\
\hline PU-SOL-THERM-001 & 6 & $95 \%{ }^{239} \mathrm{Pu}$ plutonium nitrate & Light water & $\begin{array}{l}\text { Water-Reflected 11.5-in.-Diameter Spheres of Plutonium } \\
\text { Nitrate Solutions }\end{array}$ \\
\hline PU-SOL-THERM-002 & 7 & $97 \%{ }^{239} \mathrm{Pu}$ plutonium nitrate & Light water & $\begin{array}{l}\text { Water-Reflected 12-in.-Diameter Spheres of Plutonium Nitrate } \\
\text { Solutions }\end{array}$ \\
\hline PU-SOL-THERM-003 & 8 & $98 \%{ }^{239} \mathrm{Pu}$ plutonium nitrate & Light water & $\begin{array}{l}\text { Water-Reflected 13-in.-Diameter Spheres of Plutonium Nitrate } \\
\text { Solutions }\end{array}$ \\
\hline PU-SOL-THERM-004 & 13 & $\begin{array}{l}\text { Various } \mathrm{Pu} \text { vectors plutonium } \\
\text { nitrate }\end{array}$ & Light water & $\begin{array}{l}\text { Water-Reflected 14-in.-Diameter Spheres of Plutonium Nitrate } \\
\text { Solutions, } 0.54 \% \text { to } 3.43 \%{ }^{240} \mathrm{Pu}\end{array}$ \\
\hline PU-SOL-THERM-005 & 9 & $\begin{array}{l}\text { Various } \mathrm{Pu} \text { vectors plutonium } \\
\text { nitrate }\end{array}$ & Light water & $\begin{array}{l}\text { Water-Reflected 14-in.-Diameter Spheres of Plutonium Nitrate } \\
\text { Solutions, } 4.05 \% \text { to } 4.40 \%{ }^{240} \mathrm{Pu}\end{array}$ \\
\hline
\end{tabular}


Table 2. Critical benchmark experiments available in VALID library (continued)

\begin{tabular}{|c|c|c|c|c|}
\hline Evaluation & Cases & Fissile material & Moderator & Experiment description \\
\hline PU-SOL-THERM-006 & 3 & $97 \%{ }^{239} \mathrm{Pu}$ plutonium nitrate & Light water & $\begin{array}{l}\text { Water-Reflected 15-in.-Diameter Spheres of Plutonium Nitrate } \\
\text { Solutions }\end{array}$ \\
\hline PU-SOL-THERM-007 & 8 & $95 \%{ }^{239} \mathrm{Pu}$ plutonium nitrate & Light water & $\begin{array}{l}\text { Water-Reflected 11.5-in.-Diameter Spheres Partly Filled with } \\
\text { Plutonium Nitrate Solutions }\end{array}$ \\
\hline PU-SOL-THERM-011 & 12 & $96 \%{ }^{239} \mathrm{Pu}$ plutonium nitrate & Light water & $\begin{array}{l}\text { Bare 16- and 18-in.-Diameter Spheres of Plutonium Nitrate } \\
\text { Solutions }\end{array}$ \\
\hline PU-SOL-THERM-020 & $15^{c}$ & $95 \%{ }^{239} \mathrm{Pu}$ plutonium nitrate & Light water & $\begin{array}{l}\text { Water-Reflected and Water-Cadmium-Reflected 14-in.- } \\
\text { Diameter Spheres of Plutonium Nitrate Solutions }\end{array}$ \\
\hline
\end{tabular}

${ }^{a}$ Both detailed and simplified configuration considered.

Only simplified models considered.

${ }^{c}$ PU-SOL-THERM-020 contains two sets of eight highly correlated experiments. The evaluation states that only one set should be used in validation for a safety application. One of the cases was rejected from the evaluation because of poor calculated results and inconsistency with other similar experiments, leaving 15 cases. All of these cases are included in this validation. 



\section{CODES, DATA, AND METHODS}

A general overview of the SCALE codes and data used in the calculations as well as the methods used in validation assessment is described here. A more complete description of the codes and data is available in the SCALE manual, ${ }^{1}$ and a more complete description of methods for validation of criticality safety codes and methods for safety basis calculations can be found in Refs. 5, 8, or 9 .

\subsection{CODES}

This section briefly describes the SCALE computational codes used in this validation. As mentioned above, more detailed information related to the theory, input descriptions, and execution of each module is available in Ref. 1.

\subsubsection{Multigroup Cross-Section Processing Codes}

The CSAS5 and CSAS6 sequences utilize the BONAMI, WORKER, CENTRM, and PMC codes to process multigroup cross sections and provide the appropriate resonance corrections to the group-average cross-section values. The corrections are necessary to account for the impact of resonances on groupaverage cross sections. The impact of an individual resonance on the group-average cross section is determined by the size of the resonance, the isotopic number density of the resonance material, and the flux level at the energy of the resonance. Simplified one-dimensional models are used to solve representative unit cell problems to approximate the energy-dependent flux in the full transport problem. This flux is used to collapse the cross-section data to a set of group-average values that can be used in a multigroup transport calculation. When appropriate, lattice effect corrections are also applied to the cross sections in these modules.

The BONAMI code is used to perform resonance self-shielding calculations based on the Bondarenko method. In the process, BONAMI generates problem-dependent master cross-section libraries. The Bondarenko method is typically used in the unresolved resonance energy range and is based on the narrow resonance approximation. The Bondarenko approach is simple and fast, and most accurate and useful at high energies. BONAMI is therefore well suited and appropriate for use in the unresolved energy range.

The WORKER module is used to create a working-formatted cross-section library, appropriate for use in radiation transport calculations, from an AMPX master library. WORKER operates on the master library created by BONAMI to generate the working library that CENTRM and PMC use in the resonance selfshielding calculations in the resolved resonance range.

The CENTRM module generates a neutron spectrum based on a transport theory solution in one dimension using a combination of multigroup and pointwise data. In the CSAS sequences, the detailed flux solutions are passed to PMC to generate resonance self-shielded multigroup cross sections. The energy mesh is typically very fine, on the order of 10,000 to 70,000 points, and provides precise treatment in the resolved resonance range. This detailed treatment also allows for the incorporation of effects of resonances from different nuclides in the same mixture overlapping. With CENTRM, the energy fidelity of continuous energy treatment is preserved even when performing multigroup calculations.

The primary purpose of the PMC module is to generate problem-dependent multigroup cross sections based on the high-resolution spectral data generated in CENTRM. The detailed flux spectrum is used as a weighting function to generate a problem-dependent set of multigroup cross sections. PMC generates a multigroup, problem-dependent master library, which is then converted by WORKER into a workingformatted library for use in radiation transport calculations. 


\subsubsection{KENO V.a}

KENO V.a solves the k-effective $\left(k_{\text {eff }}\right)$ eigenvalue problem in three dimensions using the Monte Carlo method. KENO V.a has been used for this purpose in the SCALE system for many years and has been employed in criticality safety applications at sites around the world. KENO V.a allows a fairly simple description of complicated systems and is capable of using repeating Cartesian array structures and holes to facilitate system description. However, each geometry object must be oriented along a coordinate axis, and objects are not allowed to intersect.

KENO V.a operates in multigroup mode using appropriately self-shielded cross sections per the methods described in Sect. 3.1.1. Additionally, KENO V.a can operate in continuous energy mode without the need for additional resonance self-shielding calculations. In SCALE 6.1, continuous energy treatment is only available for criticality calculations, not including sensitivity analysis or depletion, which are available in multigroup mode.

This validation effort focuses on the ability of KENO to solve the $k_{\text {eff }}$ eigenvalue problem across a wide range of potential systems. These systems use different fissile materials in a range of forms and with differing energy spectra to test the code over a wide range of problems. Validation over this wide range is necessary as KENO V.a is intended as a general purpose Monte Carlo code for use in criticality safety analyses.

\subsubsection{KENO-VI}

KENO-VI has similar capabilities to KENO V.a but incorporates the SCALE Generalized Geometry Package and is therefore able to represent systems of significantly increased geometric complication. A predefined set of geometry objects can be specified to define regions. In addition, generalized quadratic surfaces can be supplied to define regions of space that are not well described by any of the predefined shapes. KENO-VI also supports rotation and therefore allows bodies to be oriented in directions that are not parallel to the major coordinate axes. KENO-VI continues to support arrays and holes. The range of arrays that can be used is significantly expanded to include triangular or hexagonal arrays as well as dodecahedral arrays. Intersecting geometry definitions can be supplied for exact modeling of features such as pipe junctions.

As with KENO V.a, the focus of this effort is on validation of the $k_{\text {eff }}$ eigenvalue problem. The range of systems considered in the KENO-VI validation is not as extensive as that used for the validation of KENO V.a. The primary reason for this is that the geometry description required for KENO-VI is more complicated than that for KENO V.a because of the added flexibility. There are therefore fewer cases in the VALID library using KENO-VI, as it is typically used only when necessary. More extensive validations of KENO-VI exist for previous SCALE versions. These are documented in Refs. 10 and 11.

\subsubsection{TSUNAMI-3D}

The TSUNAMI code suite can quantify the predicted change in system responses, such as $k_{\text {eff }}$, reactivity differences, or ratios of fluxes or reaction rates, due to changes in the energy-dependent, nuclide-reactionspecific cross-section data. Where uncertainties in the neutron cross-section data are available, the sensitivity of the system to the cross-section data can be applied to propagate the uncertainties in the cross-section data to an uncertainty in the system response. Uncertainty quantification is useful for identifying potential sources of computational biases and highlighting parameters important to code validation. The basis of the TSUNAMI validation techniques is that computational biases are primarily caused by uncertainties in the evaluation of the cross-section data, which are quantified and bounded by the cross-section-covariance data. To provide credence to this claim, sensitivity data for the benchmark 
experiments were generated with TSUNAMI-3D, and the cross-section-covariance data were propagated to uncertainties in the computed values of $k_{\text {eff. }}$.

The TSUNAMI-3D sequences combine the cross-section processing described above in Section 3.1.1 with either the KENO V.a or KENO-VI Monte Carlo transport codes described in Sections 3.1.2 and 3.1.3, respectively, and the SAMS module to generate sensitivity coefficients and propagate uncertainties

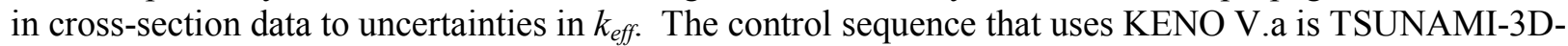
K5, and the sequence that uses KENO-VI is TSUNAMI-3D-K6. The sensitivity coefficients relate changes in cross-section data to changes in the overall system $k_{\text {eff }}$ value. These coefficients allow for quantitative comparisons among different systems to identify the similarity of the systems based on sensitivity and uncertainty due to important nuclides. These comparisons can be particularly helpful in selecting critical experiments to provide a benchmark suite for a specific criticality safety analysis. This last step will not be performed in this work because there is no specific application model. The purpose of this effort is to demonstrate the broad applicability of the KENO codes to a wide range of potential criticality safety analyses.

In the TSUNAMI-3D sequences, the KENO code, either V.a or VI, is executed twice- once in forward mode and again in adjoint mode. The Monte Carlo codes tally neutron fluxes and flux moments as well as $k_{\text {eff. }}$ The forward flux is then combined with the adjoint flux as an importance function in the SAMS module to generate sensitivity coefficients that describe the $k_{\text {eff }}$ response to cross-section changes. A sensitivity coefficient is generated for each reaction in each energy group for each isotope in each mixture in the problem. These coefficients are also collapsed to isotope and mixture-specific bases. The TSUNAMI-3D sequence generates a sensitivity data file (SDF) to provide this information to subsequent tools in the SCALE sensitivity and uncertainty analysis suite. An assessment of the uncertainty in $k_{\text {eff }}$ due to cross-section uncertainties is provided for each benchmark in Sect. 4.

\subsection{NUCLEAR DATA}

The SCALE system is distributed with several cross-section libraries, as documented in Ref. 1. This work is based on validating the performance of the ENDF/B-VII.0 (Ref. 2) cross-section libraries. Four libraries based on ENDF/B-VII.0 are distributed with SCALE: a continuous energy neutron library; a multigroup neutron library for criticality and reactor physics containing 238 energy groups; and two multigroup coupled neutron-gamma libraries for shielding analysis, one containing 200 neutron and 47 gamma groups and the other containing 27 neutron and 19 gamma groups. Only the continuous energy and 238-group neutron libraries are exercised here. While the SCALE system has historically used multigroup methods, a continuous energy Monte Carlo capability was introduced in Version 6.0. The multigroup data are still widely used and are required for sensitivity analysis and depletion calculations. For these reasons, both libraries are validated in this work and are described below.

The uncertainty in the computed $k_{\text {eff }}$ values due to uncertainties in the cross-section data are provided as part of this validation. The cross-section uncertainties are obtained from the SCALE cross-section covariance data library, which is described below.

\subsubsection{ENDF/B-VII.0 238-Group Library}

The SCALE 6.1 238-group ENDF/B-VII.0 library (v7-238) is available for general-purpose use in criticality safety calculations. The group structure is the same as used in previous version of SCALE, which is also the same as the ENDF/B-V and ENDF/B-VI.8 multigroup libraries distributed with SCALE 6.1. The weighting spectrum for the master library uses a Maxwellian shape below $0.125 \mathrm{eV}$, 1/E from $0.125 \mathrm{eV}$ to $820.8 \mathrm{keV}$, a fission spectrum from $820.8 \mathrm{keV}$ to $10 \mathrm{MeV}$, and $1 / \mathrm{E}$ above $10 \mathrm{MeV}$. The library maximum energy is $20 \mathrm{MeV}$, and the minimum energy is $10^{-5} \mathrm{eV}$. The Maxwellian 
distribution has $\mathrm{kT}=0.025 \mathrm{eV}$, and the effective temperature of the fission spectrum is $1.273 \mathrm{MeV}$. The library contains 417 nuclides, including 19 thermal-scattering moderators. The libraries are generated at multiple temperatures, which vary based on the nuclide and range from 19 to $2400 \mathrm{~K}$. Temperature interpolation is performed as part of the resonance self-shielding calculation, except for the thermalscattering data where the nearest temperature is selected. More information, including a complete description of the energy group structure and a listing of the contents of the library, is available in the SCALE manual. ${ }^{1}$

\subsubsection{ENDF/B-VII.0 Continuous Energy Library}

The SCALE 6.1 continuous energy ENDF/B-VII.0 library (ce_v7_endf) is available for general-purpose use in criticality safety calculations and is one of the most complete libraries available within the SCALE system. The same 417 nuclides available in the 238-group library are available in the continuous energy library. Thermal scattering collision kinematics data are included for the thermal moderators. Each nuclide contains data at multiple temperatures. Temperature interpolation is not performed in KENO calculations in continuous energy. Instead, the file at the closest temperature is selected and used. More information, including the available temperatures and a listing of the contents of the library, is available in the SCALE manual. ${ }^{1}$

\subsubsection{Cross-Section Covariance Data}

The SCALE cross-section covariance library is a single comprehensive library with a total of 401 materials in the SCALE 44-energy-group structure. ${ }^{1}$ The SCALE covariance library data correspond to 44-group relative uncertainties assembled from a variety of sources, including evaluations from ENDF/B-VII, ENDF/B-VI, JENDL-3.1, and more than 300 approximated uncertainties from a collaborative project performed by Brookhaven National Laboratory, Los Alamos National Laboratory, and ORNL.

Because SCALE includes separate multigroup cross-section libraries processed from ENDF/B-V, ENDF/B-VI.8, and ENDF/B-VII.0, the application of a single "generic" covariance library to all multigroup cross-section libraries obviously raises questions about consistency with any given data evaluation. In reality, much of the approximate uncertainty data in the library is based on simplifying approximations that do not depend on specific ENDF evaluations and thus can be applied to all crosssection libraries within the limitations of the assumed methodology. In other cases where a covariance evaluation has been taken from a specific nuclear data file (e.g., ENDF/B-VII, ENDF/B-VI, or JENDL-3.1), it is assumed that the same relative (rather than absolute) uncertainties can be applied to all cross-section libraries, even if these are not strictly consistent with the nuclear data evaluations. This may be questionable for some older evaluations in the ENDF/B-V data, but it should be reasonable for the SCALE ENDF/B-VI and VII cross-section libraries. The assumption is partially justified by the fact that different evaluations often use many of the same experimental measurements, since there is a limited amount of such information available. Also, because most important nuclear data are now known rather well, newer evaluations in many instances correspond to rather modest variations from previous ones and are expected to lie within the earlier uncertainties.

It should be noted that there is no inherently "true" uncertainty that can be defined unambiguously for nuclear data. While differences in nuclear data evaluations have direct impact on calculations that can be affirmed by comparisons with benchmark experiments, it is more difficult to quantify the reliability of uncertainty estimates. In general, the SCALE covariance library should be viewed as a best-estimate assessment of data uncertainties. Nevertheless, it is felt that the SCALE covariance library is a reasonable representation of the nuclear data uncertainties, given the current lack of information. The usefulness of these data uncertainties is discussed in Section 1. 


\subsection{VALID LIBRARY AND PROCEDURE}

As mentioned previously, the models of the benchmark experiments used in this work were generated and are maintained in accordance with the VALID procedure for SCALE and the Reactor and Nuclear Systems Division of Oak Ridge National Laboratory. This section discusses the VALID library and the procedure $^{6}$ that governs its development and maintenance.

The VALID library contains input, output, and other associated files generated and reviewed according to the procedure documented in Ref. 6 . The sensitivity data file (SDF) generated by TSUNAMI-3D is the most common type of other associated file. The process codified in the VALID procedure is similar to the quality assurance requirements for safety analysis work in that it requires that qualified analysts complete both the origination and the review before the models and data are entered into the archive. After a TSUNAMI-3D benchmark and its associated CSAS criticality calculation have been completed, reviewed, and added to the library, the SDFs for that evaluation are publically distributed as part of the IHECSBE. ${ }^{7,12}$ These SDFs are subsequently available to the entire criticality safety community, and the thorough review required by the procedure allows criticality safety practitioners to use the data with confidence for scoping calculations even though an internal quality assurance assessment would be required before these are used in a safety analysis.

A detailed listing of the critical experiments available in the library and used in this validation is reported above in Table 2. A reduced table is provided below to summarize the number of cases considered in each category of critical experiment. Table 3 also details which cases are performed in CSAS5/KENO V.a and which use CSAS6/KENO-VI.

Table 3. Summary of cases in the VALID library

\begin{tabular}{cllc}
\hline Sequence & \multicolumn{1}{c}{ Experiment class } & \multicolumn{1}{c}{ IHECSBE case numbers } & $\begin{array}{c}\text { Number of } \\
\text { configurations }\end{array}$ \\
\hline CSAS5/KENO V.a & HEU-MET-FAST & $15,16,17,18,19,20,21,25$, & $18 / 22^{a}$ \\
& & $30,38,40,65$ & 52 \\
& HEU-SOL-THERM & $1,13,14,16,28,29,30$ & $8 / 11^{a}$ \\
& IEU-MET-FAST & $2,3,4,5,6,7,8,9$ & 97 \\
& LEU-COMP-THERM & $1,2,10,17,42,50$ & 19 \\
& LEU-SOL-THERM & $2,3,4$ & 21 \\
& MIX-COMP-THERM & $1,2,4$ & 10 \\
& PU-MET-FAST & $1,2,5,6,8,10,18,22,23,24$ & 81 \\
& PU-SOL-THERM & $1,2,3,4,5,6,7,11,20$ & 15 \\
CSAS6/KENO-VI & HEU-MET-FAST & $5,8,9,10,11,13,24,80$ & 2 \\
& IEU-MET-FAST & 19 & 28 \\
\hline
\end{tabular}
library.

\subsection{VALIDATION METHODS}

The methods used to calculate the values reported in this validation are described in this section. These methods should not be used as an example of a rigorous or complete validation. The purpose of this report is to demonstrate the general performance of the KENO V.a and KENO-VI codes and ENDF/BVII.0 data across a wide range of problems, not to determine the bias and bias uncertainty required as part of a criticality safety assessment for a particular safety application. References 8 and 9 can be used for detailed guidance for performing a criticality safety validation. 
The performance of the codes and data is reported in terms of the calculated-to-expected $(\mathrm{C} / \mathrm{E})$ ratio. The expected $k_{\text {eff }}$ value for each benchmark model configuration is provided in the IHECSBE evaluation for each experiment. ${ }^{7}$ An estimated uncertainty is also supplied for this expected value for calculated $k_{\text {eff. }}$ The $\mathrm{C} / \mathrm{E}$ ratio and its uncertainty can be calculated from these two values in the evaluation and the calculated $k_{\text {eff }}$ and uncertainty from KENO. The $\mathrm{C} / \mathrm{E}$ is calculated as shown in Eq. (1), and the uncertainty in the $\mathrm{C} / \mathrm{E}$ is determined as shown in Eq. (2).

$$
\frac{C}{E}=\frac{k_{e f f}^{\text {calc }}}{k_{\text {eff }}^{\text {evaluation }}},
$$

where

$$
\begin{aligned}
& \mathrm{C} / \mathrm{E}=\text { calculated-to-expected ratio, } \\
& k_{\text {eff }}^{\text {calc }}=k_{\text {eff }} \text { value calculated by KENO V.a or KENO-VI, } \\
& k_{\text {eff }}^{\text {evaluation }}=k_{\text {eff }} \text { value from the evaluation for the configuration. } \\
& \sigma_{C / E}=\frac{C}{E}\left(\sqrt{\left(\frac{\sigma_{\text {calc }}}{k_{\text {eff }}^{\text {calc }}}\right)^{2}+\left(\frac{\sigma_{\text {evaluation }}}{k_{\text {eff }}^{\text {evaluation }}}\right)^{2}}\right) \text {, }
\end{aligned}
$$

where

$$
\begin{array}{ll}
\sigma_{C / E} & =\text { uncertainty in the } \mathrm{C} / \mathrm{E} \\
\mathrm{C} / \mathrm{E} & =\text { calculated-to-expected ratio, } \\
\sigma_{\text {calc }} & =\text { calculated uncertainty in the } k_{\text {eff }} \text { value from KENO V.a or KENO-VI, } \\
k_{\text {eff }}^{\text {calc }} & =k_{\text {eff }} \text { value calculated by KENO V.a or KENO-VI, } \\
\sigma_{\text {evaluation }} & =\text { uncertainty value reported in the evaluation for the configuration, } \\
k_{\text {eff }}^{\text {evaluation }} & =k_{\text {eff }} \text { value from the evaluation for the configuration. }
\end{array}
$$

An average $\mathrm{C} / \mathrm{E}$ value is determined for each category of experiment for each code, as shown in Section 4. A category of experiments is defined as a unique combination of fissile species, fissile form, and spectrum. An example of a category of experiments is HEU-MET-FAST, using abbreviations from Table 1. The average value reported is a simple arithmetic average of the individual $\mathrm{C} / \mathrm{E}$ values. An uncertainty weighting is not used. The majority of the Monte Carlo calculations were run to achieve a small stochastic uncertainty of approximately $0.00010 \Delta k_{\text {eff. }}$. The uncertainty in the evaluated $k_{\text {eff }}$ value is on the order of 10 to 50 times this magnitude, and so the primary driver in the C/E uncertainty is the uncertainty from the evaluation. These values vary significantly among the different evaluations both in magnitude and rigor, so weighting with these uncertainties is viewed as unnecessary. Furthermore, the average value and its uncertainty are intended only to be representative of the range of values that could be expected to result from a rigorous, safety-grade validation effort. The uncertainty in the average $\mathrm{C} / \mathrm{E}$ value is determined as shown in Eq. (3).

$$
\sigma_{A v g C / E}=\frac{\sqrt{\sum_{i=1}^{N}\left(\sigma_{C / E}^{i}\right)^{2}}}{N},
$$


where

$$
\begin{aligned}
\sigma_{\mathrm{AvgC} / \mathrm{E}} & =\text { uncertainty in the average } \mathrm{C} / \mathrm{E} \text { value, } \\
\sigma_{C / E}^{i} & =\text { uncertainty in the } \mathrm{C} / \mathrm{E} \text { value for a single configuration, } \\
\mathrm{N} & =\text { number of configurations included for a category of experiments. }
\end{aligned}
$$

As mentioned previously, all calculations are performed for both the 238-group and continuous energy ENDF/B-VII.0 libraries. The results for each case and category of experiments are generated and reported for each library, allowing comparison of the multigroup and continuous energy performance of the KENO codes based on the same benchmark models.

No rigorous trending analysis is performed in this validation. As discussed in Refs. 5, 8, and 9, a complete validation to support a criticality safety analysis should include an examination of the data for trends in independent variables. The primary reason for neglecting such an analysis here is, as mentioned previously, that this effort is intended to demonstrate the general performance of the KENO codes across a wide range of potential systems. Trending across such wide ranges in typical parameters such as enrichment and spectral indicators would be unlikely to result in a significant and useful trend. Trends that are apparent or implied by the results provided in Sect. 4 are discussed in Sect. 5.

The deviations of each case from a $\mathrm{C} / \mathrm{E}$ of unity are characterized in two different ways in various portions of this report. The simpler comparison is simply the difference between the $\mathrm{C} / \mathrm{E}$ and 1.0. This difference is sometimes reported in $\% \Delta k_{\text {eff }}$, which is determined by dividing the absolute difference by 100. In some cases, the difference is also reported in standard deviations. The absolute difference is divided by the uncertainty in the $\mathrm{C} / \mathrm{E}$ value to determine the deviation from unity in standard deviations. 



\section{RESULTS}

This section presents the results of the validation of KENO V.a and KENO-VI in SCALE 6.1. The results for each version of KENO are reported in separate subsections, which first report general trends by benchmark category and then provide a more detailed assessment for each category as a subsection. A complete listing of the calculated $k_{\text {eff }}$ and its uncertainty, the benchmark model $k_{\text {eff }}$ and its uncertainty, C/E values, and cross-section uncertainties is presented in Appendix A for KENO V.a cases and in Appendix B for KENO-VI cases.

\subsection{KENO V.A}

The overwhelming majority of the KENO V.a cases executed for this validation converged to a Monte Carlo stochastic uncertainty of $0.00010 \Delta k_{\text {eff. }}$. A few cases converged to $0.00050 \Delta k_{\text {eff }}$, and some cases had final uncertainty values between the two. The maximum reported uncertainty for both the 238-group and continuous energy calculations is $0.00049 \Delta k_{\text {eff. }}$ As mentioned previously in Section 3.4, this stochastic uncertainty in the calculation is at least a factor of two smaller than the benchmark evaluation uncertainty reported in Ref. 7. The uncertainty ratio for most cases is in the range of 20 to 50. The most significant factor affecting the uncertainty of the calculated $\mathrm{C} / \mathrm{E}$ values is therefore the tabulated uncertainty in the evaluation.

The average $\mathrm{C} / \mathrm{E}$ value and its uncertainty for each category of experiments is provided in Table 4 for both the 238-group and continuous energy cross-section libraries. The results show that the average $\mathrm{C} / \mathrm{E}$ values are near 1.0.

Table 4. Results by category for KENO V.a calculations

\begin{tabular}{lcccc}
\hline \multirow{2}{*}{ Category } & \multicolumn{2}{c}{ 238-group calculations } & \multicolumn{2}{c}{ Continuous energy calculations } \\
\cline { 2 - 5 } & Average C/E & $\begin{array}{c}\text { Average C/E } \\
\text { uncertainty }\end{array}$ & $\begin{array}{c}\text { Average C/E } \\
\text { Average C/E } \\
\text { uncertainty }\end{array}$ \\
\hline HEU-MET-FAST & 1.00422 & 0.00041 & 1.00004 & 0.00041 \\
HEU-SOL-THERM & 0.99904 & 0.00072 & 0.99777 & 0.00072 \\
IEU-MET-FAST & 1.00868 & 0.00083 & 1.00284 & 0.00083 \\
LEU-COMP-THERM & 0.99851 & 0.00025 & 0.99944 & 0.00025 \\
LEU-SOL-THERM & 0.99871 & 0.00083 & 0.99842 & 0.00083 \\
MIX-COMP-THERM & 0.99847 & 0.00087 & 0.99654 & 0.00087 \\
PU-MET-FAST & 1.00035 & 0.00068 & 1.00013 & 0.00068 \\
PU-SOL-THERM & 1.00430 & 0.00056 & 1.00142 & 0.00056 \\
\hline
\end{tabular}

For the 238-group calculations, the largest deviation from unity on an absolute basis occurs for the intermediate enrichment fast metal systems (IEU-MET-FAST or IMF) and is approximately $0.87 \% \Delta k_{\text {eff. }}$. The largest deviation on a relative error basis also occurs for the IMF systems and is more than 10 standard deviations from unity. It is worth noting that four of the eight categories have an average $\mathrm{C} / \mathrm{E}$ difference from unity of less than two standard deviations. Both IMF and fast metal high enriched uranium systems (HEU-MET-FAST or HMF) show a greater than 10 sigma deviation from unity for average $\mathrm{C} / \mathrm{E}$. Two other categories, low enriched uranium compound (LEU-COMP-THERM or LCT) and plutonium thermal solution (PU-SOL-THERM or PST) systems, show discrepancies of 6 to 8 sigma. The LCT experiments form the only category showing significant deviations that exhibits a negative bias with this cross-section library. 
For the continuous energy calculations, the largest deviation from unity on an absolute basis occurs for the thermal mixed compound systems (MIX-COMP-THERM or MCT) and is about $-0.35 \% \Delta k_{\text {eff. }}$. The largest deviation on a relative error basis also occurs for the MCT systems and is just under four standard deviations from unity. Only three of the eight categories have an average $\mathrm{C} / \mathrm{E}$ within two standard deviations of unity.

The average $\mathrm{C} / \mathrm{E}$ difference from unity is shown in Fig. 1 for each of the eight categories for both multigroup and continuous energy. The results are also presented in standard deviations from unity in Fig. 2. In general, it appears that the continuous energy calculations exhibit a lower $\mathrm{C} / \mathrm{E}$ deviation from unity than do the 238-group calculations. Five of the eight categories have a lower deviation for the continuous energy library. The difference between the average $\mathrm{C} / \mathrm{E}$ results is less than one standard deviation for an additional category. Only for the HST and MCT experiments do the continuous energy results demonstrate a greater deviation from unity than the 238-group library.

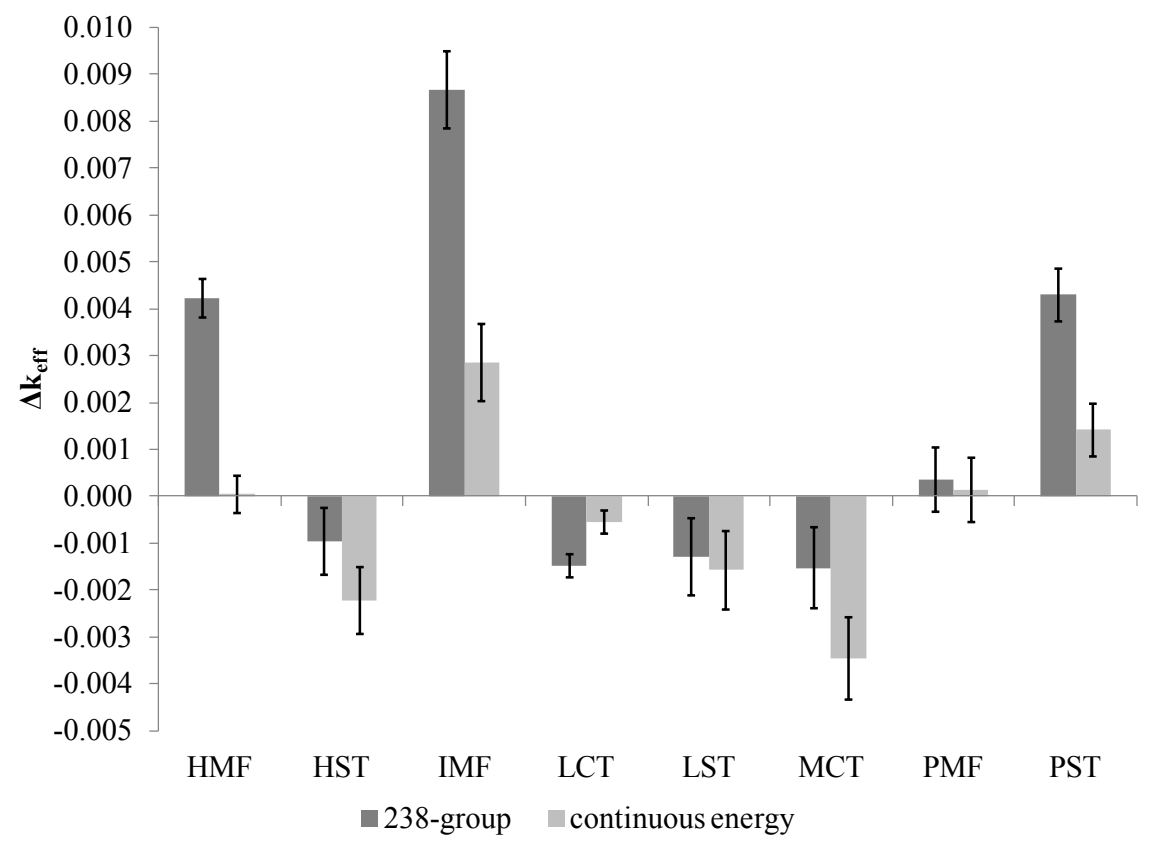

Fig. 1. Difference from unity of average C/E value by category for KENO V.a $\left(\Delta k_{\text {eff }}\right)$. 


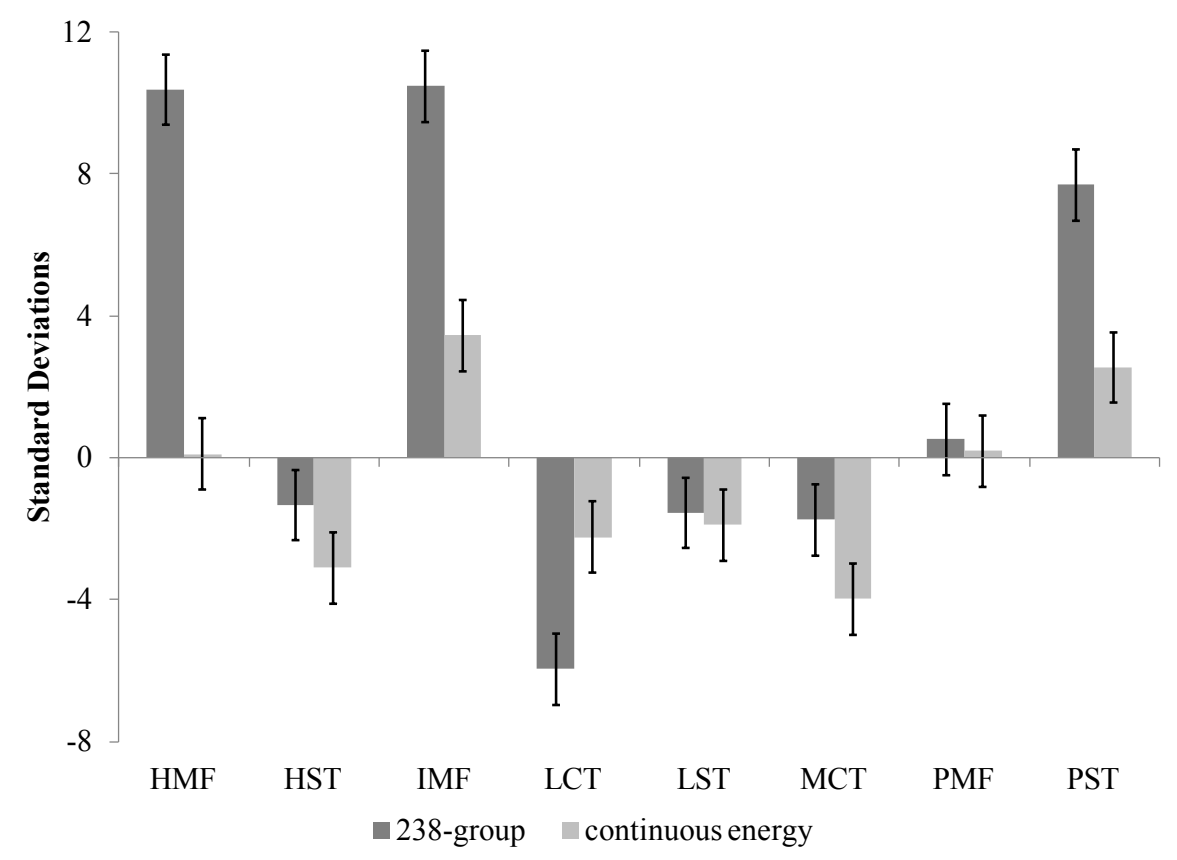

Fig. 2. Deviation from unity of average C/E value by category for KENO V.a (standard deviations).

The multigroup and continuous energy $\mathrm{C} / \mathrm{E}$ values, the benchmark $k_{\text {eff }}$ uncertainty as reported in the IHECSBE, and the uncertainty in $k_{\text {eff }}$ due to uncertainties tabulated in the cross-section covariance data for each case in each category of benchmarks are detailed in the subsections below. In the C/E figures, the reported benchmark uncertainty for each case is also shown as dotted lines, and the multigroup crosssection uncertainty values are shown as dashed lines.

\subsubsection{HMF Systems}

The C/E data for the HMF systems presented in Fig. 3 demonstrate a generally bimodal distribution of differences between multigroup and continuous energy $\mathrm{C} / \mathrm{E}$ values. A majority of the cases show good agreement with $\mathrm{C} / \mathrm{E}$ values within $0.25 \%$ of each other. Most of the rest of the cases exhibit differences between $0.5 \%$ and $1 \%$. The HMF- 025 series of experiments is of particular interest as the agreement between multigroup and continuous energy results is good for Case 1 and deviates nearly linearly with increasing case number. The HMF-025 experiments use axial reflectors of increasing thickness. The increased reflector thickness is likely the primary cause of the increasing deviation between multigroup and continuous energy results observed in these cases.

The $\mathrm{C} / \mathrm{E}$ values are also compared to the experimental and multigroup cross-section uncertainties at the one- and two-sigma level. Regarding the benchmark uncertainties, only $41 \%$ of the multigroup cases are within two standard deviations of the expected $k_{\text {eff }}$ value. The continuous energy calculations perform slightly better with $59 \%$ of cases within two sigma. The cross-section uncertainties bound all points for both libraries at the two-sigma level, and all but two multigroup cases at the one-sigma level. 


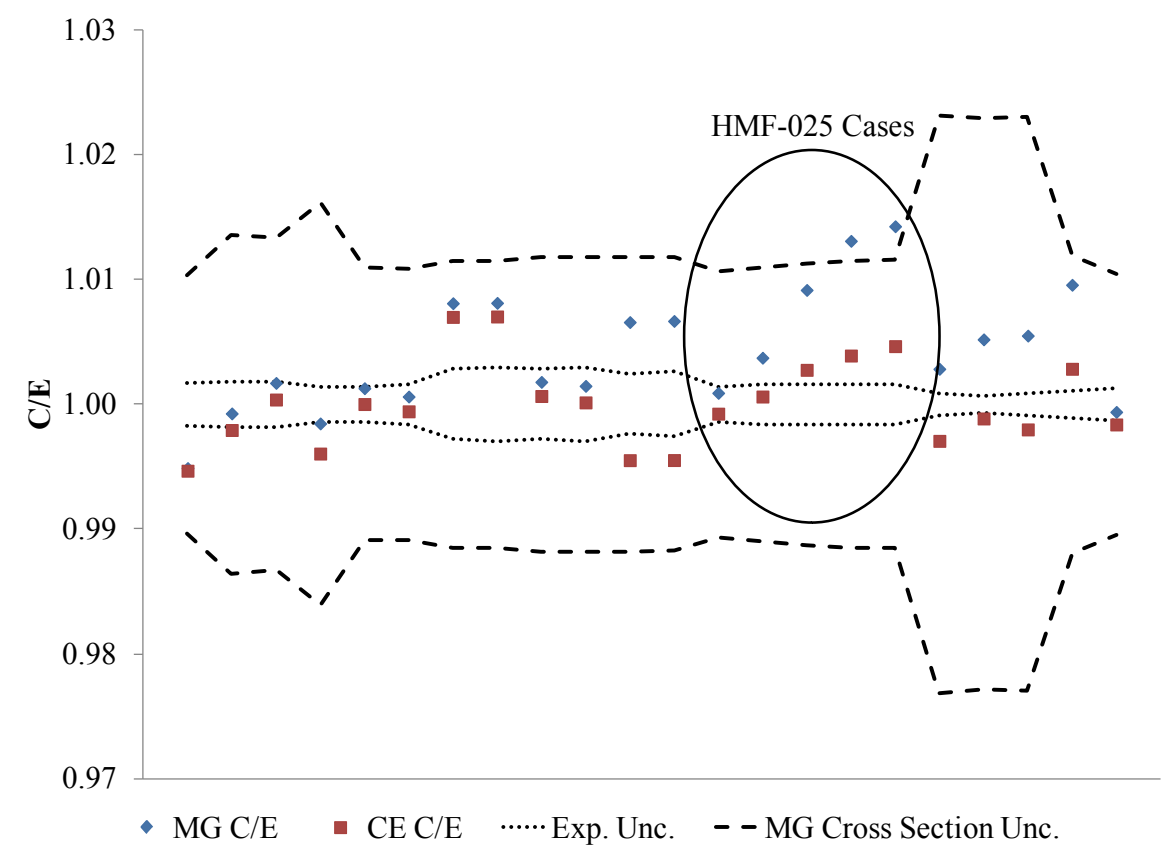

Fig. 3. Detailed results for HMF systems, KENO V.a.

\subsubsection{HST Systems}

The C/E data for the HST systems presented in Fig. 4 demonstrate generally consistent behavior between multigroup and continuous energy $\mathrm{C} / \mathrm{E}$ values. The majority of cases show good agreement with $\mathrm{C} / \mathrm{E}$ values within $0.25 \%$ of each other. The rest of the cases exhibit differences less than $0.5 \%$. Several points with high $\mathrm{C} / \mathrm{E}$ values for both multigroup and continuous energy cross-section libraries are apparent. These cases belong to the HST-014 and HST-016 series of experiments. Both series contain three cases, each with varying amounts of dissolved gadolinium. The gadolinium is introduced in the second case and increased significantly in the third case. Five additional HST experiment series reported in Ref. 7 contain soluble gadolinium, but none of those experiment series are available within the VALID library. 


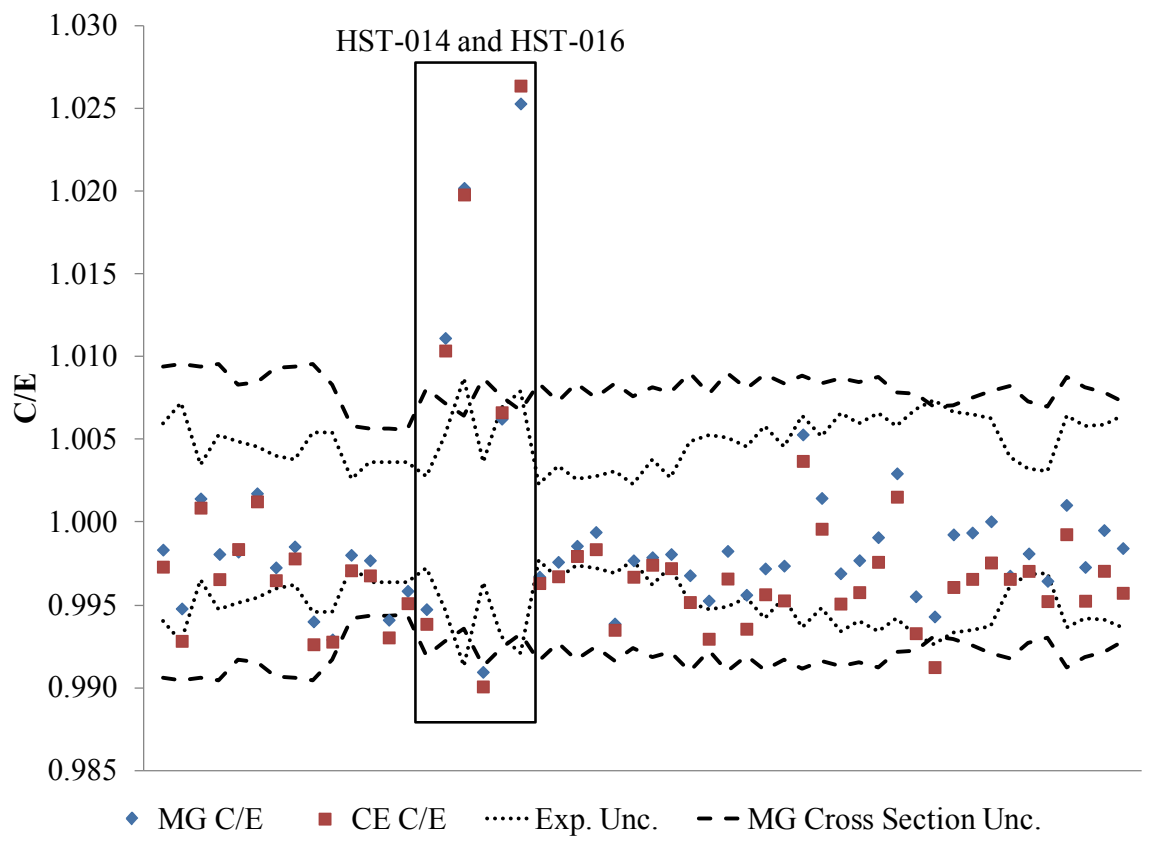

Fig. 4. Detailed results for HST systems.

A review of Section 4 of the HST-014 and HST-016 reports contained in Ref. 7 shows that sample results involving other computer codes and cross-section libraries manifest similar trends in overprediction of $k_{\text {eff }}$ with increasing gadolinium concentration. The cross-section uncertainty values determined by TSUNAMI actually decrease with increasing gadolinium concentration. The $c_{k}$ values for Case 3 in each series compared to Cases 1 and 2 in the same series are in excess of 0.98 . These high $\mathrm{c}_{\mathrm{k}}$ values indicate that the discrepancy in calculated $k_{\text {eff }}$ results is not a result of the increasing gadolinium concentration. The sensitivity of $k_{\text {eff }}$ to the ${ }^{157} \mathrm{Gd}$ cross section is shown in Fig. 5. Here it is observed that the sensitivity does increase with the increasing gadolinium concentration from case 2 to case 3 in each evaluation. However, the overall magnitude of the sensitivity indicates that any error in the ${ }^{157} \mathrm{Gd}$ cross section is not the likely source of the systematic bias for these cases. Examining HST-016 Case 3, the sensitivity of $k_{\text {eff }}$ to the ${ }^{157} \mathrm{Gd}(\mathrm{n}$,gamma) cross section is $-0.156(\Delta \mathrm{k} / \mathrm{k}) /(\Delta \sigma / \sigma)$, as indicated by the Integral Value shown in the legend of the plot. As HST-016 Case 3 demonstrates a positive bias of $2.5 \% \Delta \mathrm{k} / \mathrm{k}$, the cross section would need to be in error in excess of $1600 \%$ to cause a $2.5 \% \Delta \mathrm{k} / \mathrm{k}$ bias. As the uncertainty in the ${ }^{157} \mathrm{Gd}$ (n,gamma) cross section is less than 5\% in the energy range where this system demonstrates sensitivity, as shown in Fig. 6, it is not likely that the cross section is actually in error by $1600 \%$. In this case, the TSUNAMI tools support the conclusion that the most likely explanation for the high $\mathrm{C} / \mathrm{E}$ values for the HST-014 and HST-016 cases is some error in the experiment description, and these cases should be considered carefully before they are included in a safety evaluation. 


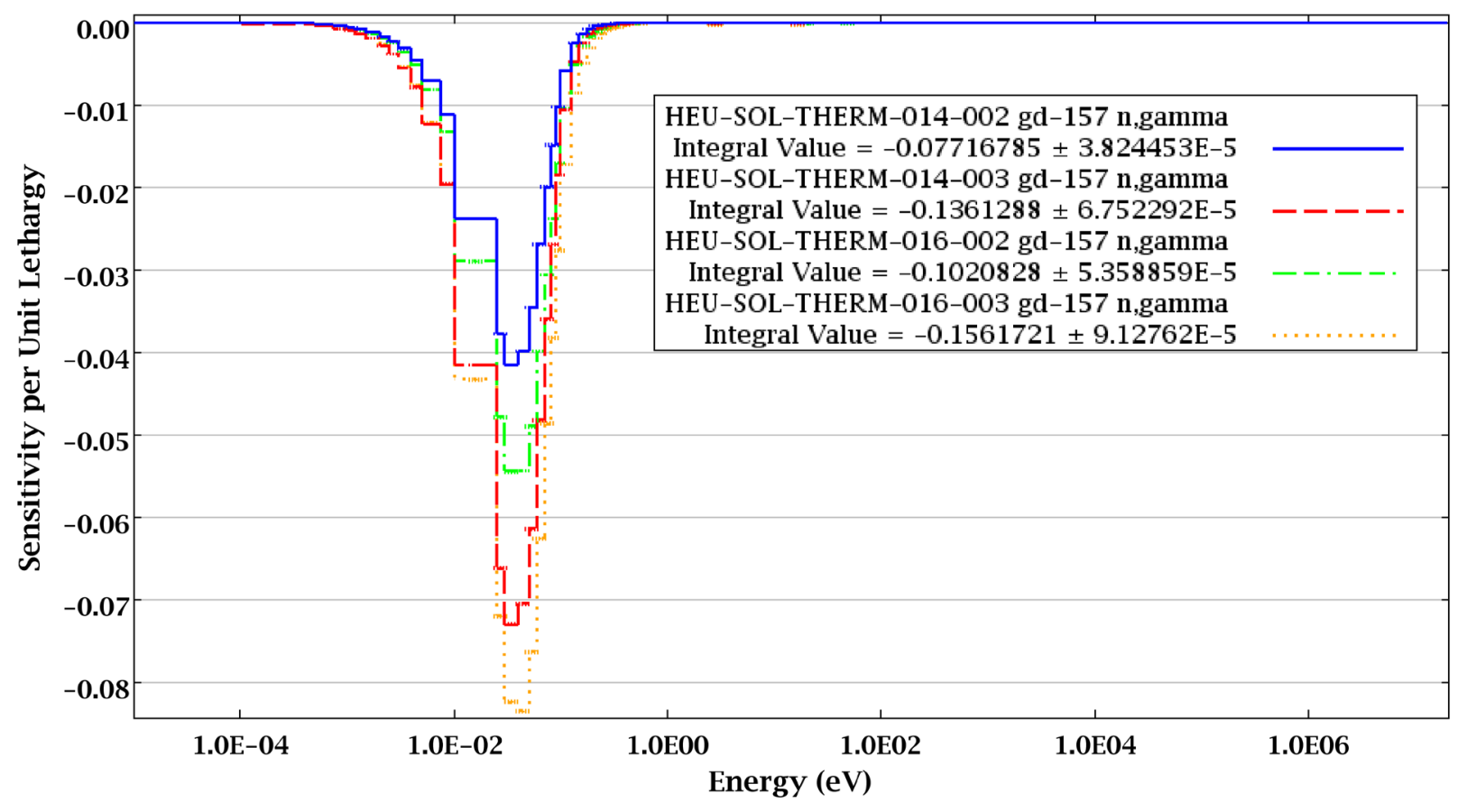

Fig. 5. Sensitivity of $k_{\text {eff }}$ to ${ }^{157}$ Gd for HST-014 and HST-016.

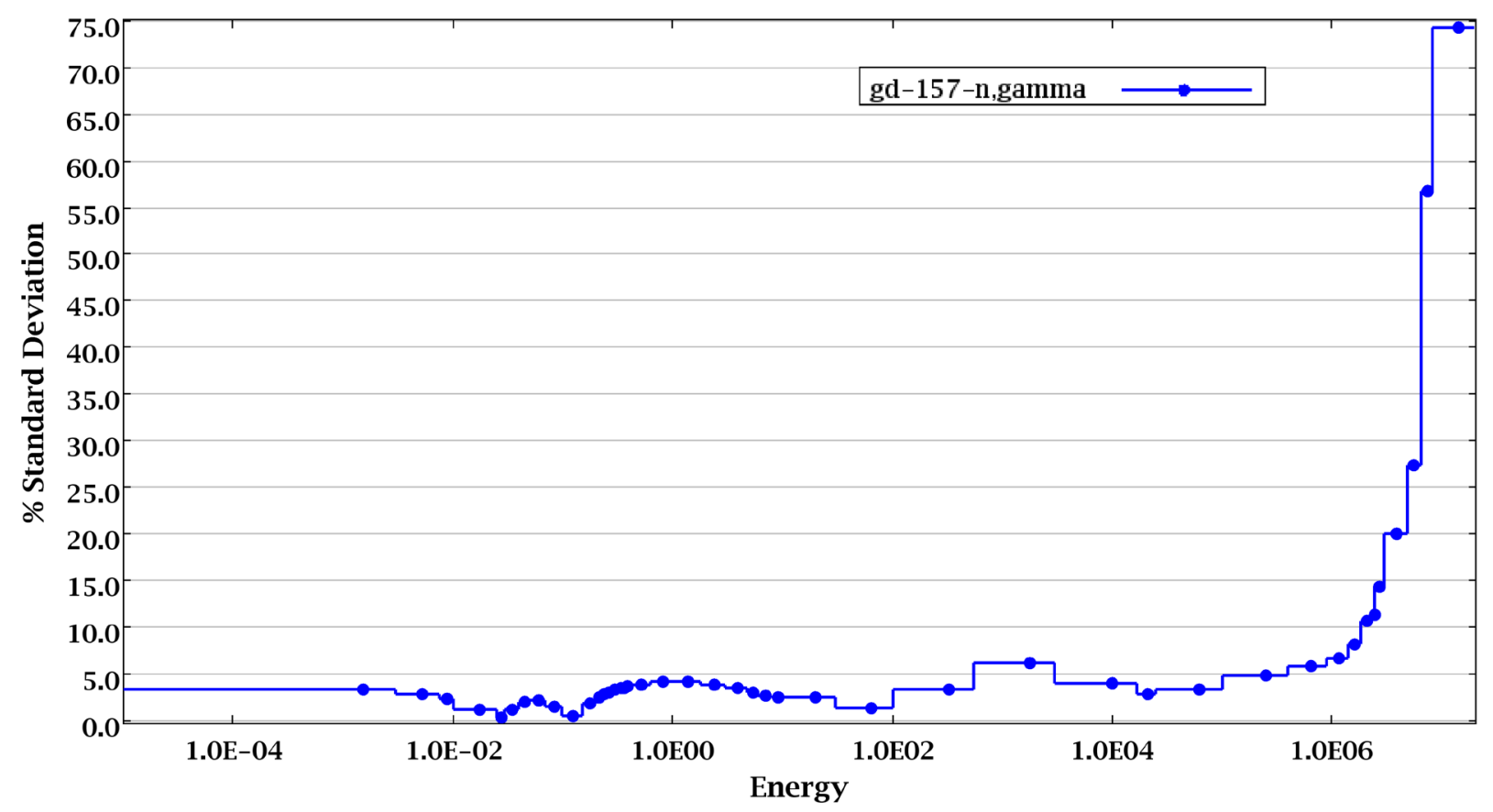

Fig. 6. Uncertainty in ${ }^{157} \mathrm{Gd}$ (n,gamma) cross section.

The $\mathrm{C} / \mathrm{E}$ values are also compared to the experimental and multigroup cross-section uncertainties at the one- and two-sigma level. The agreement is generally good. The multigroup results are slightly better than the continuous energy results, with $77 \%$ of the multigroup $\mathrm{C} / \mathrm{E}$ values within one sigma of unity and 
$63 \%$ of continuous energy cases also demonstrating this level of agreement for experimental uncertainties. The cross-section uncertainties bound all but two points for both libraries at the two-sigma level and bound $90 \%$ of cases at the one-sigma level.

\subsubsection{IMF Systems}

The C/E data for the IMF systems presented in Fig. 7 demonstrate an offset between multigroup and continuous energy $\mathrm{C} / \mathrm{E}$ values. The multigroup $\mathrm{C} / \mathrm{E}$ value is less than $0.8 \%$ higher than the continuous energy $\mathrm{C} / \mathrm{E}$ value except for the detailed and simplified models of IMF-005-001. The IMF systems show the most significant improvement between multigroup and continuous energy library results. This may be caused by more accurate representation of the ${ }^{238} \mathrm{U}$ scattering cross section in the continuous energy library. To examine this issue, IMF-003 and IMF-005 were investigated in some detail. As shown in Appendix A, the continuous energy $\mathrm{C} / \mathrm{E}$ values for these cases are approximately equivalent at 1.00243 and 1.00108 , respectively. However, the multigroup $\mathrm{C} / \mathrm{E}$ values differ substantially at 1.00577 and 1.01408 , respectively. The uncertainties in $k_{\text {eff }}$ for these systems are primarily due to ${ }^{235} \mathrm{U}$ and ${ }^{238} \mathrm{U}$ reactions, as shown in Fig. 8 and Fig. 9 for IMF-003 and IMF-005, respectively. The sensitivities to ${ }^{235} \mathrm{U}$, shown in Fig. 10, reveal that both systems respond very similarly to ${ }^{235} \mathrm{U}$. However, the sensitivities to ${ }^{238} \mathrm{U}$ (elastic) and $\left(\mathrm{n}, \mathrm{n}^{\prime}\right)$ cross sections, shown in Fig. 11, indicate differences in the system responses, and further investigation of the processing of the multigroup library is recommended. However, the difference in results between multigroup and continuous energy does not affect the usefulness of these experiments in validation. In fact, it emphasizes the need for detailed targeted validation with the same code and data library as are used in a safety evaluation. In this case, a safety evaluation using the multigroup library would be conducted using a different bias from one using the continuous energy library. If the area of applicability of the safety system is adequately covered by experiments with similar sensitivities to the cross-section data, any bias can be adequately accounted for through the validation process.

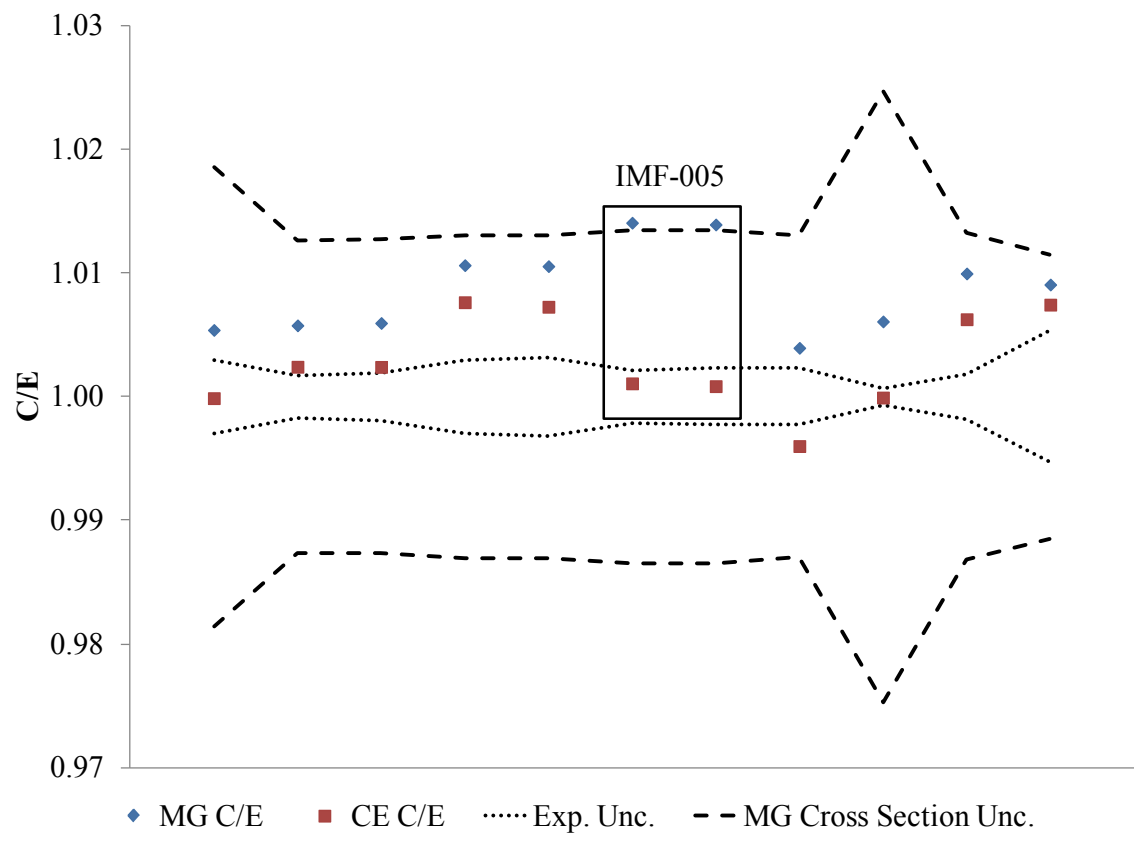

Fig. 7. Detailed results for IMF systems, KENO V.a. 


\begin{tabular}{|c|c|c|}
\hline \multicolumn{2}{|c|}{ Covariance Matrix } & Unc. in $\% \mathrm{dk} / \mathbf{k}$ \\
\hline Nuclide-Reaction & Nuclide-Reaction & Due to this Matrix \\
\hline${ }^{235} \mathrm{U}$ n,gamma & ${ }^{235} \mathrm{U}$ n,gamma & $1.1151 \mathrm{E}+00 \pm 1.1516 \mathrm{E}-04$ \\
\hline${ }^{238} \mathrm{U}$ elastic & ${ }^{238} \mathrm{U}$ n,n' & $-4.5765 \mathrm{E}-01 \pm 1.5852 \mathrm{E}-04$ \\
\hline${ }^{238} \mathrm{U}$ elastic & ${ }^{238} \mathrm{U}$ elastic & $3.6909 \mathrm{E}-01 \pm 1.8811 \mathrm{E}-05$ \\
\hline${ }^{238} \mathrm{U}$ n,n' & ${ }^{238} \mathrm{U}$ n,n' & $3.5513 \mathrm{E}-01 \pm 3.0403 \mathrm{E}-04$ \\
\hline${ }^{235} \mathrm{U}$ elastic & ${ }^{235} \mathrm{U}$ n,gamma & $3.0515 \mathrm{E}-01 \pm 1.1863 \mathrm{E}-05$ \\
\hline${ }^{235} \mathrm{U}$ chi & ${ }^{235} \mathrm{U}$ chi & $2.7049 \mathrm{E}-01 \pm 4.5186 \mathrm{E}-07$ \\
\hline${ }^{235} \mathrm{U}$ n,n' & ${ }^{235} \mathrm{U}$ n,n' & $2.6154 \mathrm{E}-01 \pm 5.6635 \mathrm{E}-05$ \\
\hline${ }^{235} \mathrm{U}$ elastic & ${ }^{235} \mathrm{U}$ n,n' & $-2.4297 \mathrm{E}-01 \pm 2.0807 \mathrm{E}-05$ \\
\hline${ }^{235} \mathrm{U}$ fission & ${ }^{235} \mathrm{U}$ fission & $2.2699 \mathrm{E}-01 \pm 1.7859 \mathrm{E}-06$ \\
\hline${ }^{238} \mathrm{U}$ nubar & ${ }^{238} \mathrm{U}$ nubar & $1.6996 \mathrm{E}-01 \pm 2.0705 \mathrm{E}-07$ \\
\hline
\end{tabular}

Fig. 8. Contributors to uncertainty in $\boldsymbol{k}_{\text {eff }}$ for IMF-003.

\begin{tabular}{|c|c|c|}
\hline \multicolumn{2}{|c|}{ Covariance Matrix } & Unc. in \% $\mathbf{d k} / \mathbf{k}$ \\
\hline Nuclide-Reaction & Nuclide-Reaction & Due to this Matrix \\
\hline${ }^{235} \mathrm{U}$ n,gamma & ${ }^{235} \mathrm{U}$ n,gamma & $1.2077 \mathrm{E}+00 \pm 1.1803 \mathrm{E}-04$ \\
\hline${ }^{235} \mathrm{U}$ chi & ${ }^{235} \mathrm{U}$ chi & $2.6004 \mathrm{E}-01 \pm 4.1739 \mathrm{E}-07$ \\
\hline${ }^{235} \mathrm{U}$ elastic & ${ }^{235} \mathrm{U}$ n,gamma & $2.4774 \mathrm{E}-01 \pm 1.0598 \mathrm{E}-05$ \\
\hline${ }^{238} \mathrm{U}$ elastic & ${ }^{238} \mathrm{U}$ elastic & $2.4699 \mathrm{E}-01 \pm 1.0719 \mathrm{E}-05$ \\
\hline${ }^{235} \mathrm{U}$ fission & ${ }^{235} \mathrm{U}$ fission & $2.2369 \mathrm{E}-01 \pm 1.6854 \mathrm{E}-06$ \\
\hline${ }^{238} \mathrm{U}$ elastic & ${ }^{238} \mathrm{U}$ n,n' & $-2.0925 \mathrm{E}-01 \pm 9.7319 \mathrm{E}-05$ \\
\hline${ }^{56} \mathrm{Fe}$ elastic & ${ }^{56} \mathrm{Fe}$ elastic & $2.0083 \mathrm{E}-01 \pm 9.0655 \mathrm{E}-06$ \\
\hline${ }^{235} \mathrm{U}$ n,n' & ${ }^{235} \mathrm{U}$ n,n' & $1.9520 \mathrm{E}-01 \pm 4.3250 \mathrm{E}-05$ \\
\hline${ }^{238} \mathrm{U}$ n,n' & ${ }^{238} \mathrm{U}$ n,n' & $1.8882 \mathrm{E}-01 \pm 2.1825 \mathrm{E}-04$ \\
\hline${ }^{235} \mathrm{U}$ elastic & ${ }^{235} \mathrm{U} n, \mathrm{n}^{\prime}$ & $-1.6855 \mathrm{E}-01 \pm 1.2801 \mathrm{E}-05$ \\
\hline
\end{tabular}

Fig. 9. Contributors to uncertainty in $\boldsymbol{k}_{\text {eff }}$ for IMF-005. 


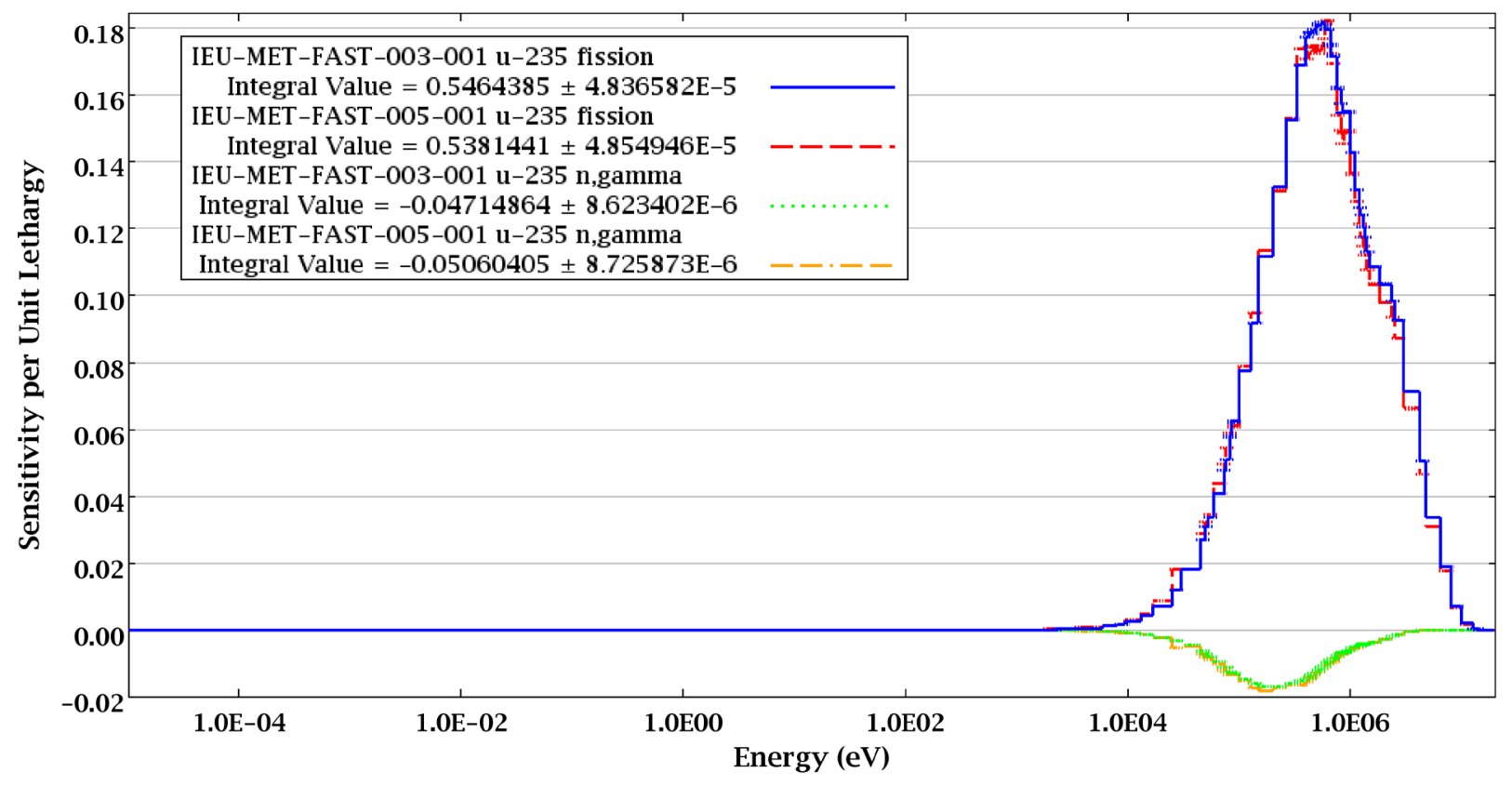

Fig. 10. ${ }^{235} \mathrm{U}$ sensitivities for IMF-003 and IMF-005.

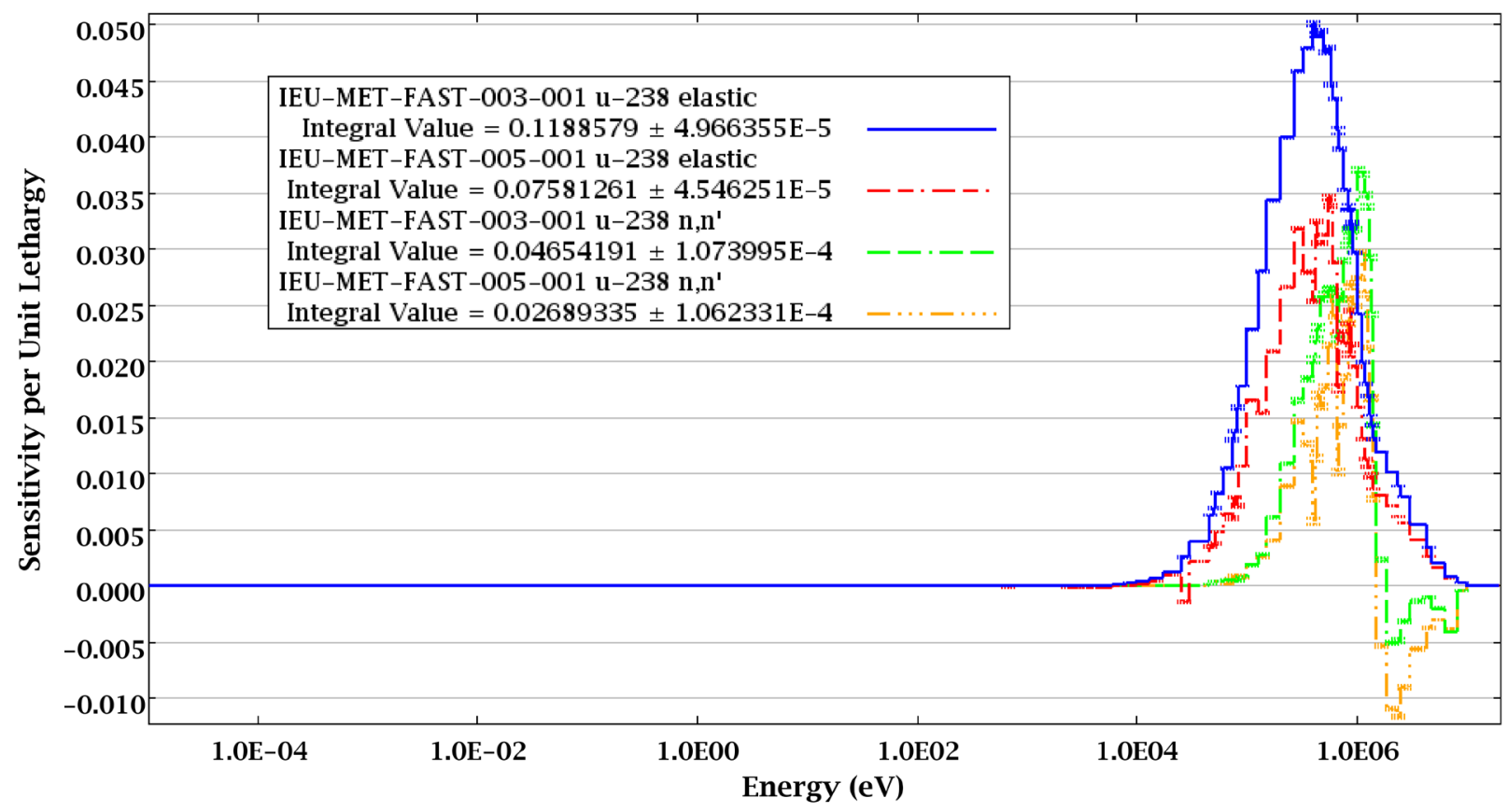

Fig. 11. ${ }^{238} \mathrm{U}$ sensitivities for IMF-003 and IMF-005.

The $\mathrm{C} / \mathrm{E}$ values are also compared to the experimental and multigroup cross-section uncertainties at the one- and two-sigma level. None of the multigroup $\mathrm{C} / \mathrm{E}$ values are within one standard deviation of the expected value based on experimental uncertainties, and only $27 \%$ are within two sigma. The continuous energy results demonstrate better agreement, with more than a third of cases within one sigma considering 
experimental uncertainty and $73 \%$ within two standard deviations. The cross-section uncertainties bound $82 \%$ of the multigroup $\mathrm{C} / \mathrm{E}$ values and all of the continuous energy $\mathrm{C} / \mathrm{E}$ values at the one-sigma level. The remaining points are captured at the two-sigma level of cross-section uncertainty.

\subsubsection{LCT Systems}

The C/E data for the LCT systems presented in Fig. 12 generally demonstrate consistent performance between multigroup and continuous energy $\mathrm{C} / \mathrm{E}$ calculations. Most of the cases show a separation between $0.05 \%$ and $0.15 \%$ between multigroup and continuous energy $\mathrm{C} / \mathrm{E}$ values. The continuous energy $\mathrm{C} / \mathrm{E}$ values tend to be slightly larger than the multigroup values, with a smaller average deviation than that observed for other categories of experiments.

There may be indications within the LCT-010 and LCT-017 data for systematic biases. In these experiment series, depleted uranium, lead, or steel reflecting walls are placed at a series of positions relative to the fissile material. The reflecting wall materials are varied, as is the pitch of the fuel rods. In most cases, a modest number of different reflector positions are used for each combination of pitch and reflector material. Given the limited number of points, it is difficult to draw reliable conclusions, but in several cases there appears to be a trend of increasing $\mathrm{C} / \mathrm{E}$ value for both multigroup and continuous energy libraries with increasing separation from the reflectors. The majority of $\mathrm{C} / \mathrm{E}$ values are less than one, so it appears that predictions improve as the reflector worth is reduced.

The C/E values are also compared to the experimental and multigroup cross-section uncertainties at the one- and two-sigma level. Almost $90 \%$ of the multigroup cases are within two standard deviations of the expected $k_{\text {eff }}$ value. The continuous energy calculations perform slightly better, with almost $95 \%$ of cases within two sigma. The cross-section uncertainties bound all points for both libraries at the one-sigma level.

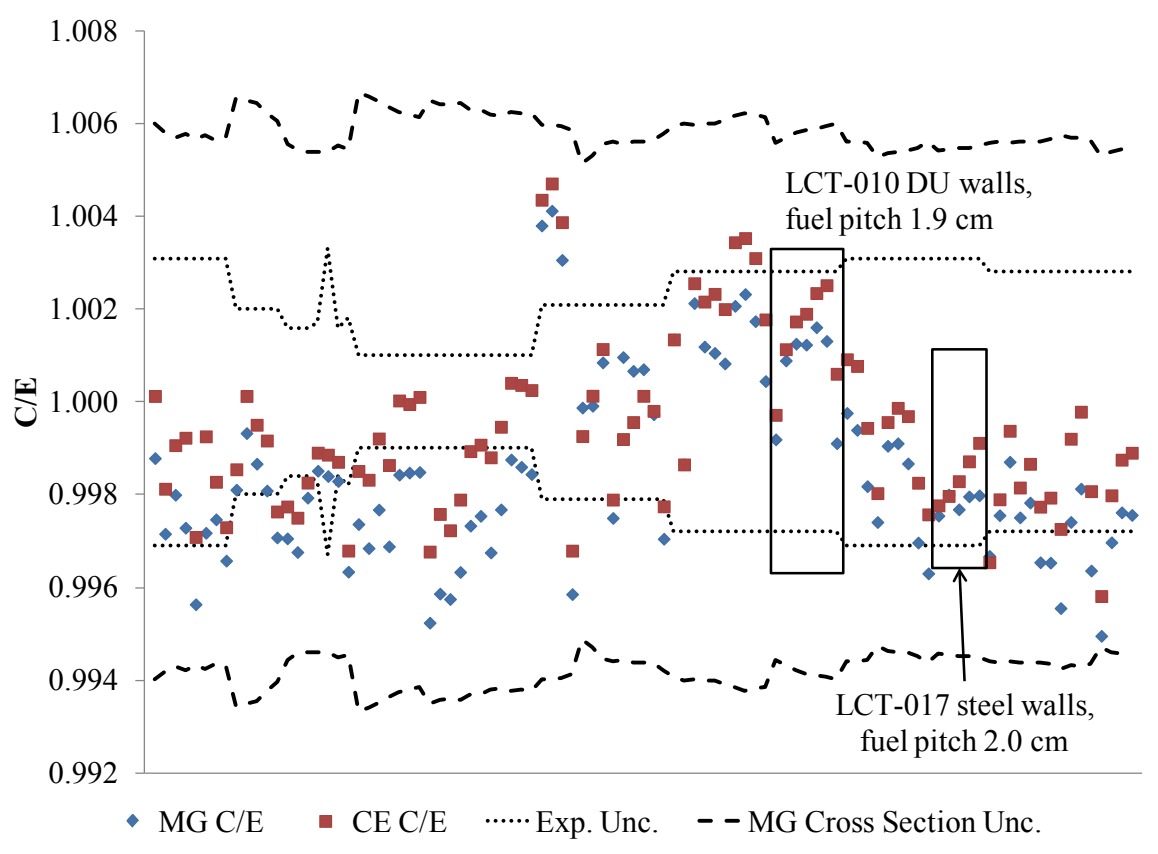

Fig. 12. Detailed results for LCT systems. 


\subsubsection{LST Systems}

The C/E data for the LST systems presented in Fig. 13 demonstrate consistent performance between multigroup and continuous energy calculations. The $\mathrm{C} / \mathrm{E}$ values for all cases are within $0.2 \%$ of each other. All but two cases are within $0.1 \%$; this category of experiments demonstrates the best agreement between multigroup and continuous energy results.

The $\mathrm{C} / \mathrm{E}$ values are also compared to the experimental and multigroup cross-section uncertainties at the one- and two-sigma level. The multigroup results are in good agreement with the expected distribution relative to the experimental uncertainty, with $63 \%$ of cases within one sigma and $95 \%$ within two. The continuous energy results show only $53 \%$ within one standard deviation of experimental uncertainty, but all cases are within two standard deviations. The cross-section uncertainties bound $89 \%$ of points for both libraries at the one-sigma level and bound all cases with both libraries at the two-sigma level.

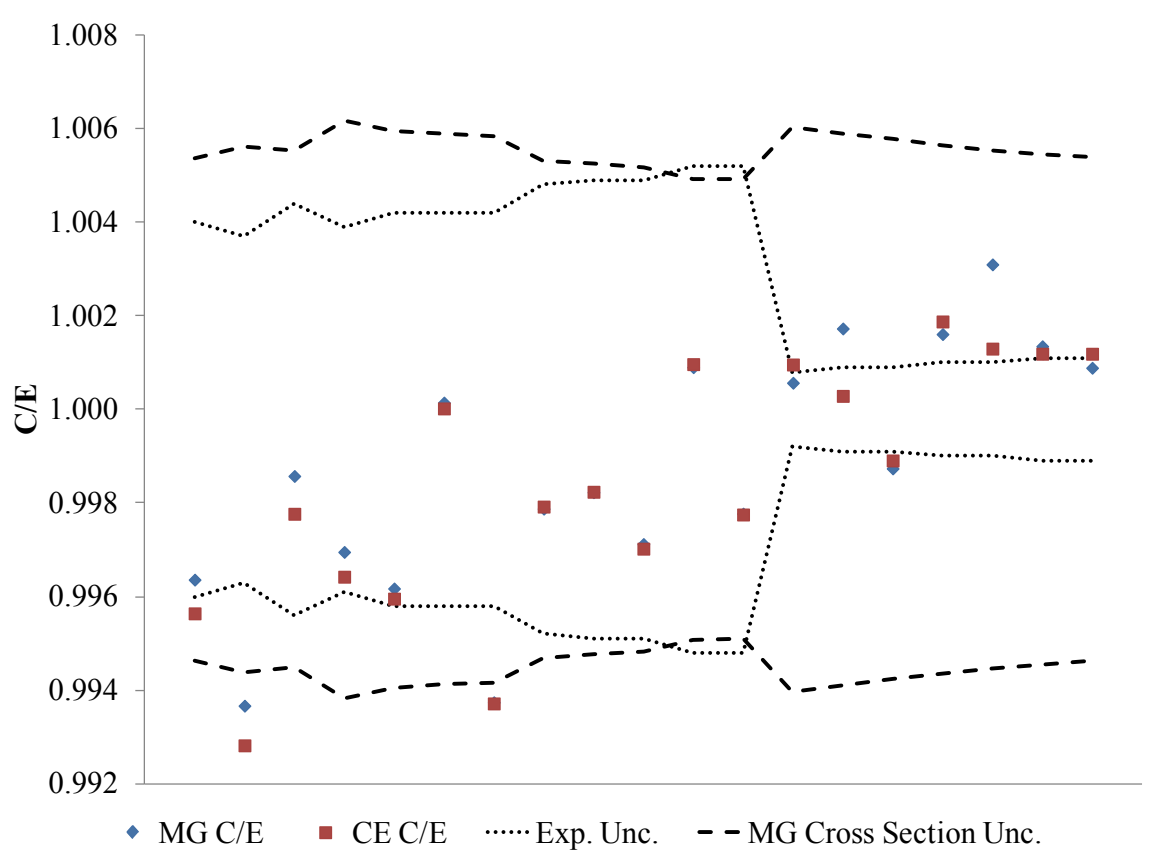

Fig. 13. Detailed results for LST systems.

\subsubsection{MCT Systems}

The $\mathrm{C} / \mathrm{E}$ data for the MCT systems presented in Fig. 14 demonstrate a somewhat discrepant behavior between multigroup and continuous energy $\mathrm{C} / \mathrm{E}$ values. Most of the cases show a separation between $0.1 \%$ and $0.3 \%$ between multigroup and continuous energy. The continuous energy $\mathrm{C} / \mathrm{E}$ values tend to be slightly lower than the multigroup values. The multigroup bias appears to be less than the continuous energy bias for this category of experiments.

There appear to be two trends within the MCT-004 data. In this evaluation, a series of fuel-rod pitches is examined over a period of several years. For the first trend, as the fuel-rod pitch is increased from $1.825 \mathrm{~cm}$ for Case 1 up to 2.474 for Case 11, there appears to be a systematic bias between multigroup and continuous energy results that diminishes for increasing rod pitch. The difference in $\mathrm{C} / \mathrm{E}$ between multigroup and continuous energy is $0.28 \% \Delta \mathrm{k}$ for Case 1 and $0.09 \% \Delta \mathrm{k}$ for Case 11 . An examination of the continuous energy processing of the $S(\alpha, \beta)$ data has revealed an opportunity for improvement in the 
continuous energy processing strategy that is a significant contributor to this trend. The sensitivity of $k_{\text {eff }}$ to ${ }^{1} \mathrm{H}$ elastic scattering and ${ }^{240} \mathrm{Pu}$, shown in Fig. 15, demonstrates the effect of the increased rod pitch from Case 1 to Case 11. The smaller pitch for Case 1 results in spectral hardening and increases the sensitivity of $k_{\text {eff }}$ to the $1 \mathrm{eV}$ resonance of ${ }^{240} \mathrm{Pu}$. The sensitivity of ${ }^{1} \mathrm{H}$ elastic scattering is correspondingly increased at $1 \mathrm{eV}$, as any scattering that results in an increased resonance escape probability would contribute to an increase in $k_{\text {eff. }}$. The differences in the multigroup and continuous energy $\mathrm{S}(\alpha, \beta)$ treatments are exacerbated by spectral hardening in these systems. Currently, this systemic bias in the continuous energy results can be quantified through robust validation, and the continuous energy data will be updated in the next release of SCALE.

In addition to the rod-pitch variation, the time scale over which the experiments were performed allows for a significant decay period for ${ }^{241} \mathrm{Pu}$ to transition to ${ }^{241} \mathrm{Am}$. As the experiment number is increased, the $\mathrm{C} / \mathrm{E}$ values for both multigroup and continuous energy calculations approach unity.

The total sensitivities for ${ }^{239} \mathrm{Pu},{ }^{241} \mathrm{Pu}$, and ${ }^{241} \mathrm{Am}$ are shown in Fig. 16, and the total sensitivities for ${ }^{235} \mathrm{U}$ and ${ }^{238} \mathrm{U}$ are shown in Fig. 17. As the ${ }^{241} \mathrm{Pu} /{ }^{241} \mathrm{Am}$ ratio is a variable in these experiments, it would be a likely candidate for the systematic bias for both the multigroup and continuous energy calculations.

However, the sensitivity data demonstrate that this may not be the most significant contributor to this systematic bias. As shown in Fig. 16, the ${ }^{239} \mathrm{Pu}$ sensitivity is substantially larger and varies more between the cases than either ${ }^{241} \mathrm{Pu}$ or ${ }^{241} \mathrm{Am}$. As shown in Fig. 17, the ${ }^{235} \mathrm{U}$ sensitivity varies in approximately the same manner as the ${ }^{241} \mathrm{Am}$ sensitivity, and the ${ }^{238} \mathrm{U}$ sensitivity remains constant at thermal energies but varies at intermediate and fast energies between Cases 1 and 11. The increase in the fuel-rod pitch and its impact on ${ }^{239} \mathrm{Pu}$ and ${ }^{238} \mathrm{U}$ is the most likely contributor to the $0.281 \%$ change in $\mathrm{C} / \mathrm{E}$ for the multigroup data between Cases 1 and 11. However, this series of experiments demonstrates the need for careful consideration of all aspects of experiment design and operation.

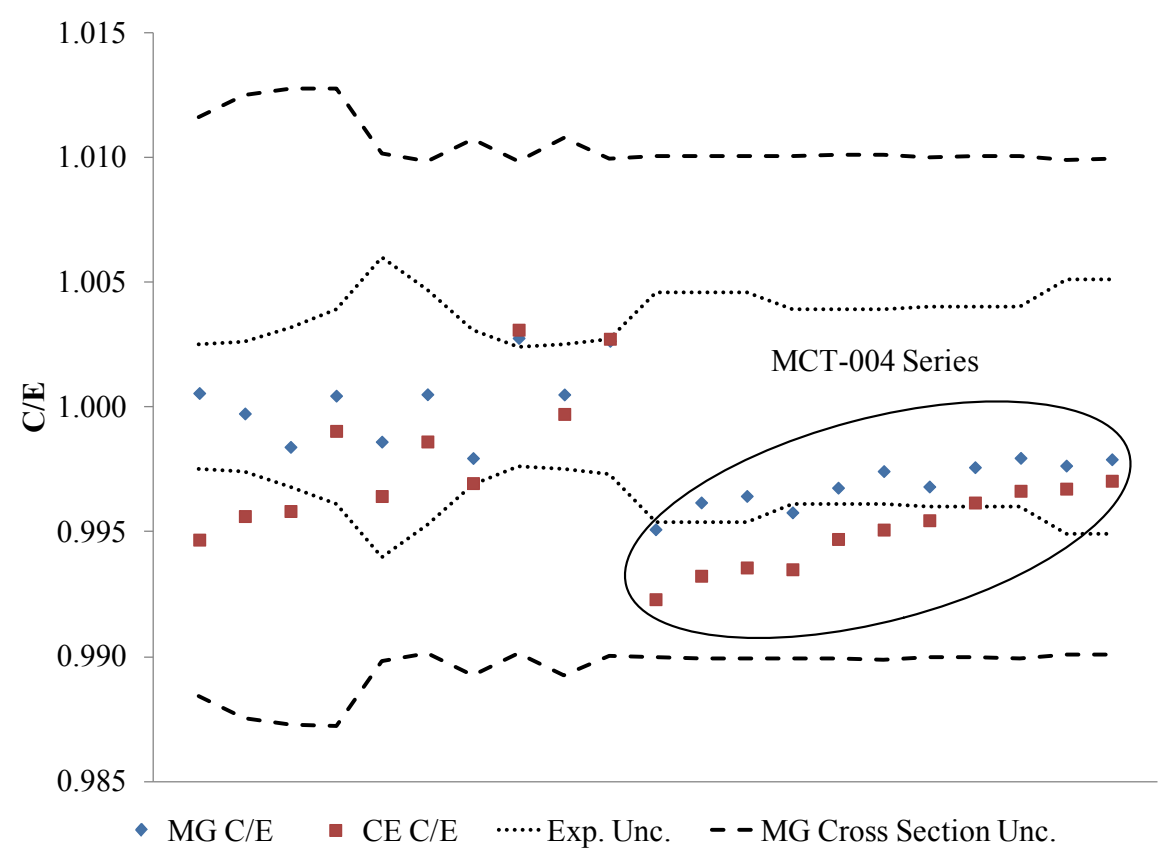

Fig. 14. Detailed results for MCT systems, KENO V.a. 


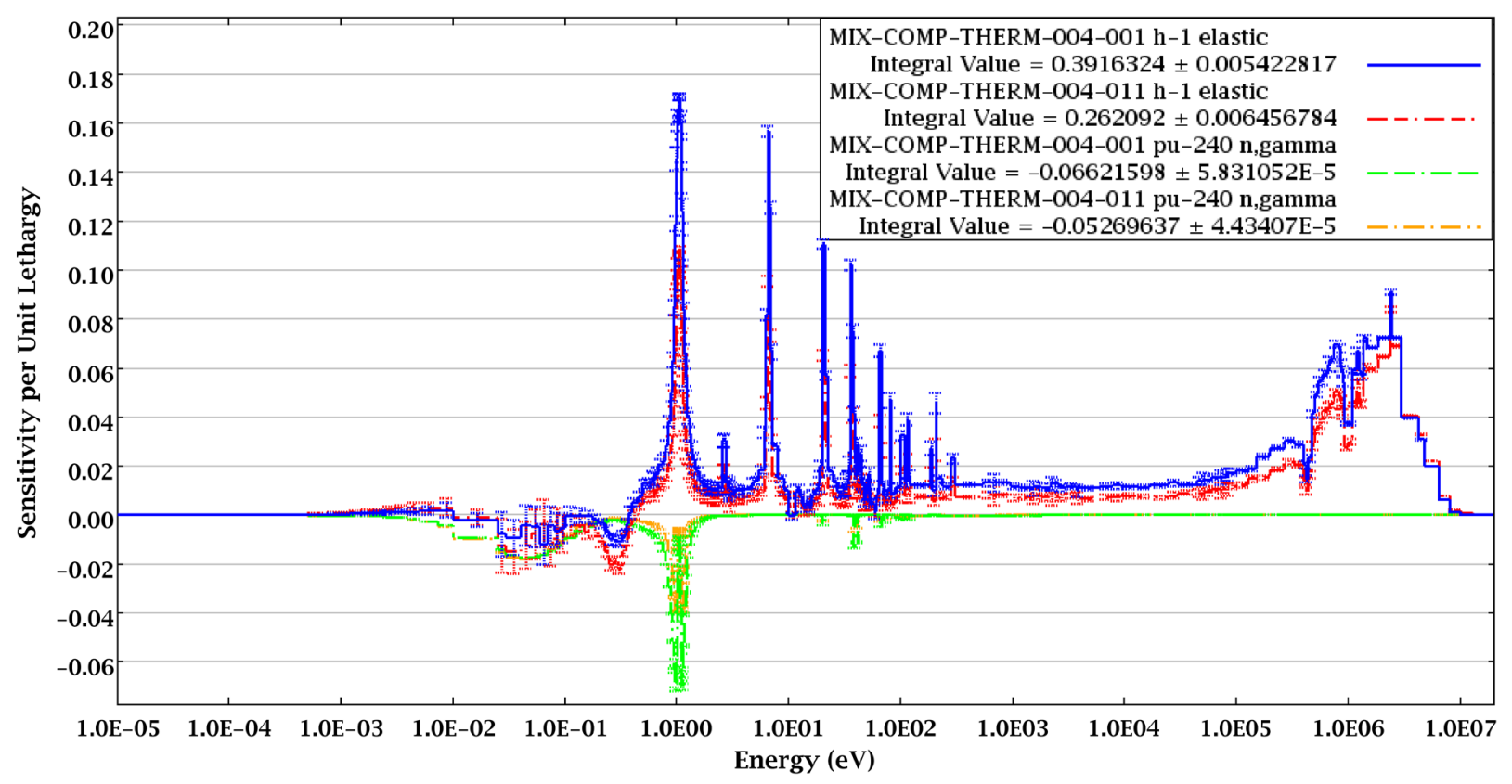

Fig. 15. Sensitivity of $k_{\text {eff }}$ to ${ }^{1} \mathrm{H}$ and ${ }^{240} \mathrm{Pu}$ for MCT-004 Cases 1 and 11.

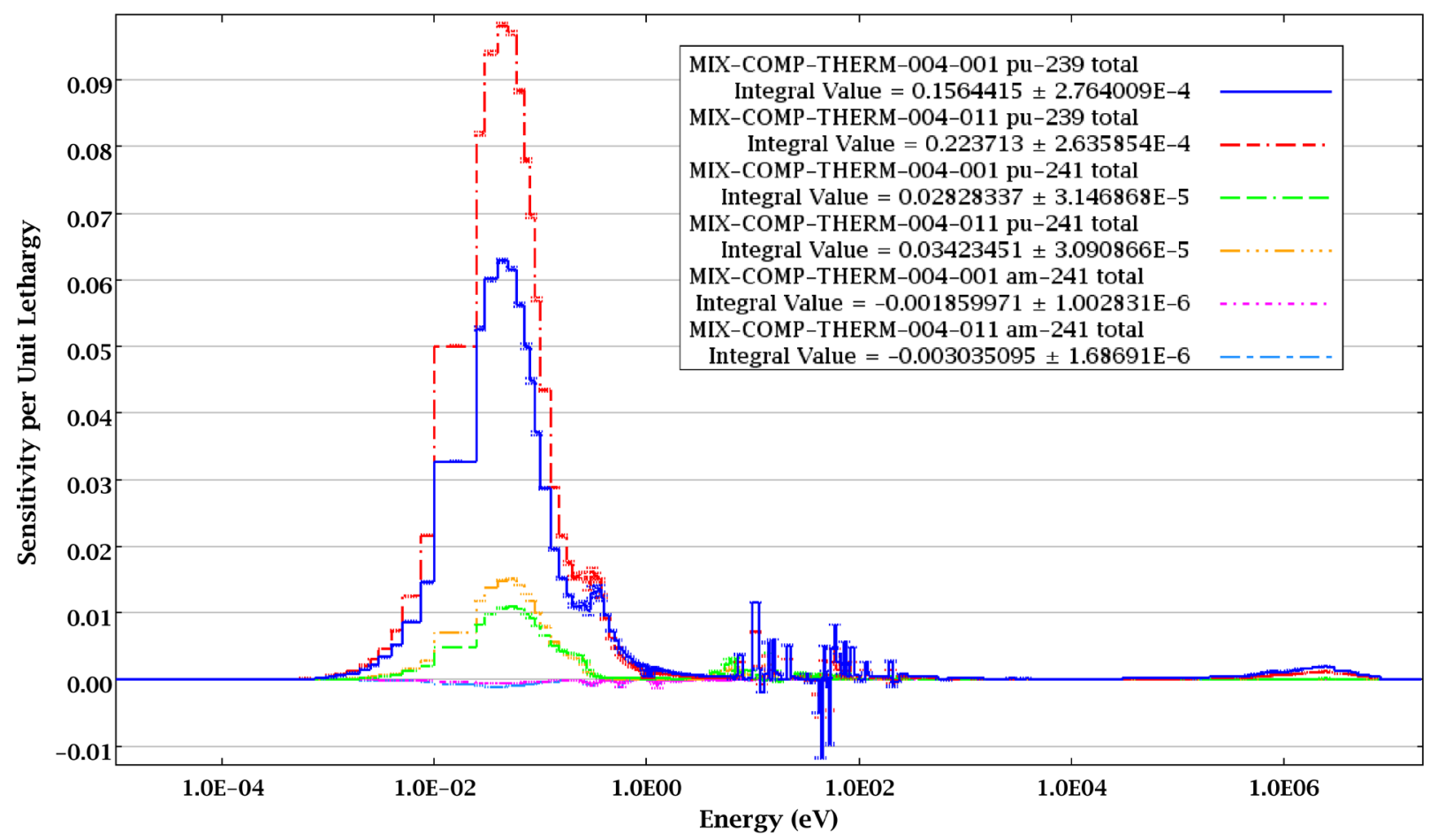

Fig. 16. Sensitivity of $k_{\text {eff }}$ to ${ }^{239} \mathrm{Pu},{ }^{241} \mathrm{Pu}$, and ${ }^{241} \mathrm{Am}$ for MCT-004 Cases 1 and 11. 


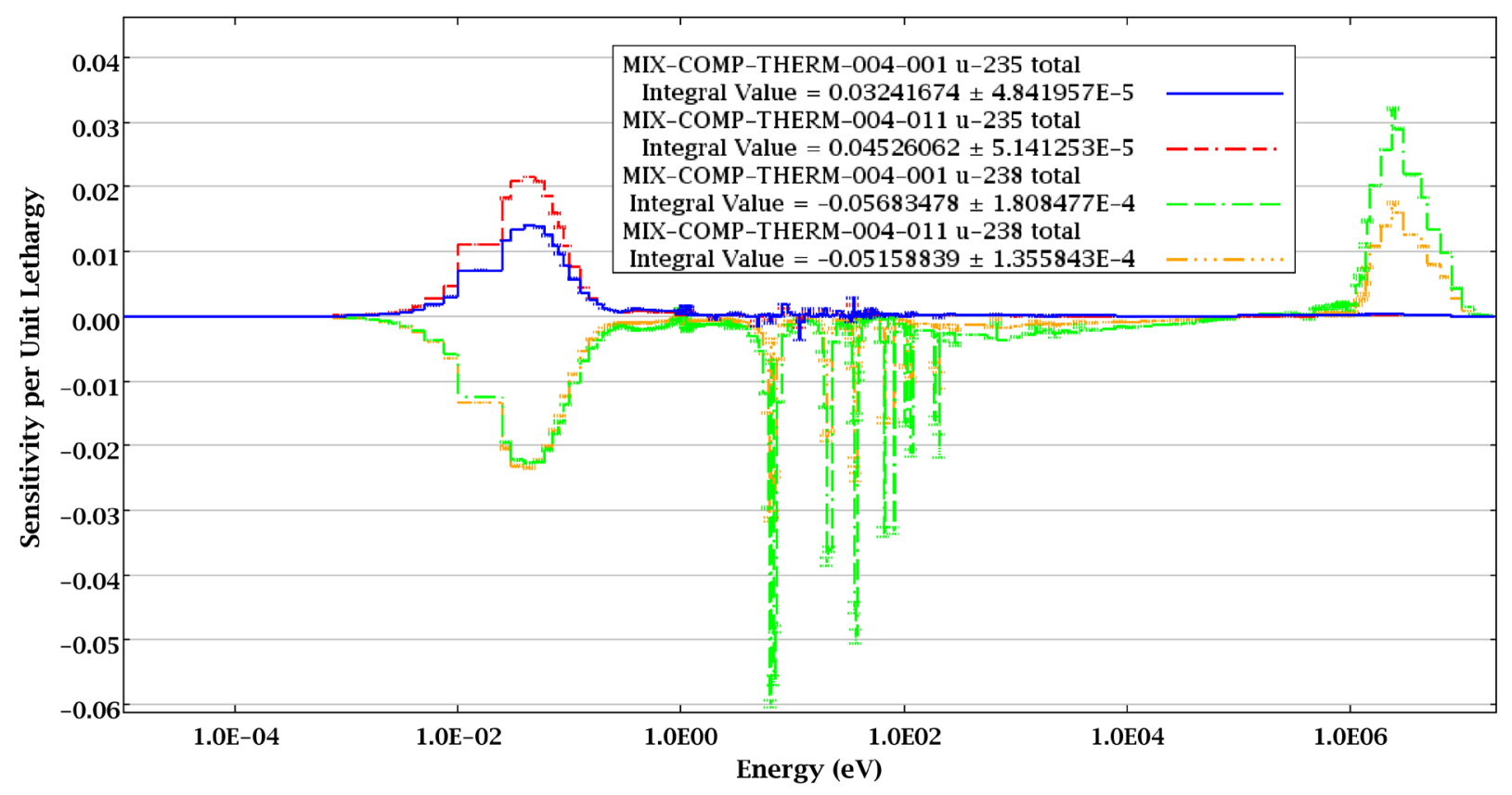

Fig. 17. Sensitivity of $k_{\text {eff }}$ to ${ }^{235} U$ and ${ }^{238} U$ for MCT-004 Cases 1 and 11.

The $\mathrm{C} / \mathrm{E}$ values are also compared to the experimental and multigroup cross-section uncertainties at the one- and two-sigma level. Almost $90 \%$ of the multigroup cases are within one standard deviation of the expected $k_{\text {eff }}$ value for experimental uncertainty. All cases are within two standard deviations. The continuous energy results show larger deviations. Only $43 \%$ of cases are within one sigma, and $95 \%$ are within two standard deviations. The cross-section uncertainties bound all points for both libraries at the one-sigma level.

\subsubsection{PMF Systems}

The $\mathrm{C} / \mathrm{E}$ data for the PMF systems presented in Fig. 18 demonstrate a fairly consistent behavior between multigroup and continuous energy $\mathrm{C} / \mathrm{E}$ values. Most of the cases show very good agreement, with $\mathrm{C} / \mathrm{E}$ values within $0.15 \%$ of each other. 


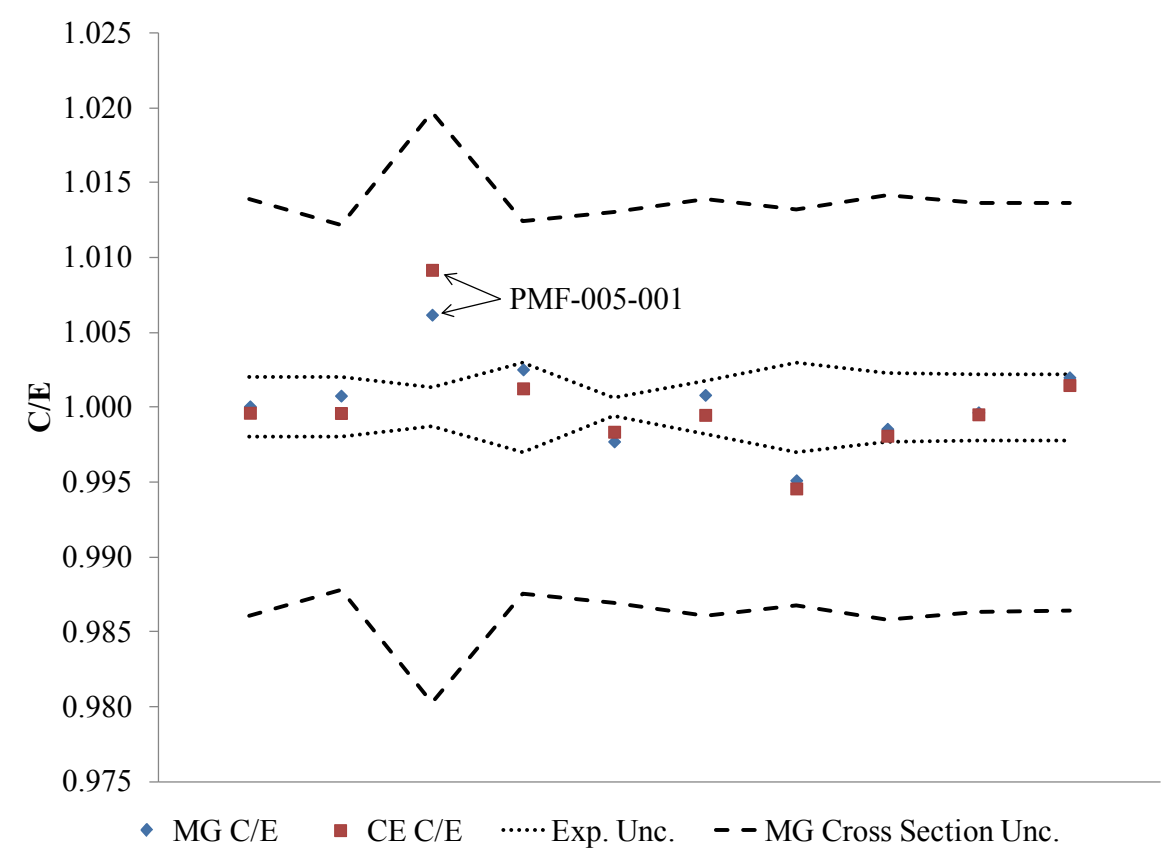

Fig. 18. Detailed results for PMF systems.

PMF-005-001 shows a relatively large C/E for both multigroup and continuous energy calculations, and the deviation from unity is nearly twice as large for the continuous energy calculation as it is for the multigroup result. The most likely cause of these aberrant results is the presence of a tungsten reflector in this experiment. No other cases within the VALID library contain a significant quantity of tungsten to provide any additional information about the accuracy of the tungsten cross sections. TSUNAMI reports the contribution of each reaction in each nuclide to the total cross-section uncertainty. The elastic and inelastic scattering cross sections for ${ }^{182} \mathrm{~W},{ }^{183} \mathrm{~W},{ }^{184} \mathrm{~W}$, and ${ }^{186} \mathrm{~W}$ are significant contributors to the overall cross-section uncertainty for this case, as shown in Fig. 19. This increase in total cross-section uncertainty is obvious in Fig. 18 for PMF-005-001. The sensitivity of $k_{\text {eff }}$ to the tungsten elastic scattering cross sections and the uncertainties in the same cross sections are shown in Fig. 20 and Fig. 21, respectively. Similarly, the data for tungsten inelastic scattering are shown in Fig. 22 and Fig. 23. Note that for both elastic and inelastic scattering the uncertainty is as high as $90 \%$ at fast energies relevant to these systems. A large bias is to be expected for calculations involving such highly uncertain cross sections, supporting the conclusion that the presence of a significant quantity of tungsten is causing the large $\mathrm{C} / \mathrm{E}$ deviations. Further investigation of the tungsten cross sections is warranted, but the uncertainty analysis does provide a bounding estimate for the actual bias observed in this system. 


\begin{tabular}{|c|c|c|}
\hline \multicolumn{2}{|c|}{ Covariance Matrix } & Unc. in $\% \mathbf{d k} / \mathbf{k}$ \\
\hline Nuclide-Reaction & Nuclide-Reaction & Due to this Matrix \\
\hline${ }^{239} \mathrm{Pu}$ nubar & ${ }^{239} \mathrm{Pu}$ nubar & $1.1953 \mathrm{E}+00 \pm 1.2703 \mathrm{E}-05$ \\
\hline${ }^{184} \mathrm{~W}$ n,n' & ${ }^{184} \mathrm{~W}$ n,n' & $7.8394 \mathrm{E}-01 \pm 5.4380 \mathrm{E}-04$ \\
\hline${ }^{186} \mathrm{~W}$ n,n' & ${ }^{186} \mathrm{~W}$ n,n' & $7.2679 \mathrm{E}-01 \pm 4.7947 \mathrm{E}-04$ \\
\hline${ }^{182} \mathrm{~W} n, \mathrm{n}^{\prime}$ & ${ }^{182} \mathrm{~W}$ n,n' & $6.7679 \mathrm{E}-01 \pm 3.8972 \mathrm{E}-04$ \\
\hline${ }^{239} \mathrm{Pu} n, n^{\prime}$ & ${ }^{239} \mathrm{Pu}$ n,n' & $5.5915 \mathrm{E}-01 \pm 3.3604 \mathrm{E}-04$ \\
\hline${ }^{183} \mathrm{~W} n, n^{\prime}$ & ${ }^{183} \mathrm{~W}$ n,n' & 5.5555E-01 $\pm 2.3994 \mathrm{E}-04$ \\
\hline${ }^{239} \mathrm{Pu}$ elastic & ${ }^{239} \mathrm{Pu}$ n,n' & $-5.2229 \mathrm{E}-01 \pm 1.6806 \mathrm{E}-04$ \\
\hline${ }^{184} \mathrm{~W}$ elastic & ${ }^{184} \mathrm{~W}$ elastic & $3.2915 \mathrm{E}-01 \pm 4.8450 \mathrm{E}-05$ \\
\hline${ }^{186} \mathrm{~W}$ elastic & ${ }^{186} \mathrm{~W}$ elastic & $3.2714 \mathrm{E}-01 \pm 4.5977 \mathrm{E}-05$ \\
\hline${ }^{239} \mathrm{Pu}$ fission & ${ }^{239} \mathrm{Pu}$ fission & $3.2659 \mathrm{E}-01 \pm 7.9042 \mathrm{E}-06$ \\
\hline${ }^{182} \mathrm{~W}$ elastic & ${ }^{182} \mathrm{~W}$ elastic & $2.5963 \mathrm{E}-01 \pm 3.1905 \mathrm{E}-05$ \\
\hline
\end{tabular}

Fig. 19. Contributors to uncertainty in $k_{\text {eff }}$ for PMF-005-001.

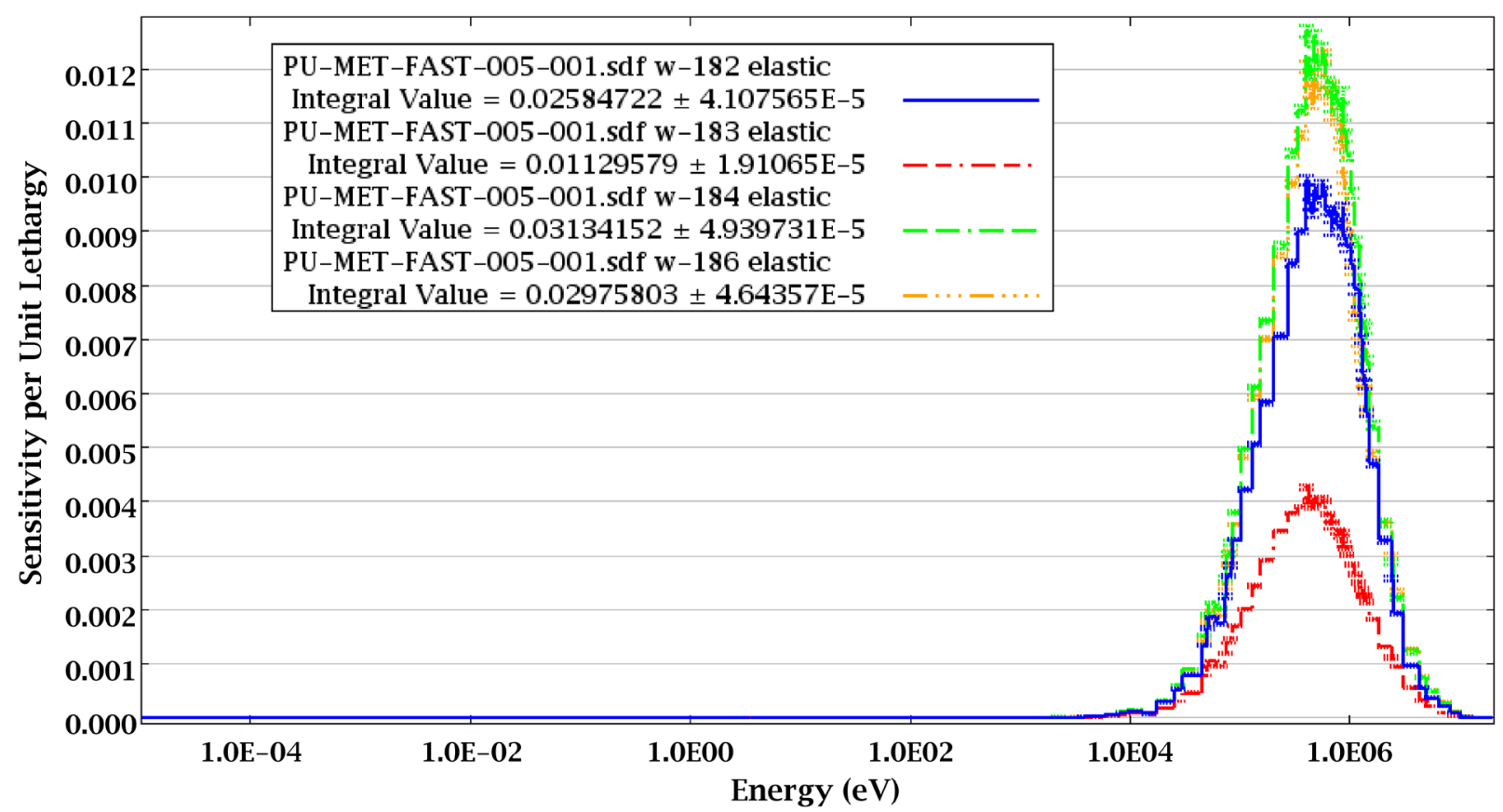

Fig. 20. Sensitivity of $\boldsymbol{k}_{\text {eff }}$ to tungsten elastic scattering cross sections for PMF-005-001. 


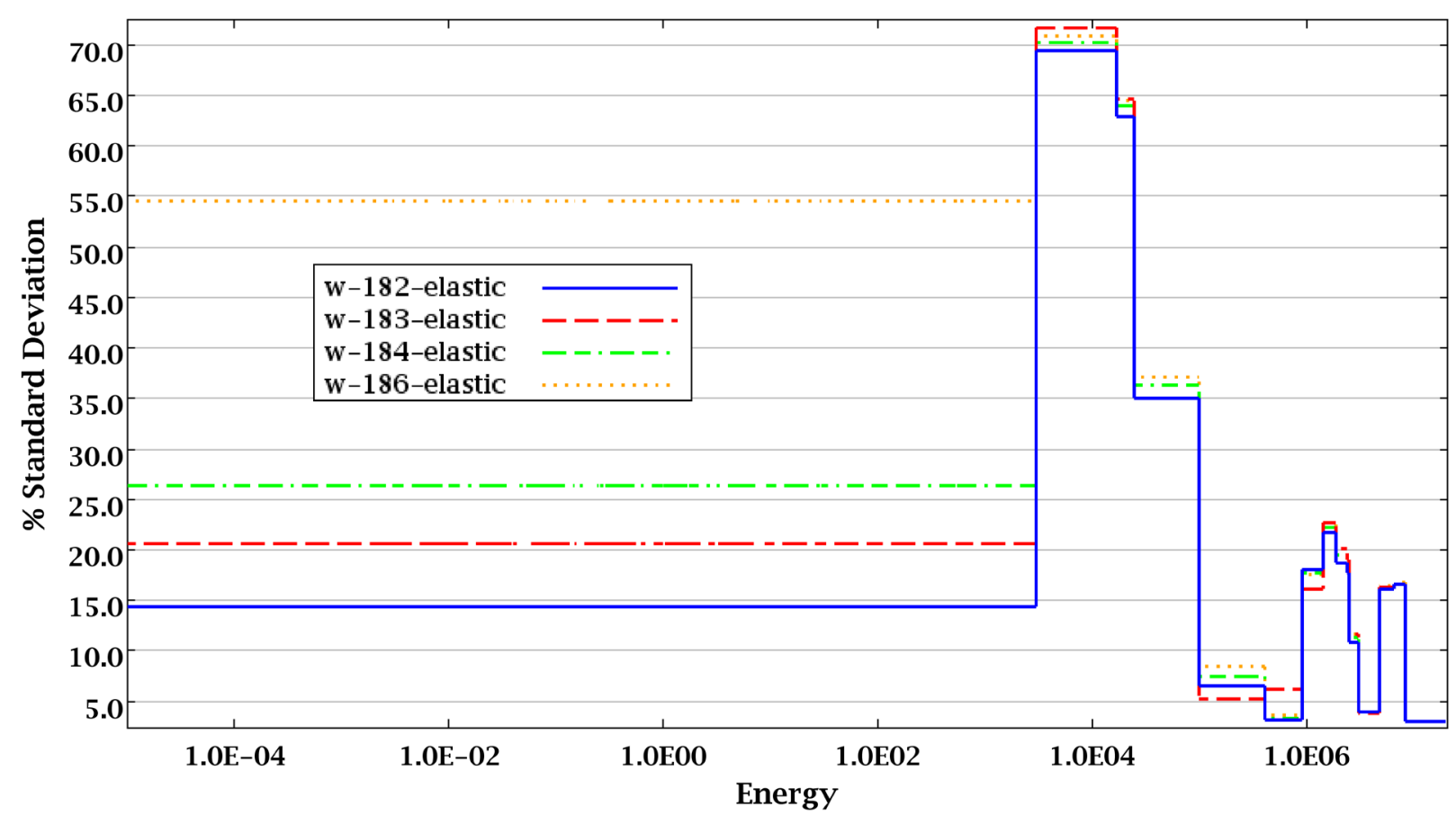

Fig. 21. Uncertainty in tungsten elastic scattering cross sections.

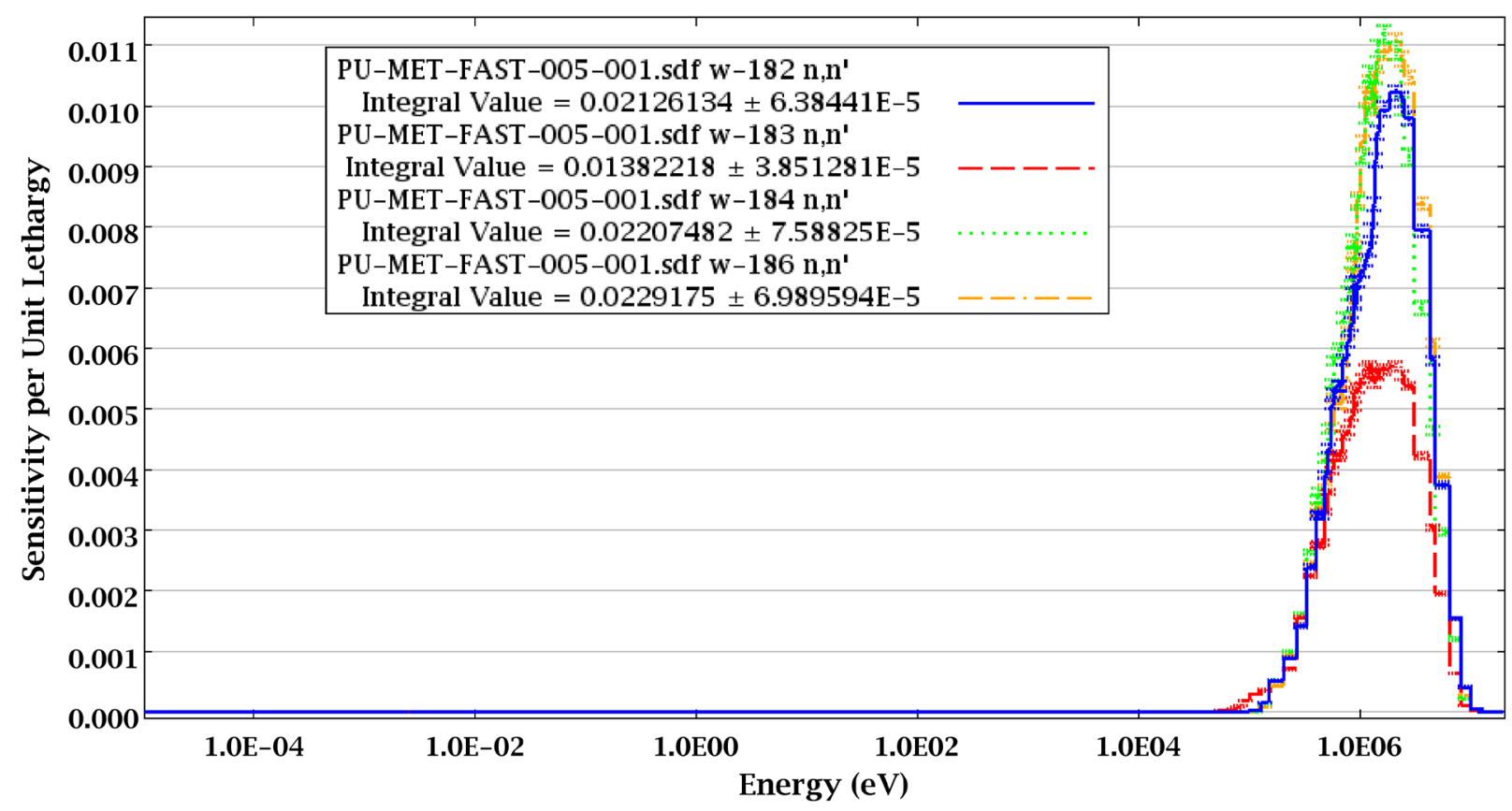

Fig. 22. Sensitivity of $\boldsymbol{k}_{\text {eff }}$ to tungsten (n,n') cross sections for PMF-005-001. 


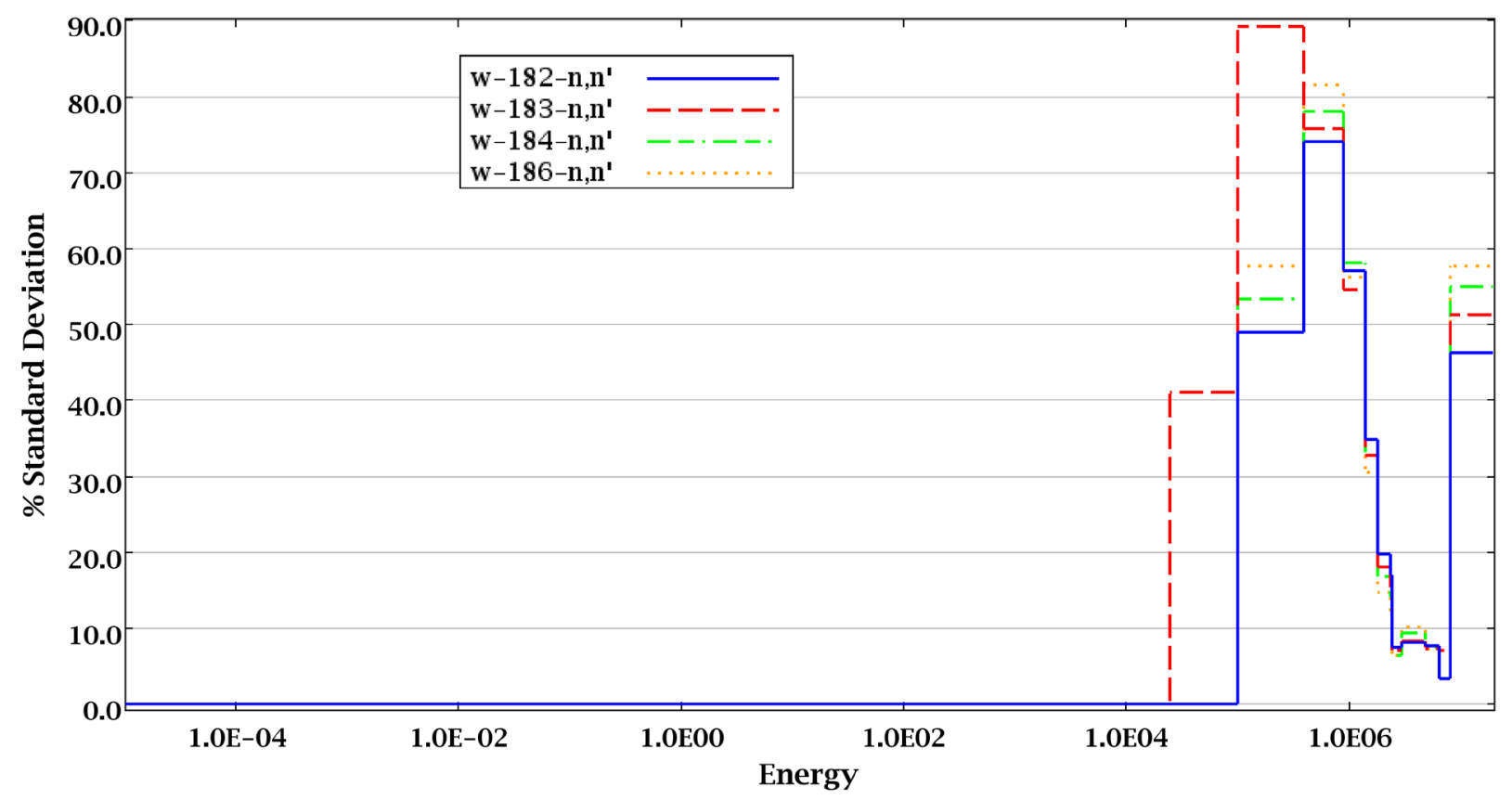

Fig. 23. Uncertainty in tungsten (n,n') cross sections.

The $\mathrm{C} / \mathrm{E}$ values are also compared to the experimental and multigroup cross-section uncertainties at the one- and two-sigma level. The multigroup cases are within one standard deviation of the expected $k_{\text {eff }}$ value for experimental uncertainty in $70 \%$ of cases, and within two standard deviations for $80 \%$ of cases. The continuous energy results demonstrate the same agreement. The cross-section uncertainties bound all points for both libraries at the one-sigma level.

\subsubsection{PST Systems}

The C/E data for the PST systems presented in Fig. 24 generally demonstrate consistent behavior between multigroup and continuous energy $\mathrm{C} / \mathrm{E}$ values. Most of the cases show a separation between $0.01 \%$ and $0.04 \%$ between multigroup and continuous energy. The continuous energy $\mathrm{C} / \mathrm{E}$ values are lower than the multigroup $\mathrm{C} / \mathrm{E}$ in all cases. For this category of experiments, the lower $\mathrm{C} / \mathrm{E}$ value generally indicates less overprediction of the system $k_{\text {eff }}$.

The largest differences between multigroup and continuous energy $\mathrm{C} / \mathrm{E}$ values occur for the PST-001 and PST-007 experiment series. These two experiment series were performed at the same laboratory using the same tank and solutions that contains $4.6 \mathrm{wt} \%{ }^{240} \mathrm{Pu}$. The differences in $k_{\text {eff }}$ between multigroup and continuous energy range from $0.5 \% \Delta \mathrm{k}$ to $1 \% \Delta \mathrm{k}$ for these cases. This is contrasted with approximately $0.2 \% \Delta \mathrm{k}$ differences between multigroup and continuous energy cases from PST-003 that contain $1.76 \mathrm{wt} \%{ }^{240} \mathrm{Pu}$. As described earlier for MCT systems, the ${ }^{240} \mathrm{Pu}$ resonance affects the sensitivity of $k_{\text {eff }}$ to ${ }^{1} \mathrm{H}$ elastic scattering, as shown in Fig. 25. The difference between the multigroup and continuous energy results are expected to be minimized with a pending $S(\alpha, \beta)$ update for the continuous energy cross sections that will be available with a subsequent release of SCALE.

The cases with the highest $\mathrm{C} / \mathrm{E}$ values for both the multigroup and continuous energy libraries come from PST-011. The first five cases within this evaluation, which are the cases with exceptionally high $\mathrm{C} / \mathrm{E}$ values, use a 16-in.-diameter sphere. The remaining seven cases for the evaluation use an 18-in.-diameter 
sphere and show results that are in closer agreement with expected results. The PU-SOL-THERM-011 report in Ref. 7 notes that the five 16-in.-diameter sphere cases show poor agreement with expected results based on the evaluators' sample calculations also overpredicting $k_{\text {eff, }}$ indicating that there may be a discrepancy within the experiment description. However, in the absence of additional information regarding the IHECSBE evaluation, the data are included in this validation.

The $\mathrm{C} / \mathrm{E}$ values are also compared to the experimental and multigroup cross-section uncertainties at the one- and two-sigma level. The multigroup results show $57 \%$ of the cases within one standard deviation of the experimental uncertainty and $90 \%$ within two. The continuous energy results are somewhat better, with $79 \%$ within one standard deviation of experimental uncertainty and $98 \%$ within two standard deviations. The cross-section uncertainties bound over $95 \%$ of points for both libraries at the one-sigma level and bound all cases with both libraries at the two-sigma level.

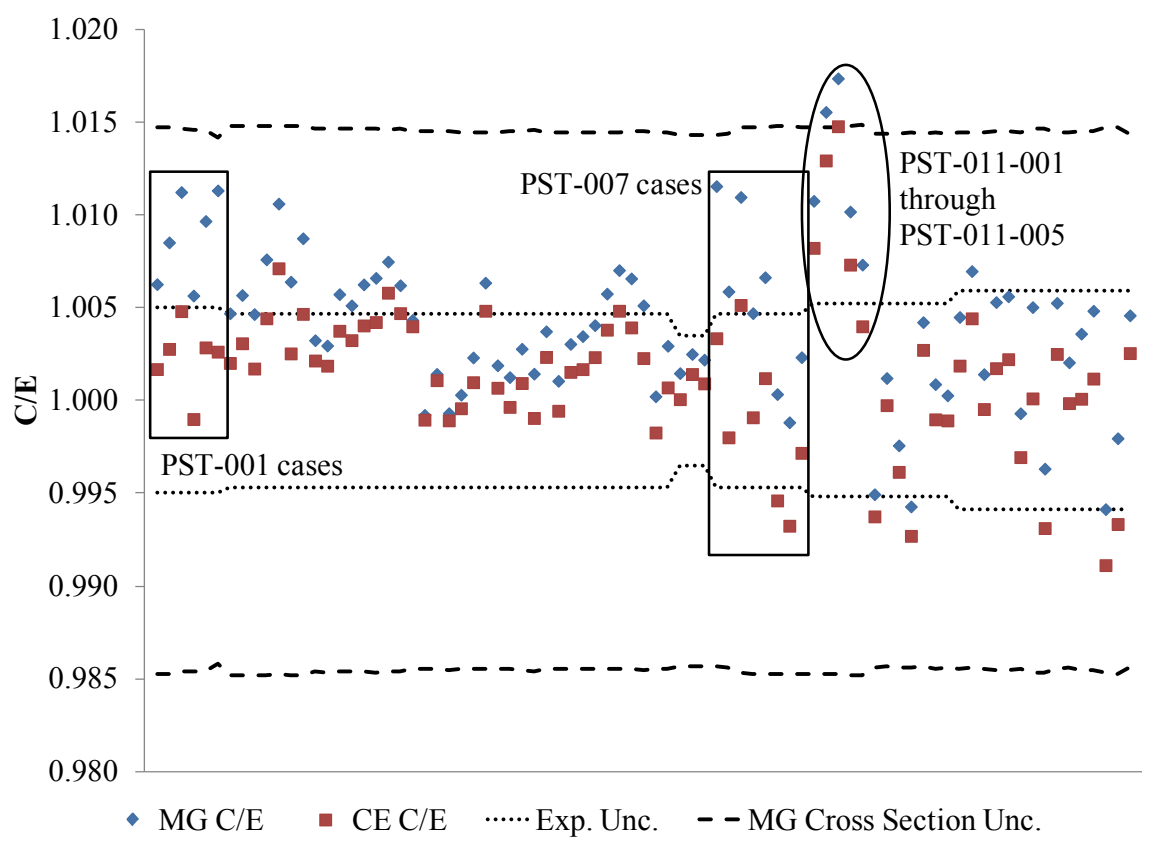

Fig. 24. Detailed results for PST systems. 


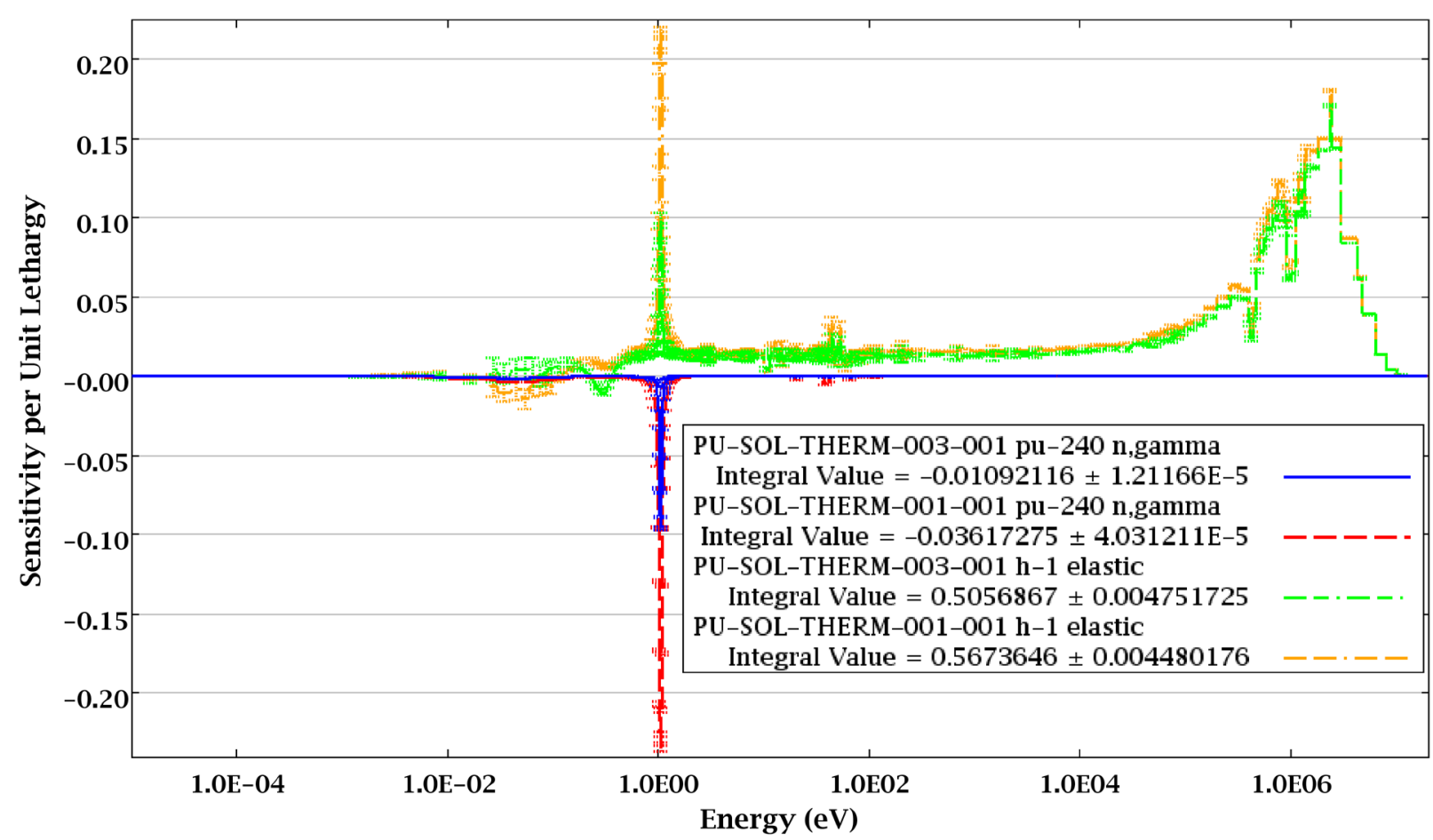

Case 1.

Fig. 25. Sensitivity of $k_{\text {eff }}$ to ${ }^{240} \mathrm{Pu}$ (n,gamma) and ${ }^{1} \mathrm{H}$ elastic scattering for PST-001 Case 1 and PST-003

\subsubsection{Pooled Results}

The results for the different categories are pooled into similar larger bins to examine performance over broader ranges of systems. The results from six of the eight categories are pooled into HEU systems, LEU systems, and plutonium systems. Note that the IMF and MCT categories are not pooled with other experiment categories because no other IEU or mixed $\mathrm{U} / \mathrm{Pu}$ systems are in the library. The results for these pooled categories of fissile material are presented in Table 5. The results from all eight categories are pooled into metal, solution, and compound systems. The results for these pooled categories of fissile form are presented in Table 6. Finally, all eight categories are pooled into fast or thermal systems. The results for these broad categories based on neutron energy spectrum are provided in Table 7 . Note that the data for all three tables is generated separately by combining the appropriate individual case results.

Table 5. Results by fissile material

\begin{tabular}{lcccc}
\hline \multirow{2}{*}{ Fissile material } & \multicolumn{2}{c}{ 238-Group calculations } & \multicolumn{2}{c}{ Continuous energy calculations } \\
\cline { 2 - 5 } & Average C/E & $\begin{array}{c}\text { Average C/E } \\
\text { uncertainty }\end{array}$ & Average C/E & $\begin{array}{c}\text { Average C/E } \\
\text { uncertainty }\end{array}$ \\
\hline HEU & 1.00058 & 0.00052 & 0.99845 & 0.00052 \\
IEU & 1.00868 & 0.00083 & 1.00284 & 0.00083 \\
LEU & 0.99855 & 0.00025 & 0.99927 & 0.00025 \\
MIX & 0.99847 & 0.00087 & 0.99654 & 0.00087 \\
$\mathrm{Pu}$ & 1.00386 & 0.00050 & 1.00128 & 0.00050 \\
\hline
\end{tabular}


Table 6. Results by fissile form

\begin{tabular}{|c|c|c|c|c|}
\hline \multirow[b]{2}{*}{ Fissile material } & \multicolumn{2}{|c|}{ 238-Group calculations } & \multicolumn{2}{|c|}{ Continuous energy calculations } \\
\hline & Average $\mathbf{C} / \mathbf{E}$ & $\begin{array}{c}\text { Average } \mathrm{C} / \mathrm{E} \\
\text { uncertainty }\end{array}$ & Average $\mathrm{C} / \mathrm{E}$ & $\begin{array}{c}\text { Average } \mathrm{C} / \mathrm{E} \\
\text { uncertainty }\end{array}$ \\
\hline Metal & 1.00446 & 0.00034 & 1.00078 & 0.00034 \\
\hline Solution & 1.00180 & 0.00040 & 0.99980 & 0.00040 \\
\hline Compound & 0.99851 & 0.00026 & 0.99892 & 0.00026 \\
\hline
\end{tabular}

Table 7. Results by neutron energy spectrum category

\begin{tabular}{ccccc}
\hline \multirow{2}{*}{ Spectrum category } & \multicolumn{2}{c}{ 238-Group calculations } & \multicolumn{2}{c}{ Continuous energy calculations } \\
\cline { 2 - 5 } & Average C/E & $\begin{array}{c}\text { Average C/E } \\
\text { uncertainty }\end{array}$ & Average C/E & $\begin{array}{c}\text { Average C/E } \\
\text { uncertainty }\end{array}$ \\
\hline Fast & 1.00446 & 0.00034 & 1.00078 & 0.00034 \\
Thermal & 1.00036 & 0.00025 & 0.99941 & 0.00025 \\
\hline
\end{tabular}

The results from Table 5 demonstrate that most fissile materials appear to be treated fairly accurately in KENO V.a. The most significant potential exception based on these results is intermediate enrichment uranium. The results also may indicate a positive bias for plutonium systems, but such a conclusion is difficult given the range of plutonium vectors considered in these experiments.

The results from Table 6 show generally good results for solution and compound systems. The metal systems appear to have a significant positive bias, but this may be largely due to problems with the intermediate enrichment systems. The continuous energy results show a significant improvement in accuracy for the metal systems compared to the multigroup results. Collapsing the solution and compound systems together as thermal spectrum systems, as shown in Table 7, demonstrates good agreement as expected. The multigroup and continuous energy average $\mathrm{C} / \mathrm{E}$ values show a statistically significant difference from each other and from unity.

\subsubsection{Outlier Cases}

The results of all cases are surveyed to determine the greatest difference from a $\mathrm{C} / \mathrm{E}$ of unity for each category. The case with the largest difference in absolute and relative error is identified and reported in Table 8 and Table 9, respectively. The relative errors provided in Table 9 are determined with the uncertainty in the C/E value, as discussed in Sect. 3.4.

Table 8. Maximum individual case absolute differences for KENO V.a

\begin{tabular}{|c|c|c|c|c|}
\hline \multirow[b]{2}{*}{ Category } & \multicolumn{2}{|c|}{ 238-Group calculations } & \multicolumn{2}{|c|}{ Continuous energy calculations } \\
\hline & $\begin{array}{c}\text { Maximum } \\
\text { difference } \\
(\% \Delta k)\end{array}$ & Case & $\begin{array}{c}\text { Maximum } \\
\text { difference } \\
(\% \Delta \mathbf{k})\end{array}$ & Case \\
\hline HEU-MET-FAST & 1.43 & HMF-025-025 & 0.70 & HMF-019-001S \\
\hline HEU-SOL-THERM & 2.53 & HST-016-003 & 2.64 & HST-016-003 \\
\hline IEU-MET-FAST & 1.41 & IMF-005-001 & 0.76 & IMF-004-001 \\
\hline LEU-COMP-THERM & -0.50 & LCT-017-026 & 0.47 & LCT-010-002 \\
\hline LEU-SOL-THERM & -0.63 & LST-002-002 & -0.72 & LST-002-002 \\
\hline MIX-COMP-THERM & -0.49 & MCT-004-001 & -0.77 & MCT-004-001 \\
\hline PU-MET-FAST & 0.62 & PMF-005-001 & 0.92 & PMF-005-001 \\
\hline PU-SOL-THERM & 1.74 & PST-011-003 & 1.48 & PST-011-003 \\
\hline
\end{tabular}


Table 9. Maximum individual case relative differences for KENO V.a

\begin{tabular}{lcccc}
\hline \multirow{2}{*}{ Category } & \multicolumn{2}{c}{$\mathbf{2 3 8 - G r o u p ~ c a l c u l a t i o n s}$} & \multicolumn{2}{c}{ Continuous energy calculations } \\
\cline { 2 - 5 } & $\begin{array}{c}\text { Maximum } \\
\text { deviation } \\
\left(\boldsymbol{\sigma}_{\mathrm{C/E} / \mathbf{E}}\right)\end{array}$ & Case & $\begin{array}{c}\text { Maximum } \\
\text { deviation } \\
\left(\boldsymbol{\sigma}_{\mathrm{C/E}}\right)\end{array}$ & Case \\
\hline HEU-MET-FAST & 8.8 & HMF-025-025 & -3.2 & HMF-030-001 \\
HEU-SOL-THERM & 3.1 & HST-016-003 & 3.3 & HST-016-003 \\
IEU-MET-FAST & 8.6 & IMF-007-001 & 3.5 & IMF-008-001 \\
LEU-COMP-THERM & -4.8 & LCT-050-008 & -3.2 & LCT-050-008 \\
LEU-SOL-THERM & 2.9 & LST-004-005 & -2.0 & LST-002-002 \\
MIX-COMP-THERM & 1.1 & MCT-002-004S & -2.1 & MCT-001-001 \\
PU-MET-FAST & 4.7 & PMF-005-001 & 7.0 & PMF-005-001 \\
PU-SOL-THERM & 3.3 & PST-011-003 & 2.8 & PST-011-003 \\
\hline
\end{tabular}

The existence of some outliers is expected and explained in the detailed sections above.

\subsubsection{Normality Testing}

The Shapiro-Wilk test ${ }^{13}$ is used to test the $\mathrm{C} / \mathrm{E}$ ratios for normality within each category of experiments. The null hypothesis is that the data are normally distributed, and $95 \%$ confidence is required to reject this assumption in this work. The hypothesis of normality is not rejected for most categories. The exceptions in which normality is rejected are HST experiments in both multigroup and continuous energy, LCT experiments in both multigroup and continuous energy, and continuous energy only for PMF and PST experiments. No normality testing is performed on any of the pooled data sets shown in Tables 5-7.

\subsection{KENO-VI}

Almost all of the KENO-VI cases executed for this validation converged to a Monte Carlo stochastic uncertainty of $0.00010 \Delta k_{\text {eff. }}$ The two exceptions are HMF-024-001, which was run to an uncertainty of $0.00005 \Delta k_{\text {eff }}$, and MCT-008-001, which was converged to $0.00007 \Delta k_{\text {eff. }}$ The maximum reported uncertainty for both the 238-group and continuous energy calculations is $0.00010 \Delta k_{\text {eff. }}$. As mentioned previously in Section 3.4, this stochastic uncertainty on the calculation is a factor of at least two smaller than the benchmark evaluation uncertainty reported in Ref. 7. This uncertainty ratio for most cases is in the range of 20 to 50 . The most significant factor affecting the uncertainty of the calculated $\mathrm{C} / \mathrm{E}$ values is therefore the tabulated uncertainty in the evaluation.

The average $\mathrm{C} / \mathrm{E}$ value and its uncertainty for each category of experiments are provided in Table 10 for both the 238-group and continuous energy cross-section libraries. The results show that the average $\mathrm{C} / \mathrm{E}$ values are near 1.0 .

Table 10. Results by category for KENO-VI calculations

\begin{tabular}{lcccc}
\hline \multirow{2}{*}{ Category } & \multicolumn{2}{c}{ 238-Group calculations } & \multicolumn{2}{c}{ Continuous energy calculations } \\
\cline { 2 - 5 } & Average C/E & $\begin{array}{c}\text { Average C/E } \\
\text { uncertainty }\end{array}$ & $\begin{array}{c}\text { Average C/E } \\
\text { Average C/E }\end{array}$ & $\begin{array}{c}\text { uncertainty } \\
\text { und-MET-FAST }\end{array}$ \\
HEU-MET-FAST & 0.99801 & 0.00066 & 0.99664 & 0.00066 \\
IEU-MET & 1.00765 & 0.00275 & 1.00534 & 0.00275 \\
MIX-COMP-THERM & 0.99443 & 0.00078 & 0.99215 & 0.00078 \\
\hline
\end{tabular}


For the 238-group calculations, the largest deviation from unity on an absolute basis occurs for the IMF systems and is approximately $0.77 \% \Delta k_{\text {eff. }}$ The largest deviation on a relative error basis occurs for the MCT systems and is more than seven standard deviations from unity. All three categories of experiments run with KENO-VI show deviations of more than two sigma from unity. The IMF systems appear to be overpredicted, while the HMF and MCT cases show average $\mathrm{C} / \mathrm{E}$ values less than unity.

For the continuous energy calculations, the largest deviation from unity on an absolute basis occurs for the MCT systems and is about $-0.79 \% \Delta k_{\text {eff. }}$. The largest deviation on a relative error basis also occurs for the MCT systems and is just over 10 standard deviations from unity. Only the IMF systems have an average $\mathrm{C} / \mathrm{E}$ within two standard deviations of unity, though the uncertainty in the average $\mathrm{C} / \mathrm{E}$ is quite large because only two systems were considered. As with the multigroup library results, the IMF systems have an average $\mathrm{C} / \mathrm{E}$ value greater than 1 , and the $\mathrm{HMF}$ and $\mathrm{MCT}$ results have an average $\mathrm{C} / \mathrm{E}$ less than unity.

The average $\mathrm{C} / \mathrm{E}$ difference from unity is shown in Fig. 26 for each of the three categories for both multigroup and continuous energy libraries. The results are also presented in standard deviations from unity in Fig. 27. In general, it appears that the continuous energy calculations exhibit a higher $\mathrm{C} / \mathrm{E}$ deviation from unity than do the 238-group calculations. Two of the three categories have a lower deviation for the multigroup library. It is difficult to draw a generic conclusion based on only the three categories of experiments, especially given the relatively small number of cases in each category. The multigroup results are, however, statistically significantly less different from unity for both the HMF and MCT experiments. The continuous energy results are statistically insignificantly different from the multigroup results for the two IMF cases. In both comparisons, significance is tested at the one-sigma level.

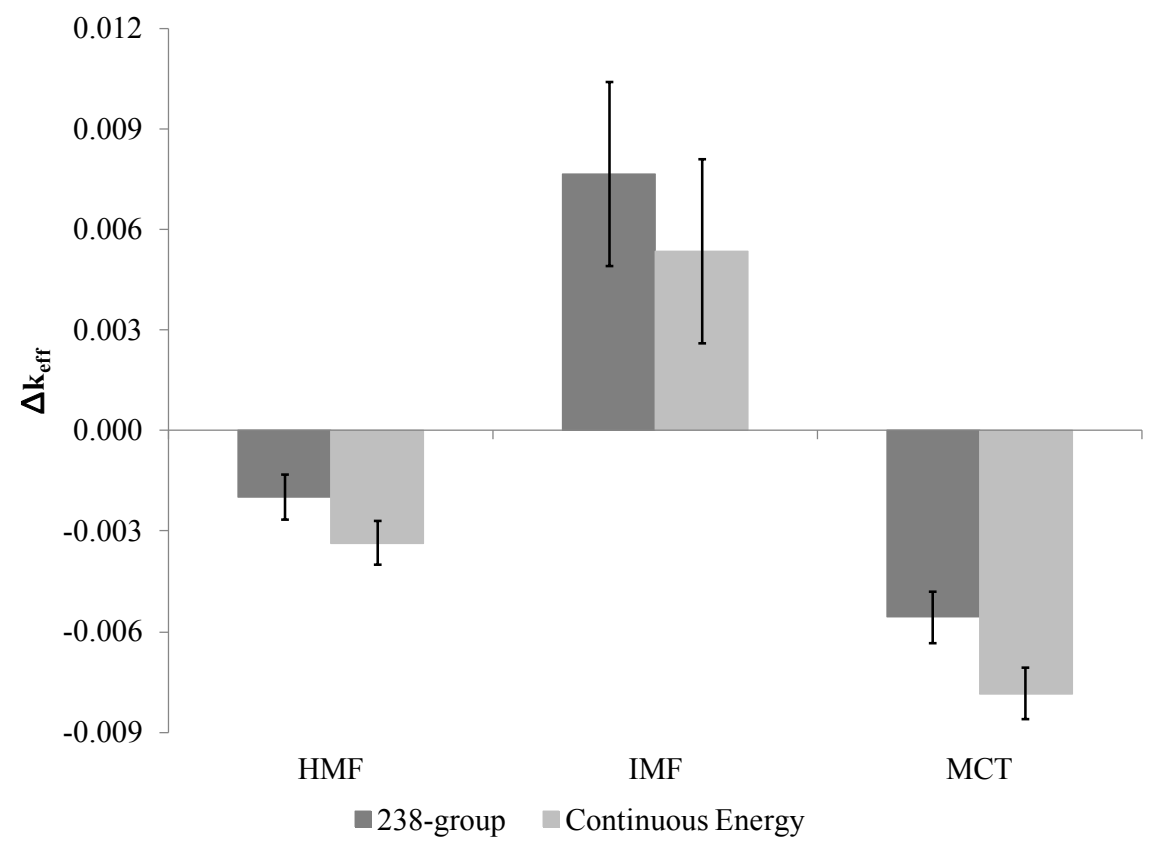

Fig. 26. Difference from unity of average C/E value by category for KENO-VI ( $\left.\Delta k_{\text {eff }}\right)$. 


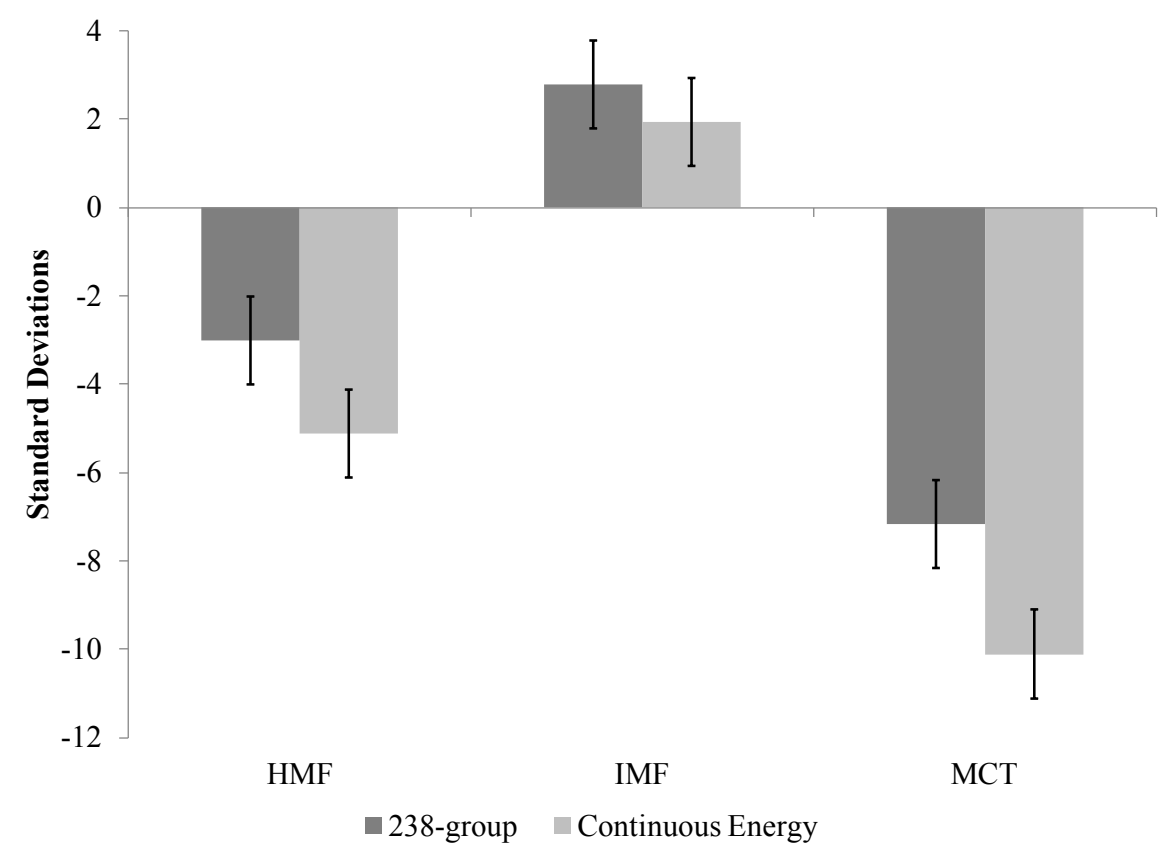

Fig. 27. Deviation from unity of average C/E value by category for KENO-VI (standard deviations).

The multigroup and continuous energy $\mathrm{C} / \mathrm{E}$ values for each case in each category of benchmarks are detailed in the subsections below. In the $\mathrm{C} / \mathrm{E}$ figures, the reported benchmark uncertainty for each case is also shown as dotted lines, and the multigroup cross section uncertainty values are shown as dashed lines.

\subsubsection{HMF Systems}

The C/E data for the HMF systems presented in Fig. 28 demonstrate generally good agreement between multigroup and continuous energy $\mathrm{C} / \mathrm{E}$ values with all 15 cases agreeing within $0.3 \%$. Two cases, HMF005-004 and HMF-080-001, are noticeable outliers from the expected $k_{\text {eff }}$ value despite the good agreement between multigroup and continuous energy calculations. HMF-005-004 is significantly below the expected value, while HMF-080-001 is well above the expected result.

The $k_{\text {eff }}$ value calculated for HMF-005-004 is about $1 \%$ low, which is consistent with the MCNP result reported for this case in the HEU-MET-FAST-005 report in Ref. 7. It is also worth noting that HMF-005-004 is the only case that uses the "U3-tube" in the HMF-005 series. It is possible that the discrepancy is related to the use or description of this tube. A closer examination of these systems reveals that Case 4 displays the greatest sensitivity to the bound cross section for beryllium, as shown in Fig. 29. Cases with smaller beryllium sensitivities exhibit less bias between the multigroup and continuous energy results. In fact, Case 1 has no beryllium and displays less than a $0.001 \Delta \mathrm{k}$ difference between multigroup and continuous energy calculations. 


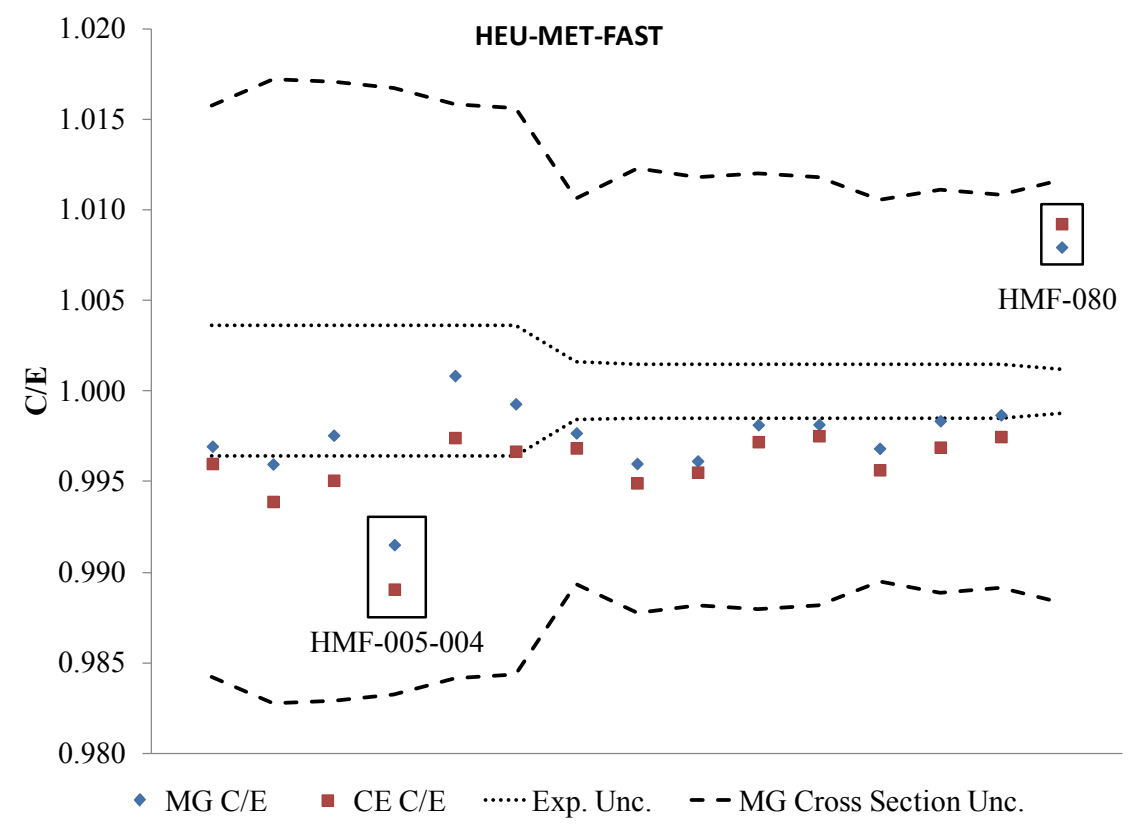

Fig. 28. Detailed results for HMF systems, KENO-VI.

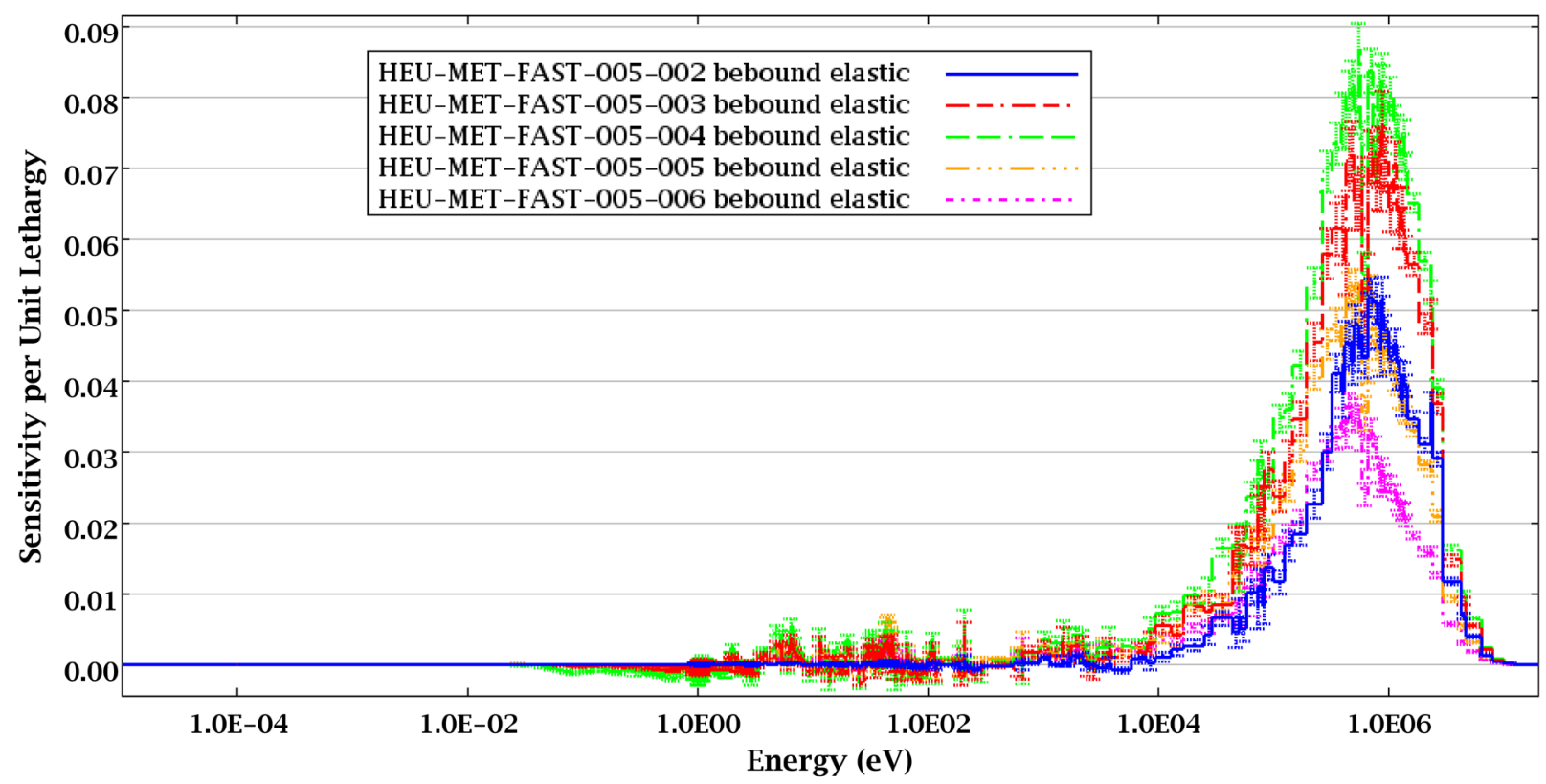

Fig. 29. Sensitivity of $\boldsymbol{k}_{\text {eff }}$ to the bound cross section for beryllium for HMF-005.

Both the multigroup and continuous energy libraries significantly overpredict the $k_{\text {eff }}$ value for HMF-080-001. This case is a model of the CALIBAN reactor at the CEA facility in Valduc, France. The sample results presented in Ref. 7 indicate that MCNP, MCNPX, and TRIPOLI with differing nuclear data libraries also calculate a $k_{\text {eff }}$ nearly $1 \%$ high for this case. This indicates that the most likely explanation for the discrepant results is in the experiment description. 
The $\mathrm{C} / \mathrm{E}$ values are also compared to the experimental and multigroup cross-section uncertainties at the one- and two-sigma level. Only $33 \%$ of the multigroup cases are within one standard deviation of the expected $k_{e f f}$ value based on experimental uncertainty, and $67 \%$ are within two standard deviations. The continuous energy calculations appear significantly worse, with only $13 \%$ of cases within one sigma and $60 \%$ within two. The cross-section uncertainties bound all points for both libraries at the one-sigma level.

\subsubsection{IMF Systems}

The data set for IMF systems modeled in KENO-VI includes only two data points. The results for both cases demonstrate consistent behavior between continuous energy and multigroup calculations with a difference of about $0.25 \%$. The $\mathrm{C} / \mathrm{E}$ values for both libraries are significantly above unity. The continuous energy and multigroup results are approximately $0.5 \%$ and nearly $0.75 \%$ above unity, respectively. A plot of the $\mathrm{C} / \mathrm{E}$ values is shown in Fig. 30. The uncertainty in $k_{\text {eff }}$ due to cross-section data is primarily due to high uncertainties in the fast ${ }^{235} \mathrm{U}$ (n,gamma) and ${ }^{238} \mathrm{U}\left(\mathrm{n}, \mathrm{n}^{\prime}\right)$ cross sections, both of which are important in these systems. As shown in Fig. $31, k_{\text {eff }}$ is much more sensitive to ${ }^{235} \mathrm{U}$ fission than ${ }^{235} \mathrm{U}\left(\mathrm{n}\right.$,gamma) or ${ }^{238} \mathrm{U}\left(\mathrm{n}, \mathrm{n}^{\prime}\right)$. However, the uncertainty in ${ }^{235} \mathrm{U}$ fission is approximately $0.5 \%$ at fast energies, where ${ }^{238} U\left(n, n^{\prime}\right)$ exceeds $30 \%$ and ${ }^{235} U$ (n,gamma) exceeds $60 \%$, as shown in Fig. 32. Thus, ${ }^{235} \mathrm{U}\left(\mathrm{n}\right.$, gamma) and ${ }^{238} \mathrm{U}\left(\mathrm{n}, \mathrm{n}^{\prime}\right)$ are the most likely sources of the observed biases for these cases.

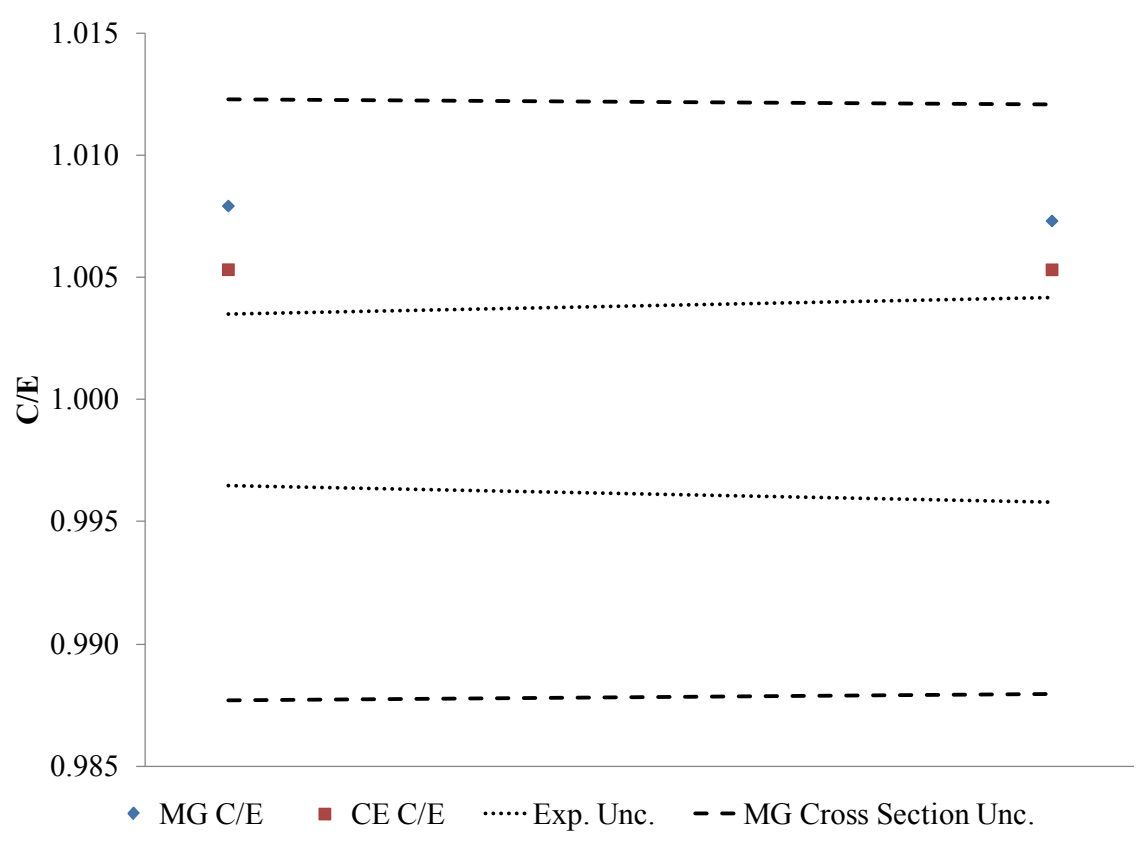

Fig. 30. Detailed results for IMF systems, KENO-VI. 


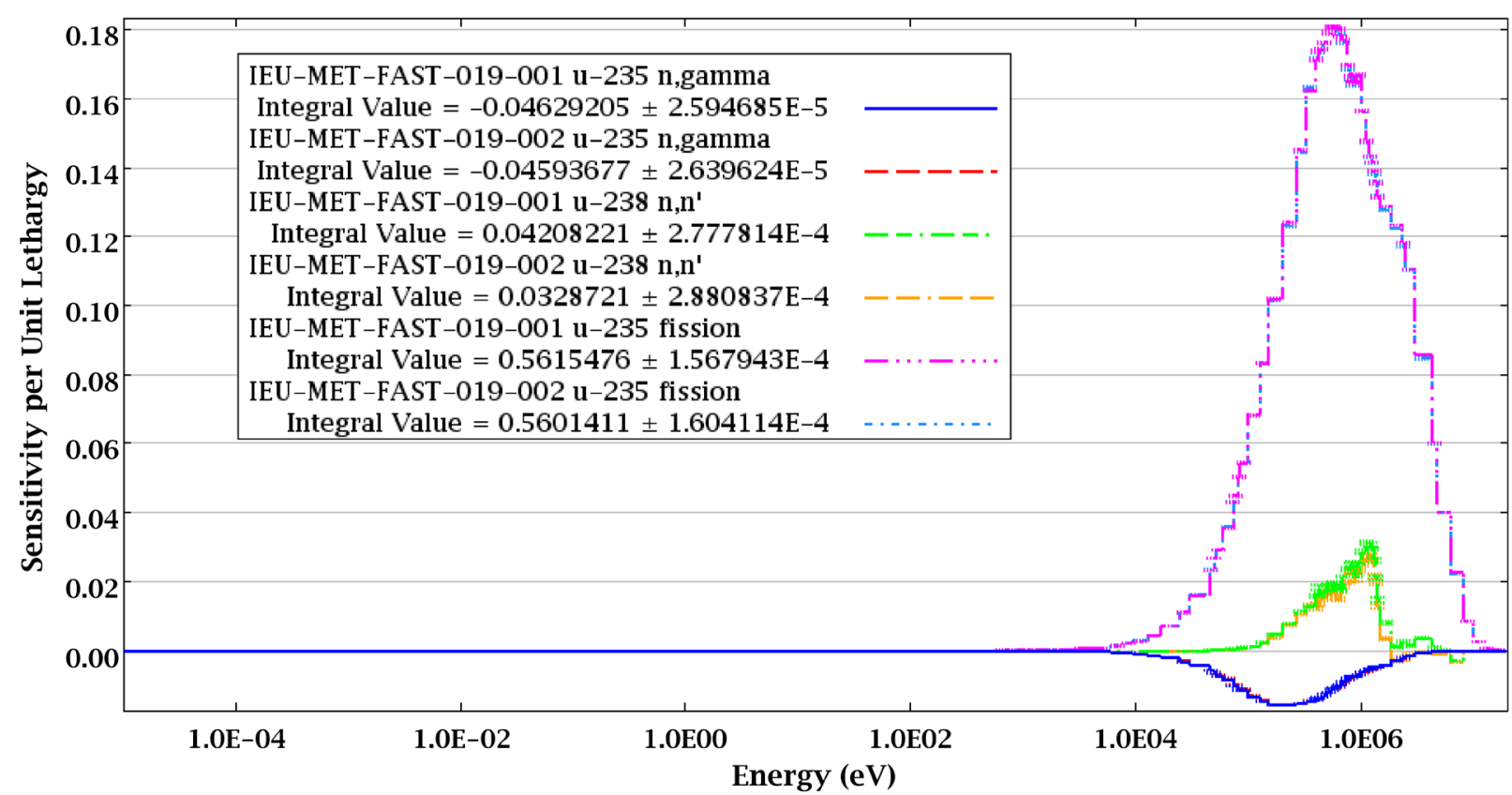

Fig. 31. Sensitivity of $k_{\text {eff }}$ to ${ }^{235} U$ (n,gamma), ${ }^{238} U$ (n,n'), and ${ }^{235} U$ fission cross sections for IMF-019.

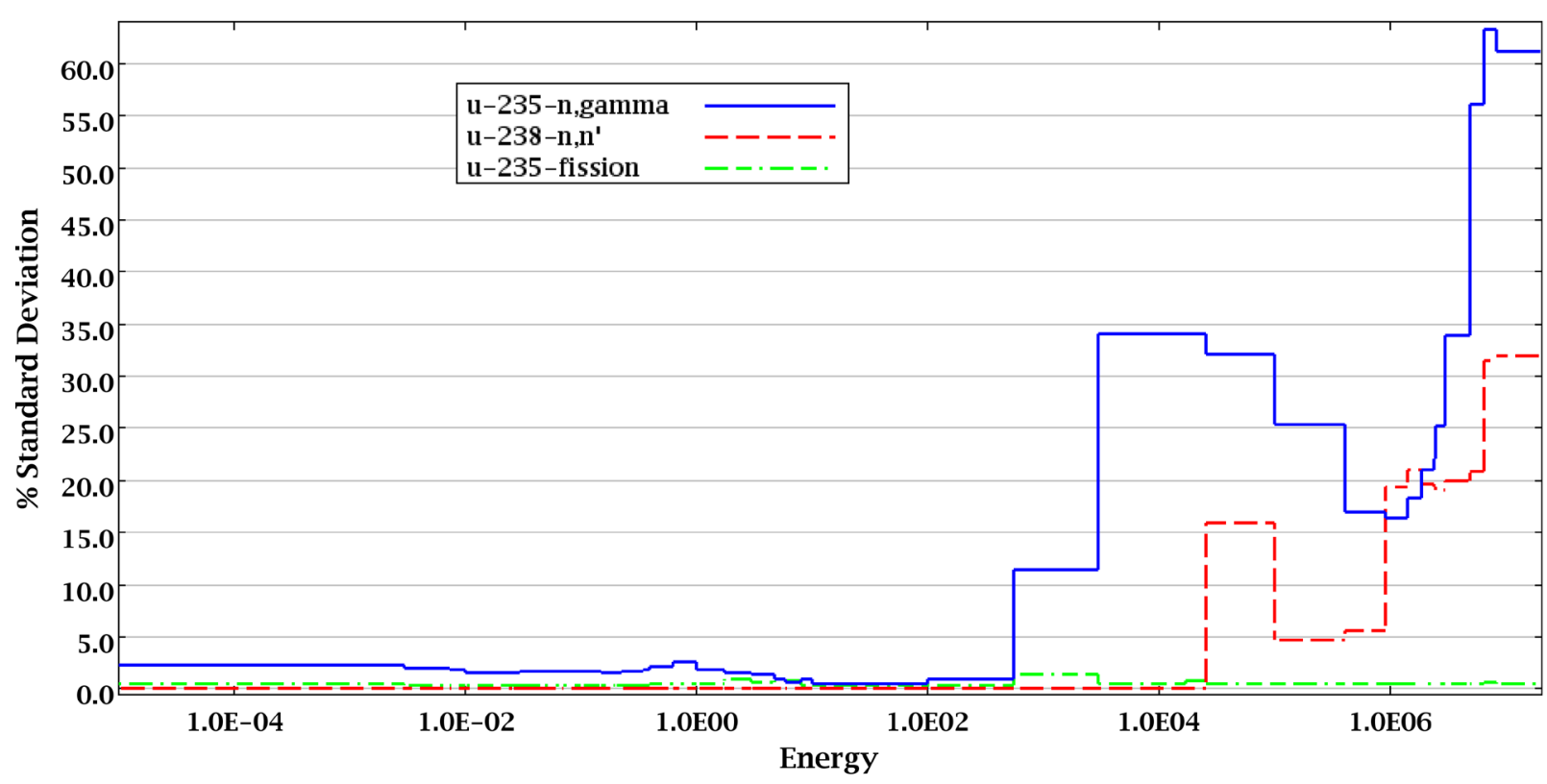

Fig. 32. Uncertainty in ${ }^{235} \mathrm{U}$ (n,gamma), ${ }^{238} \mathrm{U}\left(\mathrm{n}, \mathrm{n}^{\prime}\right)$, and ${ }^{235} \mathrm{U}$ fission cross sections.

The $\mathrm{C} / \mathrm{E}$ values are also compared to the experimental and multigroup cross-section uncertainties at the one- and two-sigma level. Neither case is within one standard deviation of the expected $k_{\text {eff }}$ value based on experimental uncertainty for either the continuous energy or multigroup libraries. One case is within two standard deviations for the multigroup results, and both cases are within this range for the continuous energy results. The cross-section uncertainties bound both points for both libraries at the one-sigma level. 


\subsubsection{MCT Systems}

The C/E data for the MCT systems presented in Fig. 33 demonstrate a fairly consistent behavior between multigroup and continuous energy $\mathrm{C} / \mathrm{E}$ values. Most of the cases show $\mathrm{C} / \mathrm{E}$ values with a difference of approximately $0.25 \%$. The continuous energy $\mathrm{C} / \mathrm{E}$ values are, in all cases, slightly lower than the multigroup values. The multigroup bias appears to be less than the continuous energy bias for this category of experiments.

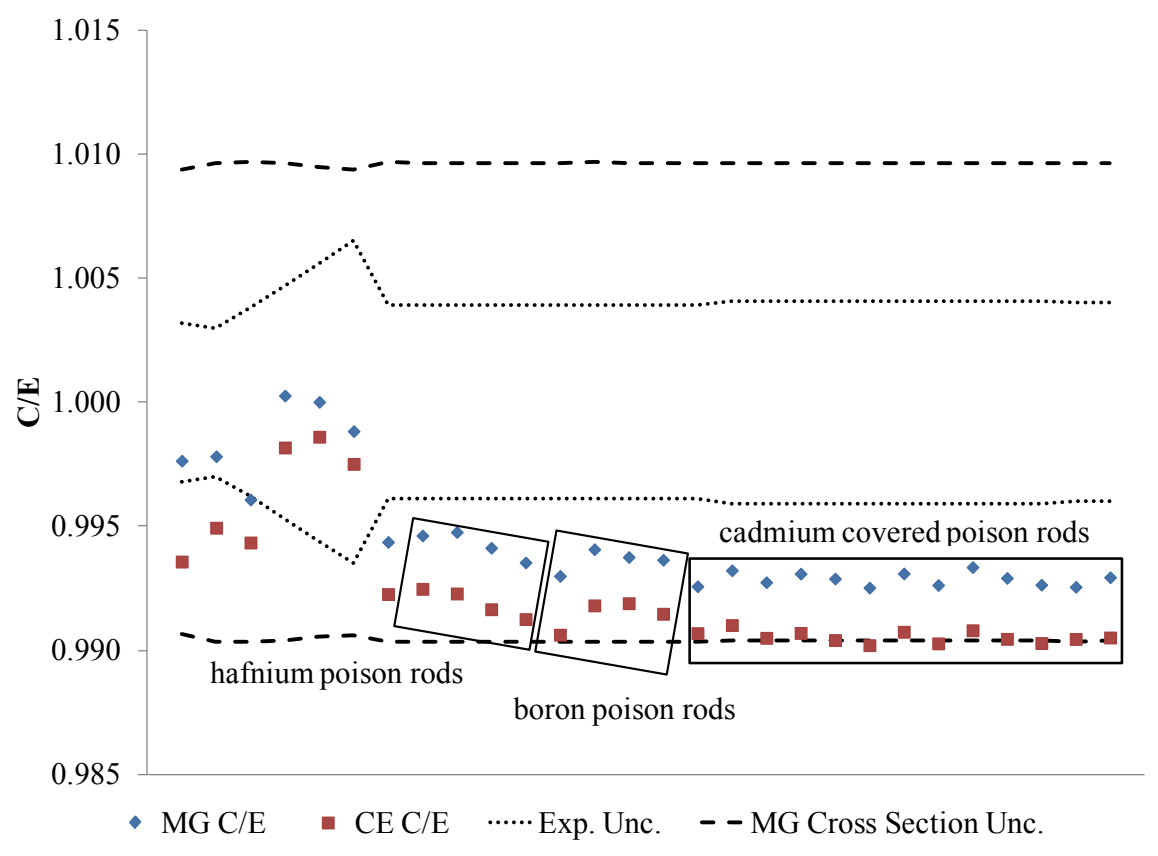

Fig. 33. Detailed results for MCT systems, KENO-VI.

The data set for MCT systems modeled with KENO-VI contains only the 28 cases contained in the MCT-008 series of experiments. This experiment series contains two distinct subsets of cases. The first six cases constitute a series of fuel-rod pitches ranging from an undermoderated array to an overmoderated one. The other 22 cases use the pitch associated with Case 3 and replace the center fuel rod in the array with various poison rods containing aluminum, hafnium, or boron. Case 7 uses an aluminum rod, Cases 8 through 12 use hafnium rods with increasing hafnium loadings, and Cases 13 through 16 use boron rods with increasing loadings. The $\mathrm{C} / \mathrm{E}$ for both libraries seems to trend lower with increasing poison loadings for both elements. A cadmium sleeve is used to cover the poison rods in Cases 17 through 28. The presence of the cadmium appears to eliminate the trend related to poison loading.

As explained above with the KENO V.a MCT cases, the differences between the multigroup and continuous energy results are expected to be minimized with a pending $S(\alpha, \beta)$ update for the continuous energy cross sections that will be available with a subsequent release of SCALE. For other materials, it is worth noting that a nearly constant uncertainty in $k_{\text {eff }}$ due to the cross-section uncertainties is maintained for all cases, as the overall uncertainty is dominated by the plutonium and uranium isotopes in the fuel pins as well has hydrogen in the moderator. These sensitivities are nearly identical for all poisoned cases, as demonstrated in Fig. 34 for Cases 8 and 12, with the minimum and maximum hafnium loading. These 
experiments are ideally suited for bias extraction for test materials using advanced TSUNAMI methods for reactivity experiments using the TSURFER and TSAR tools of SCALE. ${ }^{14}$

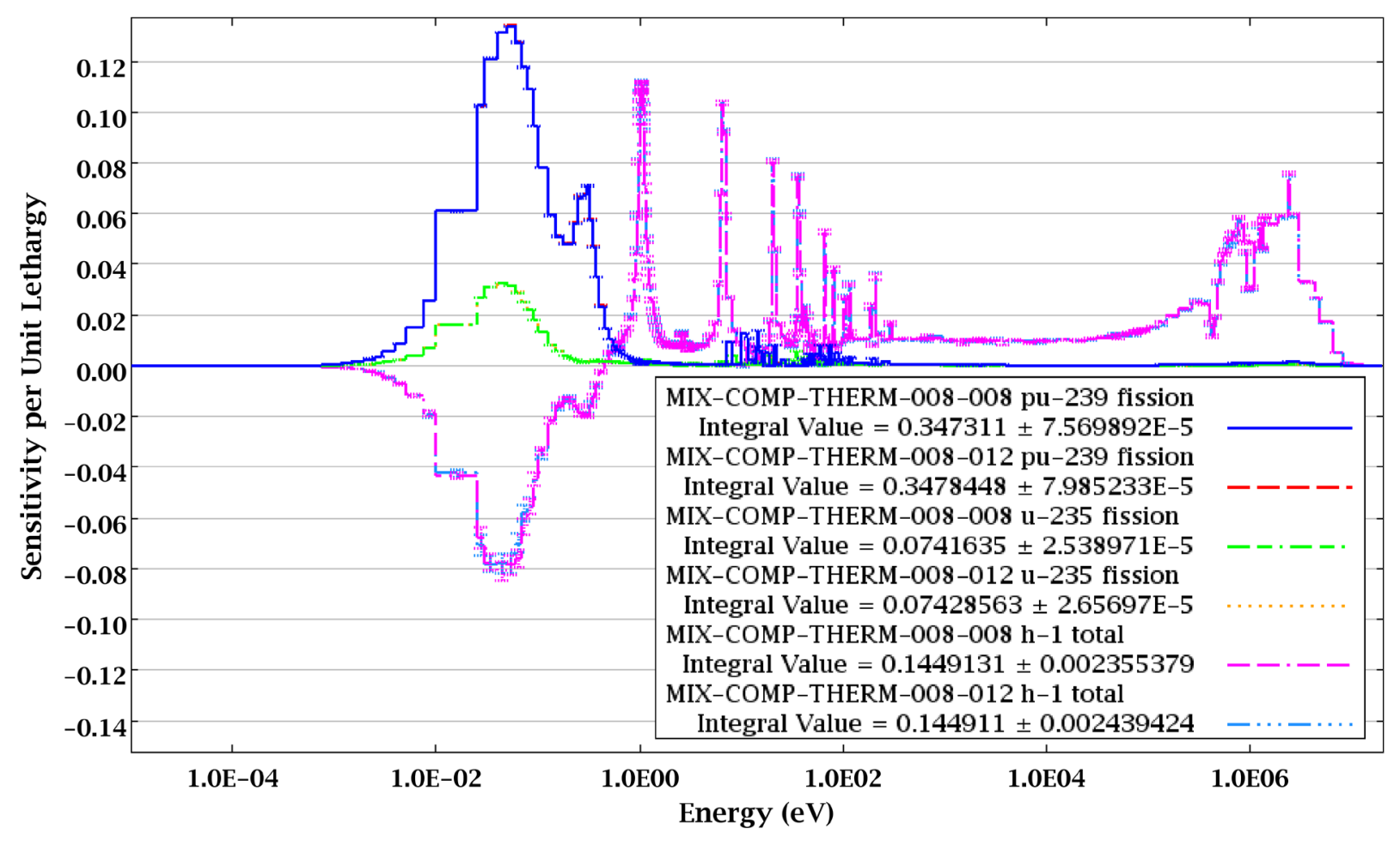

Fig. 34. Sensitivity of $k_{\text {eff }}$ to ${ }^{239} \mathrm{Pu}$ fission, ${ }^{235} \mathrm{U}$ fission, and ${ }^{1} \mathrm{H}$ total for MCT-008 Cases 8 and 12.

The series of experiments with hafnium poison rods demonstrates a systematic bias as a function of hafnium loading. The sensitivity of $k_{\text {eff }}$ to hafnium increases as a function of loading, as shown in Fig. 35 for Case 8 and 12 with the minimum and maximum loadings, respectively. For these cases, the hafnium cross section is a likely source of the systematic bias. Similarly, the cases with boron poison rods also demonstrate a systematic bias, although it does not precisely align with the boron loading. Examination of the sensitivity of $k_{\text {eff }}$ to ${ }^{10} \mathrm{~B}$ (n,alpha) in Fig. 36 reveals that the higher boron loadings actually create a spectral shift in the region of the poison rod. The observed biases actually trend more closely with the boron sensitivity than they do with the boron loading. Lastly, the cadmium cases show little trend in bias as a function of cadmium loading. As shown in Fig. 37, the sensitivity of $k_{\text {eff }}$ due to cadmium is very similar between the least and most loaded configurations. This effect is likely due to spatial self-shielding of the poison material, which could possibly have been avoided if sensitivity methods were available and employed during the experiment design process. With similar sensitivities, a similar computation bias is expected for all cadmium configurations. 


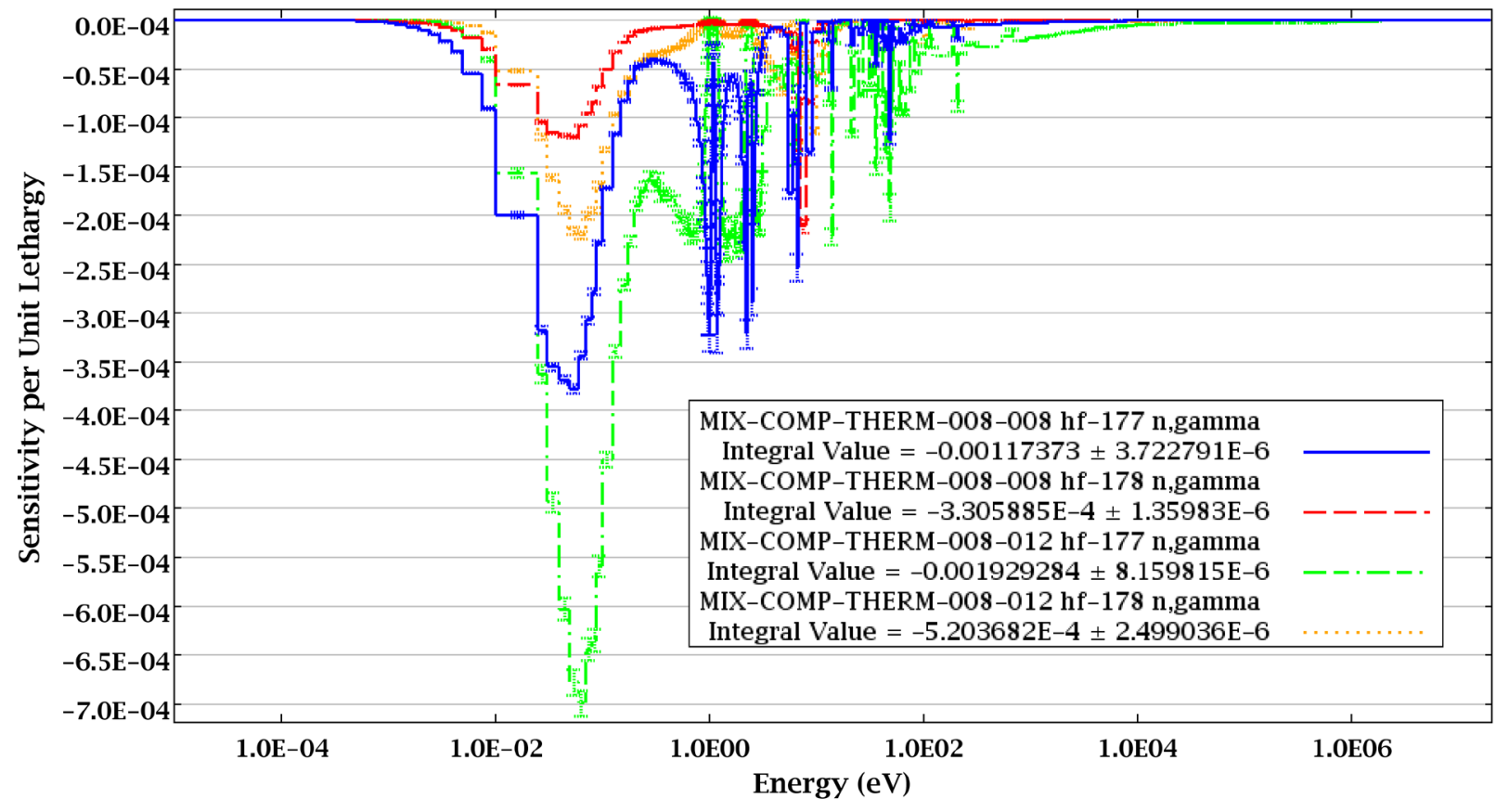

Fig. 35. Sensitivity of $k_{\text {eff }}$ to ${ }^{177} \mathrm{Hf}$ and ${ }^{178} \mathrm{Hf}$ (n,gamma) for MCT-008 Cases 8 and 12 .

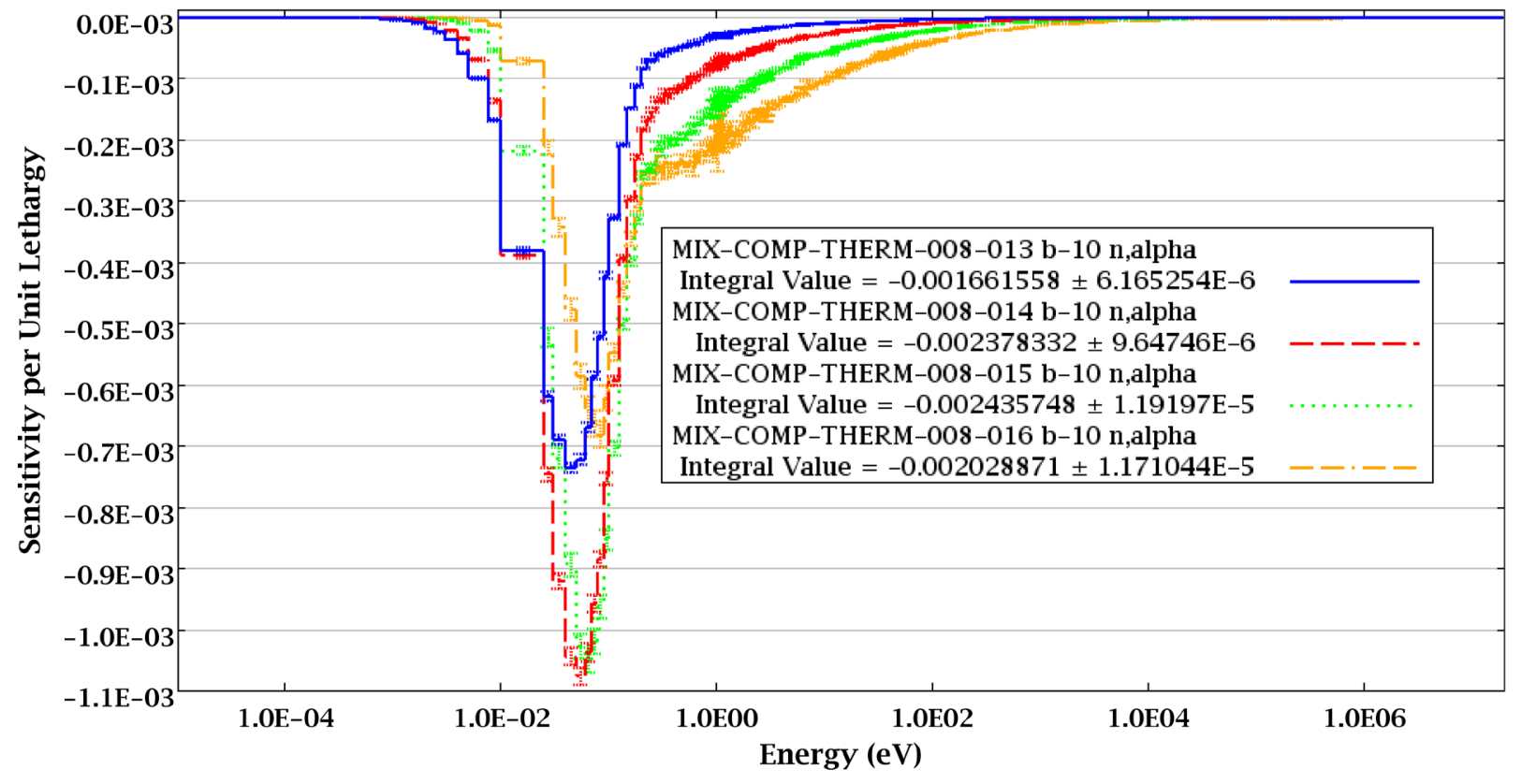

Fig. 36. Sensitivity of $k_{\text {eff }}$ to ${ }^{10} \mathrm{~B}$ (n,alpha) MCT-008 for Cases 13-16. 


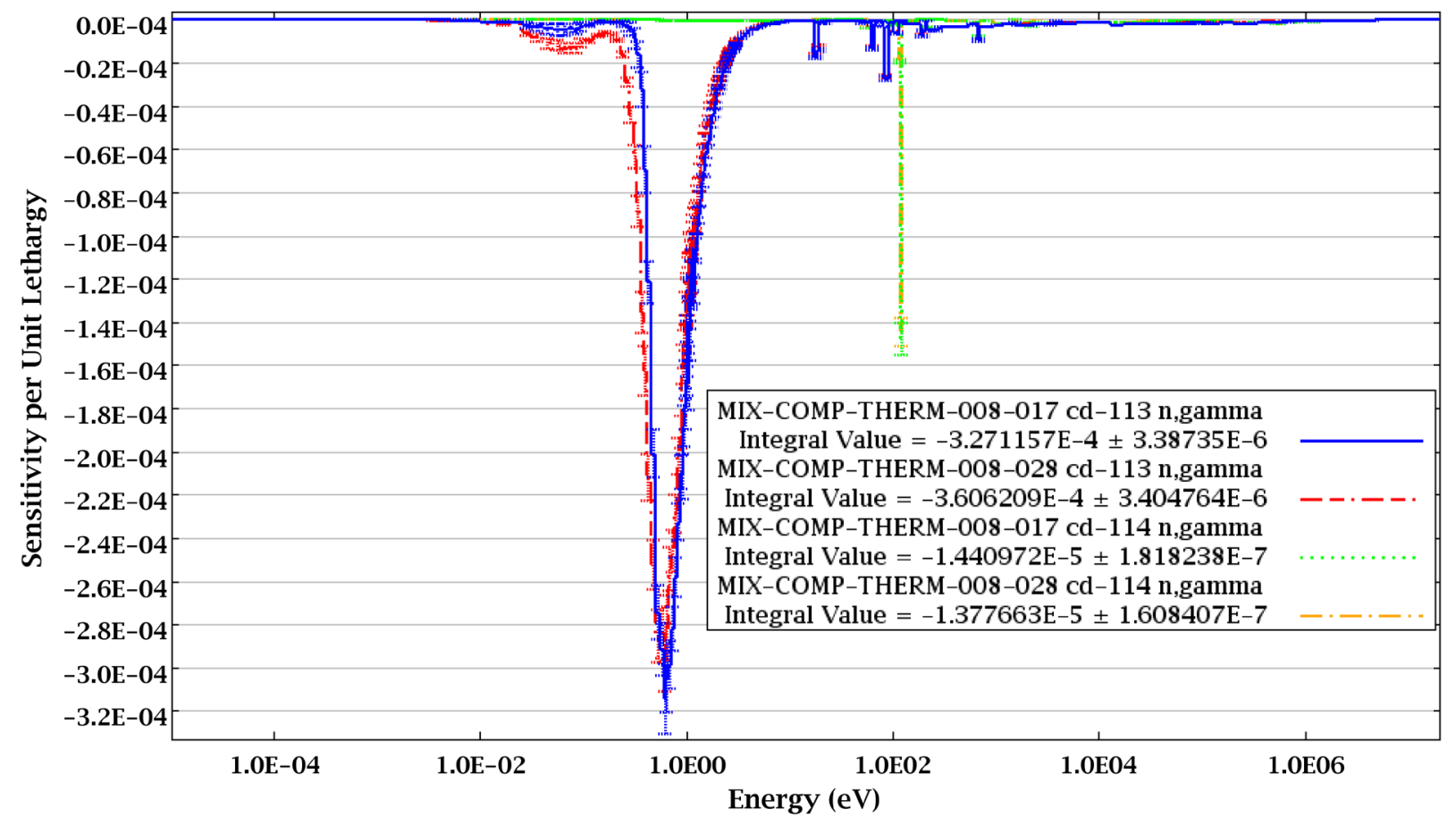

Fig. 37. Sensitivity of $k_{\text {eff }}$ to ${ }^{113} \mathrm{Cd}$ and ${ }^{114} \mathrm{Cd}$ (n,gamma) for MCT-008 Cases 17 and 28.

The $\mathrm{C} / \mathrm{E}$ values are also compared to the experimental and multigroup cross-section uncertainties at the one- and two-sigma level. Only $18 \%$ of the multigroup cases are within one standard deviation of the expected $k_{\text {eff }}$ value for experimental uncertainty. All cases are within two standard deviations. The continuous energy results show larger deviations. Only $11 \%$ of cases are within one sigma, and $29 \%$ are within two standard deviations. The cross-section uncertainties bound all points for the multigroup library at the one-sigma level. The cross-section uncertainties bound $89 \%$ of the continuous energy results within one sigma, and all points are within two standard deviations of unity.

\subsubsection{Outlier Cases}

The results of all cases are surveyed to determine the greatest difference from a $\mathrm{C} / \mathrm{E}$ of unity for each category. The case with the largest difference in absolute and relative error is identified and reported in Table 11 and Table 12, respectively. The relative errors provided in Table 12 are determined with the uncertainty in the C/E value, as discussed in Sect. 3.4.

Table 11. Maximum individual case absolute differences for KENO-VI

\begin{tabular}{|c|c|c|c|c|}
\hline \multirow[b]{2}{*}{ Category } & \multicolumn{2}{|c|}{ 238-Group calculations } & \multicolumn{2}{|c|}{ Continuous energy calculations } \\
\hline & $\begin{array}{c}\text { Maximum } \\
\text { difference } \\
(\% \Delta \mathbf{k})\end{array}$ & Case & $\begin{array}{c}\text { Maximum } \\
\text { difference } \\
(\% \Delta k)\end{array}$ & Case \\
\hline HEU-MET-FAST & 0.80 & HMF-080-001 & -1.09 & HMF-005-004 \\
\hline IEU-MET-FAST & 0.80 & IMF-019-001 & 0.53 & IMF-019-001 \\
\hline MIX-COMP-THERM & -0.75 & MCT-008-021 & -0.98 & МCT-008-021 \\
\hline
\end{tabular}


Table 12. Maximum individual case relative differences for KENO-VI

\begin{tabular}{lcccc}
\hline \multirow{2}{*}{ Category } & \multicolumn{2}{c}{$\mathbf{2 3 8 - G r o u p ~ c a l c u l a t i o n s}$} & \multicolumn{2}{c}{ Continuous energy calculations } \\
\cline { 2 - 5 } & $\begin{array}{c}\text { Maximum } \\
\text { Deviation } \\
\left(\boldsymbol{\sigma}_{\mathrm{C} / \mathbf{E}}\right)\end{array}$ & Case & $\begin{array}{c}\text { Maximum } \\
\text { deviation } \\
\left(\boldsymbol{\sigma}_{\mathrm{C} / \mathrm{E}}\right)\end{array}$ & Case \\
\hline HEU-MET-FAST & 6.6 & HMF-080-001 & 7.6 & HMF-080-001 \\
IEU-MET-FAST & 2.3 & IMF-019-001 & 1.5 & IMF-019-001 \\
MIX-COMP-THERM & -1.9 & MCT-008-016 & -2.4 & MCT-008-012 \\
\hline
\end{tabular}

The existence of some outliers is expected and explained in the detailed sections above.

\subsubsection{Normality Testing}

The Shapiro-Wilk test is used to test the $\mathrm{C} / \mathrm{E}$ ratios for normality within the HMF and MCT categories of experiments. The IMF category is not tested because it contains only two data points. The null hypothesis for the test is that the data are normally distributed, and $95 \%$ confidence is required to reject this assumption in this work. The hypothesis of normality is rejected for both multigroup and continuous energy libraries for both HMF and MCT experiments. 


\section{SUMMARY AND CONCLUSIONS}

The results presented in the previous section provide the basis for several conclusions regarding the validation of the KENO V.a and KENO-VI codes within the SCALE 6.1 code package. The average C/E values shown in Table 4 and Table 10 indicate that the code bias for a wide range of potential systems is fairly small. The bias is less than $1 \%$ for all categories of systems examined, and less than $0.5 \%$ for almost all categories in KENO V.a. The biases appear to be larger in KENO-VI, but all biases are less than $0.8 \%$. The higher apparent biases for KENO-VI may be a result of the increased geometric complexity of the benchmark experiments, which require the use of the generalized geometry capabilities. Further investigation of KENO V.a and KENO-VI should be performed in the future to understand possible differences between the codes and identify the sources of any real differences.

The validation studies reported here also compare the 238-group and continuous energy ENDF/B-VII.0 libraries. The continuous energy capability appears to present a systematic bias due to needed improvement in the $S(\alpha, \beta)$ treatment, which will be included in a future version of SCALE.

The data generated and reported here can also be used to identify potential cases within the IHECSBE, ${ }^{7}$ which should be examined for poor experiment descriptions, improved benchmark $k_{\text {eff }}$ values, and possibly enhanced experimental uncertainty quantification. A review of outlier cases and discrepancies identified in Sect. 4. can provide the initial list of candidate evaluations for such examinations.

An examination of potential cross-section errors in both the multigroup and continuous energy libraries is also possible based on the data generated for this validation. In several experiment series, trends have been identified that may provide insight on the nuclide and even the energy range that merits further investigation. The cases that exhibit unusual disagreement between multigroup and continuous energy results can also be used to search for these cross-section issues or to identify and quantify methodology limitations on resonance self-shielding calculations.

There are indications that the overall cross-section uncertainty as quantified through the SCALE covariance library is overestimated. All categories of experiments in both KENO V.a and KENO-VI show significantly more than the expected $67 \%$ of cases within one standard deviation of unity based on the calculated cross-section uncertainty values. Only 2 of the 358 cases considered lie more than two standard deviations from unity. The cause of this overestimation should be identified and corrected for two reasons. First, bringing the actual number of cases that exceed one-sigma uncertainty in line with the expected value will lend more credibility to the method. Second, reducing the potential for excessive conservatism in validation efforts will reduce penalties based on cross-section uncertainty. The uncertainties can be used to provide a bounding estimate of the bias that could occur for a particular nuclide that lacks sufficient coverage in the validation suite, so an overestimate of the uncertainty could lead to penalties that are unnecessarily large.

Overall, the KENO V.a and KENO-VI codes have been shown to provide consistent, low bias results across a range of systems that are commonly encountered in criticality safety applications. The data presented here is of particular value because the results are based on the models included in the VALID library and have undergone the quality checks described in Ref. 6. 



\section{RECOMMENDATIONS FOR FUTURE WORK}

Many recommendations for future work are mentioned throughout this report. These suggestions and others are summarized here. No attempt has been made to organize this list in order of importance, level of effort required, or any other order.

- Existing nuclear data evaluations can be examined in light of the outlier cases, unique occurrences, unexpected trends, and discrepancies described in this report, and needed improvements can be identified and made.

- Several of the reports included in the IHECSBE should be revised to include more rigorous calculation of the expected $k_{\text {eff }}$ value, which may resolve many of the apparent discrepancies identified herein. In addition, more rigor and consistency in the reporting of experimental uncertainties may be useful.

- The number of KENO V.a cases in the VALID library should be increased. Only three of the eight categories of experiments contain more than 50 cases. Currently, light water is the only moderating material represented in the library. Additional materials should be added, especially given the potential importance of graphite in many advanced reactor concepts.

- The number of KENO-VI cases in the VALID library should be increased. Only 45 such cases are in the library, and only three categories of experiments are represented. Two of those three categories are represented with a single experiment series.

- Some KENO V.a cases in the library should be replicated in KENO-VI and added to the library, thereby providing a basis for directly comparing the two codes.

- The cause(s) of the apparent overestimation of the cross-section uncertainties should be identified and, if possible, corrected.

- Additional multigroup libraries should be made available and used to calculate the benchmark cases contained in this report. The different multigroup structures could help elucidate the causes of some of the discrepancies observed herein. Additional testing could also identify situations in which the current multigroup processing codes have methodology limitations independent of the fidelity of the group structure. It is also possible that different multigroup libraries may be preferable for certain types of systems. 



\section{REFERENCES}

1. Scale: A Comprehensive Modeling and Simulation Suite for Nuclear Safety Analysis and Design, ORNL/TM-2005/39, Version 6.1, Oak Ridge National Laboratory, Oak Ridge, Tennessee, June 2011. Available from Radiation Safety Information Computational Center at Oak Ridge National Laboratory as CCC-785.

2. M. B. Chadwick et al., "ENDF/B-VII.0: Next Generation Evaluated Nuclear Data Library for Nuclear Science and Technology," Nuclear Data Sheets 107(12), 2931-3059 (December 2006).

3. American National Standards for Nuclear Criticality Safety in Operations with Fissionable Materials Outside Reactors, ANSI/ANS-8.1-1998; R2007, American National Standards Institute, New York.

4. Criticality Safety Criteria for Handling, Storage, and Transportation of LWR Fuel Outside Reactors, ANSI/ANS-8.17-2004; R2009, American National Standards Institute, New York.

5. American National Standards for Validation of Neutron Transport Methods for Nuclear Criticality Safety Calculations, ANSI/ANS-8.24-2007, American National Standards Institute, New York.

6. D. A. Reed, SCALE Procedure for Verified, Archived Library of Input and Data (VALID), SCALECMP-012, Revision 1, Oak Ridge National Laboratory, Oak Ridge, Tenn., September 15, 2010.

7. International Handbook of Evaluated Criticality Safety Benchmark Experiments, NEA/NSC/DOC(95)03, Nuclear Energy Agency/Organisation for Economic Co-operation and Development, September 2010.

8. J. C. Dean and R.W. Tayloe, Guide for Validation of Nuclear Criticality Safety Calculational Methodology, NUREG/CR-6698, prepared for the Nuclear Regulatory Commission by Science Applications International Corporation (SAIC), Oak Ridge, Tenn., January 2001.

9. J. J. Lichtenwalter et al., Criticality Benchmark Guide for Light-Water-Reactor Fuel in Transportation and Storage Packages, NUREG/CR-6361, prepared for the Nuclear Regulatory Commission by Oak Ridge National Laboratory, Oak Ridge, Tenn., March 1997.

10. P. B. Fox and D. F. Hollenbach, KENO-VI Validation, ORNL/TM-2004/60, Oak Ridge National Laboratory, Oak Ridge, Tenn., May 2005.

11. P. B. Fox and L. M. Petrie, Validation and Comparison of KENO V.a and KENO-VI, ORNL/TM2001/110, Oak Ridge National Laboratory, Oak Ridge, Tenn., May 2002.

12. B. T. Rearden, D. A. Reed, R. A. Lefebvre, D. E. Mueller, and W. J. Marshall, "Scale/TSUNAMI Sensitivity Data for ICSBEP Evaluations," Proceedings of the International Conference on Nuclear Criticality 2011, Edinburgh, Scotland, September 2011.

13. R. B. D’Agostino and M. A. Stephens, eds., Goodness of Fit Techniques, Marcel Dekker, Inc., New York, 1986.

14. B. T. Rearden, M. L. Williams, M. A. Jessee, D. E. Mueller, and D. A. Wiarda, "Sensitivity and Uncertainty Analysis Capabilities and Data in SCALE," Nucl. Technol. 174(2), 236-288 (May 2011). 



\section{APPENDIX A: DETAILED RESULTS FOR KENO V.a}

All uncertainties reported in this appendix are at the one sigma level. The Monte Carlo and experimental uncertainty values are absolute uncertainties and are reported in $\Delta k_{\text {eff }}$ units. The cross-section uncertainty values are relative uncertainties and are reported in $\Delta k_{\text {eff }} / k_{\text {eff }}$ units.

Table A.1. Detailed multigroup results for KENO V.a HMF systems

\begin{tabular}{lccccccc}
\hline \multicolumn{1}{c}{ Case } & $\boldsymbol{k}_{\text {eff }}$ & $\boldsymbol{\sigma}$ & $\begin{array}{c}\text { Expected } \\
\boldsymbol{k}_{\text {eff }}\end{array}$ & $\begin{array}{c}\text { Experimental } \\
\text { uncertainty }\end{array}$ & $\mathbf{C} / \mathbf{E}$ & $\begin{array}{c}\text { C/E } \\
\text { uncertainty }\end{array}$ & $\begin{array}{c}\text { Cross-section } \\
\text { uncertainty }\end{array}$ \\
\hline $015-001$ & 0.99450 & 0.00010 & 0.9996 & 0.0017 & 0.99490 & 0.00169 & 0.01032 \\
$016-001$ & 0.99888 & 0.00010 & 0.9996 & 0.0018 & 0.99927 & 0.00180 & 0.01354 \\
$016-002$ & 1.00132 & 0.00010 & 0.9996 & 0.0018 & 1.00172 & 0.00181 & 0.01333 \\
$017-001$ & 0.99777 & 0.00010 & 0.9993 & 0.0014 & 0.99847 & 0.00140 & 0.01612 \\
$018-001$ & 1.00130 & 0.00010 & 1.0000 & 0.0014 & 1.00130 & 0.00141 & 0.01092 \\
$018-001 \mathrm{~S}$ & 1.00063 & 0.00010 & 1.0000 & 0.0016 & 1.00063 & 0.00160 & 0.01088 \\
$019-001$ & 1.00811 & 0.00010 & 1.0000 & 0.0028 & 1.00811 & 0.00282 & 0.01152 \\
$019-001 \mathrm{~S}$ & 1.00814 & 0.00010 & 1.0000 & 0.0030 & 1.00814 & 0.00303 & 0.01152 \\
$020-001$ & 1.00180 & 0.00010 & 1.0000 & 0.0028 & 1.00180 & 0.00281 & 0.01180 \\
$020-001 \mathrm{~S}$ & 1.00148 & 0.00010 & 1.0000 & 0.0030 & 1.00148 & 0.00301 & 0.01181 \\
$021-001$ & 1.00660 & 0.00010 & 1.0000 & 0.0024 & 1.00660 & 0.00242 & 0.01178 \\
$021-001 \mathrm{~S}$ & 1.00669 & 0.00010 & 1.0000 & 0.0026 & 1.00669 & 0.00262 & 0.01174 \\
$025-001$ & 0.99962 & 0.00010 & 0.9987 & 0.0014 & 1.00092 & 0.00141 & 0.01066 \\
$025-002$ & 1.00273 & 0.00010 & 0.9990 & 0.0016 & 1.00374 & 0.00161 & 0.01095 \\
$025-003$ & 1.00826 & 0.00010 & 0.9991 & 0.0016 & 1.00917 & 0.00162 & 0.01127 \\
$025-004$ & 1.01260 & 0.00010 & 0.9995 & 0.0016 & 1.01310 & 0.00162 & 0.01152 \\
$025-005$ & 1.01336 & 0.00010 & 0.9991 & 0.0016 & 1.01427 & 0.00163 & 0.01153 \\
$030-001$ & 1.00285 & 0.00009 & 1.0000 & 0.0009 & 1.00285 & 0.00091 & 0.02312 \\
$038-001$ & 1.00511 & 0.00009 & 0.9999 & 0.0007 & 1.00521 & 0.00071 & 0.02289 \\
$038-002$ & 1.00541 & 0.00009 & 0.9999 & 0.0009 & 1.00551 & 0.00091 & 0.02299 \\
$040-001$ & 1.00868 & 0.00010 & 0.9991 & 0.0011 & 1.00958 & 0.00112 & 0.01194 \\
$065-001$ & 0.99890 & 0.00010 & 0.9995 & 0.0013 & 0.99940 & 0.00130 & 0.01046 \\
\hline
\end{tabular}


Table A.2. Detailed continuous energy results for KENO V.a HMF systems

\begin{tabular}{lcccccc}
\hline \multicolumn{1}{c}{ Case } & $\boldsymbol{k}_{\text {eff }}$ & $\boldsymbol{\sigma}$ & $\begin{array}{c}\text { Expected } \\
\boldsymbol{k}_{\text {eff }}\end{array}$ & $\begin{array}{c}\text { Experimental } \\
\text { uncertainty }\end{array}$ & $\boldsymbol{C} / \mathbf{E}$ & $\begin{array}{c}\text { C/E } \\
\text { uncertainty }\end{array}$ \\
\hline $015-001$ & 0.99429 & 0.00010 & 0.9996 & 0.0017 & 0.99468 & 0.00169 \\
$016-001$ & 0.99755 & 0.00010 & 0.9996 & 0.0018 & 0.99795 & 0.00180 \\
$016-002$ & 0.99999 & 0.00010 & 0.9996 & 0.0018 & 1.00039 & 0.00180 \\
$017-001$ & 0.99536 & 0.00010 & 0.9993 & 0.0014 & 0.99606 & 0.00140 \\
$018-001$ & 1.00003 & 0.00010 & 1.0000 & 0.0014 & 1.00003 & 0.00140 \\
$018-001 \mathrm{~S}$ & 0.99944 & 0.00010 & 1.0000 & 0.0016 & 0.99944 & 0.00160 \\
$019-001$ & 1.00701 & 0.00010 & 1.0000 & 0.0028 & 1.00701 & 0.00282 \\
$019-001 \mathrm{~S}$ & 1.00704 & 0.00010 & 1.0000 & 0.0030 & 1.00704 & 0.00302 \\
$020-001$ & 1.00067 & 0.00010 & 1.0000 & 0.0028 & 1.00067 & 0.00280 \\
$020-001 \mathrm{~S}$ & 1.00016 & 0.00010 & 1.0000 & 0.0030 & 1.00016 & 0.00300 \\
$021-001$ & 0.99553 & 0.00010 & 1.0000 & 0.0024 & 0.99553 & 0.00239 \\
$021-001 \mathrm{~S}$ & 0.99554 & 0.00010 & 1.0000 & 0.0026 & 0.99554 & 0.00259 \\
$025-001$ & 0.99796 & 0.00010 & 0.9987 & 0.0014 & 0.99926 & 0.00140 \\
$025-002$ & 0.99963 & 0.00010 & 0.9990 & 0.0016 & 1.00063 & 0.00161 \\
$025-003$ & 1.00187 & 0.00010 & 0.9991 & 0.0016 & 1.00277 & 0.00161 \\
$025-004$ & 1.00341 & 0.00010 & 0.9995 & 0.0016 & 1.00391 & 0.00161 \\
$025-005$ & 1.00376 & 0.00010 & 0.9991 & 0.0016 & 1.00467 & 0.00161 \\
$030-001$ & 0.99708 & 0.00009 & 1.0000 & 0.0009 & 0.99708 & 0.00090 \\
$038-001$ & 0.99877 & 0.00009 & 0.9999 & 0.0007 & 0.99887 & 0.00070 \\
$038-002$ & 0.99789 & 0.00009 & 0.9999 & 0.0009 & 0.99799 & 0.00090 \\
$040-001$ & 1.00195 & 0.00010 & 0.9991 & 0.0011 & 1.00285 & 0.00111 \\
$065-001$ & 0.99789 & 0.00010 & 0.9995 & 0.0013 & 0.99839 & 0.00130 \\
\hline
\end{tabular}


Table A.3. Detailed multigroup results for KENO V.a HST systems

\begin{tabular}{|c|c|c|c|c|c|c|c|}
\hline Case & $\boldsymbol{k}_{\text {eff }}$ & $\sigma$ & $\begin{array}{c}\text { Expected } \\
k_{\text {eff }} \\
\end{array}$ & $\begin{array}{c}\text { Experimental } \\
\text { uncertainty }\end{array}$ & $\mathbf{C} / \mathbf{E}$ & $\begin{array}{c}\mathrm{C} / \mathrm{E} \\
\text { uncertainty }\end{array}$ & $\begin{array}{c}\text { Cross-section } \\
\text { uncertainty }\end{array}$ \\
\hline $001-001$ & 0.99875 & 0.00010 & 1.0004 & 0.0060 & 0.99835 & 0.00599 & 0.00938 \\
\hline 001-002 & 0.99688 & 0.00010 & 1.0021 & 0.0072 & 0.99479 & 0.00715 & 0.00955 \\
\hline $001-003$ & 1.00174 & 0.00010 & 1.0003 & 0.0035 & 1.00144 & 0.00351 & 0.00938 \\
\hline 001-004 & 0.99888 & 0.00010 & 1.0008 & 0.0053 & 0.99808 & 0.00529 & 0.00955 \\
\hline 001-005 & 0.99833 & 0.00010 & 1.0001 & 0.0049 & 0.99823 & 0.00489 & 0.00832 \\
\hline 001-006 & 1.00195 & 0.00010 & 1.0002 & 0.0046 & 1.00175 & 0.00461 & 0.00844 \\
\hline 001-007 & 0.99807 & 0.00010 & 1.0008 & 0.0040 & 0.99728 & 0.00399 & 0.00936 \\
\hline 001-008 & 0.99834 & 0.00010 & 0.9998 & 0.0038 & 0.99854 & 0.00380 & 0.00940 \\
\hline 001-009 & 0.99481 & 0.00010 & 1.0008 & 0.0054 & 0.99401 & 0.00536 & 0.00953 \\
\hline 001-010 & 0.99223 & 0.00010 & 0.9993 & 0.0054 & 0.99292 & 0.00537 & 0.00833 \\
\hline 013-001 & 0.99923 & 0.00010 & 1.0012 & 0.0026 & 0.99803 & 0.00259 & 0.00578 \\
\hline 013-002 & 0.99840 & 0.00010 & 1.0007 & 0.0036 & 0.99771 & 0.00359 & 0.00569 \\
\hline 013-003 & 0.99501 & 0.00010 & 1.0009 & 0.0036 & 0.99411 & 0.00358 & 0.00562 \\
\hline 013-004 & 0.99616 & 0.00010 & 1.0003 & 0.0036 & 0.99586 & 0.00359 & 0.00559 \\
\hline 014-001 & 0.99475 & 0.00010 & 1.0000 & 0.0028 & 0.99475 & 0.00279 & 0.00810 \\
\hline 014-002 & 1.01114 & 0.00019 & 1.0000 & 0.0052 & 1.01114 & 0.00526 & 0.00724 \\
\hline 014-003 & 1.02021 & 0.00019 & 1.0000 & 0.0087 & 1.02021 & 0.00888 & 0.00644 \\
\hline 016-001 & 0.99096 & 0.00019 & 1.0000 & 0.0036 & 0.99096 & 0.00357 & 0.00869 \\
\hline 016-002 & 1.00626 & 0.00019 & 1.0000 & 0.0069 & 1.00626 & 0.00695 & 0.00760 \\
\hline 016-003 & 1.02531 & 0.00019 & 1.0000 & 0.0079 & 1.02531 & 0.00810 & 0.00673 \\
\hline 028-001 & 0.99671 & 0.00010 & 1.0000 & 0.0023 & 0.99671 & 0.00229 & 0.00836 \\
\hline 028-002 & 0.99761 & 0.00009 & 1.0000 & 0.0034 & 0.99761 & 0.00339 & 0.00730 \\
\hline 028-003 & 0.99858 & 0.00010 & 1.0000 & 0.0026 & 0.99858 & 0.00260 & 0.00835 \\
\hline 028-004 & 0.99941 & 0.00009 & 1.0000 & 0.0028 & 0.99941 & 0.00280 & 0.00750 \\
\hline 028-005 & 0.99388 & 0.00010 & 1.0000 & 0.0031 & 0.99388 & 0.00308 & 0.00836 \\
\hline 028-006 & 0.99770 & 0.00009 & 1.0000 & 0.0023 & 0.99770 & 0.00230 & 0.00763 \\
\hline 028-007 & 0.99789 & 0.00010 & 1.0000 & 0.0038 & 0.99789 & 0.00379 & 0.00819 \\
\hline 028-008 & 0.99808 & 0.00009 & 1.0000 & 0.0027 & 0.99808 & 0.00270 & 0.00783 \\
\hline 028-009 & 0.99680 & 0.00010 & 1.0000 & 0.0049 & 0.99680 & 0.00489 & 0.00901 \\
\hline 028-010 & 0.99527 & 0.00010 & 1.0000 & 0.0053 & 0.99527 & 0.00528 & 0.00775 \\
\hline 028-011 & 0.99827 & 0.00010 & 1.0000 & 0.0051 & 0.99827 & 0.00509 & 0.00901 \\
\hline 028-012 & 0.99562 & 0.00010 & 1.0000 & 0.0046 & 0.99562 & 0.00458 & 0.00808 \\
\hline $028-013$ & 0.99721 & 0.00010 & 1.0000 & 0.0058 & 0.99721 & 0.00578 & 0.00897 \\
\hline 028-014 & 0.99738 & 0.00010 & 1.0000 & 0.0046 & 0.99738 & 0.00459 & 0.00835 \\
\hline 028-015 & 1.00531 & 0.00010 & 1.0000 & 0.0064 & 1.00531 & 0.00643 & 0.00882 \\
\hline 028-016 & 1.00147 & 0.00010 & 1.0000 & 0.0052 & 1.00147 & 0.00521 & 0.00842 \\
\hline 028-017 & 0.99692 & 0.00010 & 1.0000 & 0.0066 & 0.99692 & 0.00658 & 0.00869 \\
\hline 028-018 & 0.99771 & 0.00010 & 1.0000 & 0.0060 & 0.99771 & 0.00599 & 0.00843 \\
\hline 029-001 & 0.99910 & 0.00010 & 1.0000 & 0.0066 & 0.99910 & 0.00659 & 0.00877 \\
\hline 029-002 & 1.00296 & 0.00010 & 1.0000 & 0.0058 & 1.00296 & 0.00582 & 0.00785 \\
\hline 029-003 & 0.99553 & 0.00010 & 1.0000 & 0.0068 & 0.99553 & 0.00677 & 0.00773 \\
\hline 029-004 & 0.99431 & 0.00009 & 1.0000 & 0.0074 & 0.99431 & 0.00736 & 0.00695 \\
\hline 029-005 & 0.99927 & 0.00010 & 1.0000 & 0.0067 & 0.99927 & 0.00670 & 0.00703 \\
\hline 029-006 & 0.99938 & 0.00010 & 1.0000 & 0.0065 & 0.99938 & 0.00650 & 0.00749 \\
\hline 029-007 & 1.00006 & 0.00010 & 1.0000 & 0.0063 & 1.00006 & 0.00630 & 0.00793 \\
\hline 030-001 & 0.99678 & 0.00010 & 1.0000 & 0.0039 & 0.99678 & 0.00389 & 0.00826 \\
\hline $030-002$ & 0.99812 & 0.00010 & 1.0000 & 0.0032 & 0.99812 & 0.00320 & 0.00733 \\
\hline $030-003$ & 0.99646 & 0.00009 & 1.0000 & 0.0031 & 0.99646 & 0.00309 & 0.00695 \\
\hline 030-004 & 1.00105 & 0.00011 & 1.0000 & 0.0064 & 1.00105 & 0.00641 & 0.00880 \\
\hline $030-005$ & 0.99730 & 0.00010 & 1.0000 & 0.0058 & 0.99730 & 0.00579 & 0.00812 \\
\hline $030-006$ & 0.99953 & 0.00010 & 1.0000 & 0.0059 & 0.99953 & 0.00590 & 0.00788 \\
\hline 030-007 & 0.99844 & 0.00010 & 1.0000 & 0.0064 & 0.99844 & 0.00639 & 0.00726 \\
\hline
\end{tabular}


Table A.4. Detailed continuous energy results for KENO V.a HST systems

\begin{tabular}{|c|c|c|c|c|c|c|}
\hline Case & $\boldsymbol{k}_{\text {eff }}$ & $\sigma$ & $\begin{array}{c}\text { Expected } \\
\boldsymbol{k}_{\text {eff }} \\
\end{array}$ & $\begin{array}{c}\text { Experimental } \\
\text { uncertainty }\end{array}$ & $\mathbf{C} / \mathbf{E}$ & $\begin{array}{c}\mathrm{C} / \mathrm{E} \\
\text { uncertainty }\end{array}$ \\
\hline $001-001$ & 0.99772 & 0.00010 & 1.0004 & 0.0060 & 0.99732 & 0.00598 \\
\hline 001-002 & 0.99492 & 0.00010 & 1.0021 & 0.0072 & 0.99284 & 0.00713 \\
\hline 001-003 & 1.00119 & 0.00010 & 1.0003 & 0.0035 & 1.00089 & 0.00350 \\
\hline 001-004 & 0.99736 & 0.00010 & 1.0008 & 0.0053 & 0.99657 & 0.00528 \\
\hline 001-005 & 0.99848 & 0.00010 & 1.0001 & 0.0049 & 0.99838 & 0.00489 \\
\hline 001-006 & 1.00147 & 0.00010 & 1.0002 & 0.0046 & 1.00126 & 0.00461 \\
\hline 001-007 & 0.99730 & 0.00010 & 1.0008 & 0.0040 & 0.99650 & 0.00398 \\
\hline 001-008 & 0.99762 & 0.00010 & 0.9998 & 0.0038 & 0.99782 & 0.00379 \\
\hline 001-009 & 0.99342 & 0.00010 & 1.0008 & 0.0054 & 0.99263 & 0.00536 \\
\hline 001-010 & 0.99209 & 0.00010 & 0.9993 & 0.0054 & 0.99279 & 0.00537 \\
\hline 013-001 & 0.99830 & 0.00010 & 1.0012 & 0.0026 & 0.99710 & 0.00259 \\
\hline 013-002 & 0.99749 & 0.00010 & 1.0007 & 0.0036 & 0.99679 & 0.00359 \\
\hline 013-003 & 0.99394 & 0.00010 & 1.0009 & 0.0036 & 0.99304 & 0.00357 \\
\hline 013-004 & 0.99541 & 0.00010 & 1.0003 & 0.0036 & 0.99511 & 0.00358 \\
\hline 014-001 & 0.99386 & 0.00010 & 1.0000 & 0.0028 & 0.99386 & 0.00278 \\
\hline 014-002 & 1.01038 & 0.00019 & 1.0000 & 0.0052 & 1.01038 & 0.00526 \\
\hline 014-003 & 1.01981 & 0.00020 & 1.0000 & 0.0087 & 1.01981 & 0.00887 \\
\hline 016-001 & 0.99008 & 0.00019 & 1.0000 & 0.0036 & 0.99008 & 0.00357 \\
\hline 016-002 & 1.00665 & 0.00019 & 1.0000 & 0.0069 & 1.00665 & 0.00695 \\
\hline 016-003 & 1.02639 & 0.00020 & 1.0000 & 0.0079 & 1.02639 & 0.00811 \\
\hline 028-001 & 0.99633 & 0.00009 & 1.0000 & 0.0023 & 0.99633 & 0.00229 \\
\hline 028-002 & 0.99674 & 0.00009 & 1.0000 & 0.0034 & 0.99674 & 0.00339 \\
\hline 028-003 & 0.99796 & 0.00010 & 1.0000 & 0.0026 & 0.99796 & 0.00260 \\
\hline 028-004 & 0.99838 & 0.00009 & 1.0000 & 0.0028 & 0.99838 & 0.00280 \\
\hline 028-005 & 0.99350 & 0.00010 & 1.0000 & 0.0031 & 0.99350 & 0.00308 \\
\hline 028-006 & 0.99671 & 0.00009 & 1.0000 & 0.0023 & 0.99671 & 0.00229 \\
\hline 028-007 & 0.99743 & 0.00009 & 1.0000 & 0.0038 & 0.99743 & 0.00379 \\
\hline 028-008 & 0.99723 & 0.00010 & 1.0000 & 0.0027 & 0.99723 & 0.00269 \\
\hline 028-009 & 0.99518 & 0.00010 & 1.0000 & 0.0049 & 0.99518 & 0.00488 \\
\hline 028-010 & 0.99296 & 0.00010 & 1.0000 & 0.0053 & 0.99296 & 0.00526 \\
\hline 028-011 & 0.99660 & 0.00010 & 1.0000 & 0.0051 & 0.99660 & 0.00508 \\
\hline 028-012 & 0.99357 & 0.00010 & 1.0000 & 0.0046 & 0.99357 & 0.00457 \\
\hline 028-013 & 0.99565 & 0.00010 & 1.0000 & 0.0058 & 0.99565 & 0.00578 \\
\hline 028-014 & 0.99528 & 0.00010 & 1.0000 & 0.0046 & 0.99528 & 0.00458 \\
\hline 028-015 & 1.00371 & 0.00010 & 1.0000 & 0.0064 & 1.00371 & 0.00642 \\
\hline 028-016 & 0.99961 & 0.00010 & 1.0000 & 0.0052 & 0.99961 & 0.00520 \\
\hline 028-017 & 0.99509 & 0.00010 & 1.0000 & 0.0066 & 0.99509 & 0.00657 \\
\hline 028-018 & 0.99578 & 0.00010 & 1.0000 & 0.0060 & 0.99578 & 0.00598 \\
\hline 029-001 & 0.99761 & 0.00010 & 1.0000 & 0.0066 & 0.99761 & 0.00658 \\
\hline 029-002 & 1.00155 & 0.00010 & 1.0000 & 0.0058 & 1.00155 & 0.00581 \\
\hline 029-003 & 0.99330 & 0.00010 & 1.0000 & 0.0068 & 0.99330 & 0.00676 \\
\hline 029-004 & 0.99125 & 0.00010 & 1.0000 & 0.0074 & 0.99125 & 0.00734 \\
\hline 029-005 & 0.99609 & 0.00010 & 1.0000 & 0.0067 & 0.99609 & 0.00667 \\
\hline 029-006 & 0.99658 & 0.00010 & 1.0000 & 0.0065 & 0.99658 & 0.00648 \\
\hline 029-007 & 0.99757 & 0.00010 & 1.0000 & 0.0063 & 0.99757 & 0.00629 \\
\hline 030-001 & 0.99658 & 0.00010 & 1.0000 & 0.0039 & 0.99658 & 0.00389 \\
\hline 030-002 & 0.99706 & 0.00009 & 1.0000 & 0.0032 & 0.99706 & 0.00319 \\
\hline $030-003$ & 0.99524 & 0.00009 & 1.0000 & 0.0031 & 0.99524 & 0.00309 \\
\hline 030-004 & 0.99928 & 0.00010 & 1.0000 & 0.0064 & 0.99928 & 0.00640 \\
\hline $030-005$ & 0.99526 & 0.00010 & 1.0000 & 0.0058 & 0.99526 & 0.00577 \\
\hline 030-006 & 0.99707 & 0.00010 & 1.0000 & 0.0059 & 0.99707 & 0.00588 \\
\hline $030-007$ & 0.99574 & 0.00010 & 1.0000 & 0.0064 & 0.99574 & 0.00637 \\
\hline
\end{tabular}


Table A.5. Detailed multigroup results for KENO V.a IMF systems

\begin{tabular}{lccccccc}
\hline \multicolumn{1}{c}{ Case } & $\boldsymbol{k}_{\text {eff }}$ & $\boldsymbol{\sigma}$ & $\begin{array}{c}\text { Expected } \\
\boldsymbol{k}_{\text {eff }}\end{array}$ & $\begin{array}{c}\text { Experimental } \\
\text { uncertainty }\end{array}$ & $\mathbf{C / E}$ & $\begin{array}{c}\mathbf{C} / \mathbf{E} \\
\text { uncertainty }\end{array}$ & $\begin{array}{c}\text { Cross-section } \\
\text { uncertainty }\end{array}$ \\
\hline $002-001$ & 1.00540 & 0.00010 & 1.0000 & 0.0030 & 1.00540 & 0.00302 & 0.01860 \\
$003-001$ & 1.00577 & 0.00010 & 1.0000 & 0.0017 & 1.00577 & 0.00171 & 0.01267 \\
$003-001 \mathrm{~S}$ & 1.00597 & 0.00010 & 1.0000 & 0.0019 & 1.00597 & 0.00191 & 0.01271 \\
$004-001$ & 1.01064 & 0.00010 & 1.0000 & 0.0030 & 1.01064 & 0.00303 & 0.01307 \\
$004-001 \mathrm{~S}$ & 1.01056 & 0.00010 & 1.0000 & 0.0032 & 1.01056 & 0.00324 & 0.01309 \\
$005-001$ & 1.01408 & 0.00010 & 1.0000 & 0.0021 & 1.01408 & 0.00213 & 0.01346 \\
$005-001 \mathrm{~S}$ & 1.01393 & 0.00010 & 1.0000 & 0.0023 & 1.01393 & 0.00233 & 0.01348 \\
$006-001$ & 1.00396 & 0.00010 & 1.0000 & 0.0023 & 1.00396 & 0.00231 & 0.01299 \\
$007-001$ & 1.01062 & 0.00010 & 1.0045 & 0.0007 & 1.00609 & 0.00071 & 0.02471 \\
$008-001$ & 1.00997 & 0.00010 & 1.0000 & 0.0018 & 1.00997 & 0.00182 & 0.01320 \\
$009-001$ & 1.00908 & 0.00010 & 1.0000 & 0.0053 & 1.00908 & 0.00535 & 0.01148 \\
\hline
\end{tabular}

Table A.6. Detailed continuous energy results for KENO V.a IMF systems

\begin{tabular}{lcccccc}
\hline \multicolumn{1}{c}{ Case } & $\boldsymbol{k}_{\text {eff }}$ & $\boldsymbol{\sigma}$ & $\begin{array}{c}\text { Expected } \\
\boldsymbol{k}_{\text {eff }}\end{array}$ & $\begin{array}{c}\text { Experimental } \\
\text { uncertainty }\end{array}$ & $\mathbf{C} / \mathbf{E}$ & $\begin{array}{c}\mathbf{C} / \mathbf{E} \\
\text { uncertainty }\end{array}$ \\
\hline $002-001$ & 0.99989 & 0.00010 & 1.0000 & 0.0030 & 0.99989 & 0.00300 \\
$003-001$ & 1.00243 & 0.00010 & 1.0000 & 0.0017 & 1.00243 & 0.00171 \\
$003-001 \mathrm{~S}$ & 1.00241 & 0.00010 & 1.0000 & 0.0019 & 1.00241 & 0.00191 \\
$004-001$ & 1.00765 & 0.00010 & 1.0000 & 0.0030 & 1.00765 & 0.00302 \\
$004-001 \mathrm{~S}$ & 1.00728 & 0.00010 & 1.0000 & 0.0032 & 1.00728 & 0.00322 \\
$005-001$ & 1.00108 & 0.00010 & 1.0000 & 0.0021 & 1.00108 & 0.00210 \\
$005-001 \mathrm{~S}$ & 1.00086 & 0.00010 & 1.0000 & 0.0023 & 1.00086 & 0.00230 \\
$006-001$ & 0.99601 & 0.00010 & 1.0000 & 0.0023 & 0.99601 & 0.00229 \\
$007-001$ & 1.00444 & 0.00010 & 1.0045 & 0.0007 & 0.99994 & 0.00070 \\
$008-001$ & 1.00627 & 0.00010 & 1.0000 & 0.0018 & 1.00627 & 0.00181 \\
$009-001$ & 1.00745 & 0.00010 & 1.0000 & 0.0053 & 1.00745 & 0.00534 \\
\hline
\end{tabular}

Table A.7. Detailed multigroup results for KENO V.a LCT systems

\begin{tabular}{cccccccc}
\hline Case & $\boldsymbol{k}_{\text {eff }}$ & $\boldsymbol{\sigma}$ & $\begin{array}{c}\text { Expected } \\
\boldsymbol{k}_{\text {eff }}\end{array}$ & $\begin{array}{c}\text { Experimental } \\
\text { uncertainty }\end{array}$ & $\mathbf{C} / \mathbf{E}$ & $\begin{array}{c}\text { C/E } \\
\text { uncertainty }\end{array}$ & $\begin{array}{c}\text { Cross-section } \\
\text { uncertainty }\end{array}$ \\
\hline $001-001$ & 0.99859 & 0.00049 & 0.9998 & 0.0031 & 0.99879 & 0.00314 & 0.00599 \\
$001-002$ & 0.99696 & 0.00048 & 0.9998 & 0.0031 & 0.99716 & 0.00313 & 0.00581 \\
$001-003$ & 0.99780 & 0.00046 & 0.9998 & 0.0031 & 0.99800 & 0.00313 & 0.00571 \\
$001-004$ & 0.99709 & 0.00048 & 0.9998 & 0.0031 & 0.99729 & 0.00313 & 0.00578 \\
$001-005$ & 0.99544 & 0.00041 & 0.9998 & 0.0031 & 0.99564 & 0.00311 & 0.00567 \\
$001-006$ & 0.99698 & 0.00048 & 0.9998 & 0.0031 & 0.99718 & 0.00313 & 0.00576 \\
$001-007$ & 0.99727 & 0.00037 & 0.9998 & 0.0031 & 0.99747 & 0.00311 & 0.00565 \\
$001-008$ & 0.99638 & 0.00049 & 0.9998 & 0.0031 & 0.99658 & 0.00313 & 0.00568 \\
$002-001$ & 0.99781 & 0.00012 & 0.9997 & 0.0020 & 0.99811 & 0.00200 & 0.00656 \\
$002-002$ & 0.99903 & 0.00011 & 0.9997 & 0.0020 & 0.99933 & 0.00200 & 0.00650 \\
$002-003$ & 0.99837 & 0.00012 & 0.9997 & 0.0020 & 0.99867 & 0.00200 & 0.00645 \\
$002-004$ & 0.99779 & 0.00011 & 0.9997 & 0.0020 & 0.99809 & 0.00200 & 0.00623 \\
$002-005$ & 0.99678 & 0.00012 & 0.9997 & 0.0020 & 0.99708 & 0.00200 & 0.00605 \\
$010-001$ & 1.00381 & 0.00009 & 1.0000 & 0.0021 & 1.00381 & 0.00211 & 0.00597 \\
$010-002$ & 1.00413 & 0.00010 & 1.0000 & 0.0021 & 1.00413 & 0.00211 & 0.00598 \\
$010-003$ & 1.00307 & 0.00009 & 1.0000 & 0.0021 & 1.00307 & 0.00211 & 0.00594 \\
$010-004$ & 0.99586 & 0.00009 & 1.0000 & 0.0021 & 0.99586 & 0.00209 & 0.00588 \\
$010-005$ & 0.99988 & 0.00010 & 1.0000 & 0.0021 & 0.99988 & 0.00210 & 0.00513 \\
$010-006$ & 0.99992 & 0.00010 & 1.0000 & 0.0021 & 0.99992 & 0.00210 & 0.00530
\end{tabular}


Table A.7. Detailed multigroup results for KENO V.a LCT systems (continued)

\begin{tabular}{|c|c|c|c|c|c|c|c|}
\hline Case & $\boldsymbol{k}_{\text {eff }}$ & $\sigma$ & $\begin{array}{c}\text { Expected } \\
\boldsymbol{k}_{\text {eff }}\end{array}$ & $\begin{array}{c}\text { Experimental } \\
\text { uncertainty }\end{array}$ & $\mathbf{C} / \mathbf{E}$ & $\begin{array}{c}\mathrm{C} / \mathrm{E} \\
\text { uncertainty }\end{array}$ & $\begin{array}{c}\text { Cross-section } \\
\text { uncertainty }\end{array}$ \\
\hline 010-007 & 1.00086 & 0.00010 & 1.0000 & 0.0021 & 1.00086 & 0.00210 & 0.00555 \\
\hline 010-008 & 0.99750 & 0.00010 & 1.0000 & 0.0021 & 0.99750 & 0.00210 & 0.00560 \\
\hline 010-009 & 1.00097 & 0.00009 & 1.0000 & 0.0021 & 1.00097 & 0.00210 & 0.00557 \\
\hline 010-010 & 1.00067 & 0.00010 & 1.0000 & 0.0021 & 1.00067 & 0.00210 & 0.00562 \\
\hline 010-011 & 1.00071 & 0.00010 & 1.0000 & 0.0021 & 1.00071 & 0.00210 & 0.00563 \\
\hline 010-012 & 0.99974 & 0.00010 & 1.0000 & 0.0021 & 0.99974 & 0.00210 & 0.00564 \\
\hline 010-013 & 0.99705 & 0.00009 & 1.0000 & 0.0021 & 0.99705 & 0.00210 & 0.00579 \\
\hline 010-014 & 1.00135 & 0.00010 & 1.0000 & 0.0028 & 1.00135 & 0.00281 & 0.00594 \\
\hline $010-015$ & 0.99866 & 0.00010 & 1.0000 & 0.0028 & 0.99866 & 0.00280 & 0.00601 \\
\hline $010-016$ & 1.00213 & 0.00010 & 1.0000 & 0.0028 & 1.00213 & 0.00281 & 0.00598 \\
\hline $010-017$ & 1.00120 & 0.00009 & 1.0000 & 0.0028 & 1.00120 & 0.00280 & 0.00601 \\
\hline 010-018 & 1.00106 & 0.00010 & 1.0000 & 0.0028 & 1.00106 & 0.00280 & 0.00601 \\
\hline 010-019 & 1.00083 & 0.00009 & 1.0000 & 0.0028 & 1.00083 & 0.00280 & 0.00608 \\
\hline $010-020$ & 1.00207 & 0.00010 & 1.0000 & 0.0028 & 1.00207 & 0.00281 & 0.00616 \\
\hline $010-021$ & 1.00233 & 0.00010 & 1.0000 & 0.0028 & 1.00233 & 0.00281 & 0.00624 \\
\hline $010-022$ & 1.00174 & 0.00009 & 1.0000 & 0.0028 & 1.00174 & 0.00281 & 0.00619 \\
\hline $010-023$ & 1.00045 & 0.00007 & 1.0000 & 0.0028 & 1.00045 & 0.00280 & 0.00614 \\
\hline $010-024$ & 0.99920 & 0.00010 & 1.0000 & 0.0028 & 0.99920 & 0.00280 & 0.00557 \\
\hline $010-025$ & 1.00090 & 0.00010 & 1.0000 & 0.0028 & 1.00090 & 0.00280 & 0.00569 \\
\hline $010-026$ & 1.00126 & 0.00010 & 1.0000 & 0.0028 & 1.00126 & 0.00281 & 0.00580 \\
\hline $010-027$ & 1.00124 & 0.00009 & 1.0000 & 0.0028 & 1.00124 & 0.00280 & 0.00588 \\
\hline $010-028$ & 1.00161 & 0.00010 & 1.0000 & 0.0028 & 1.00161 & 0.00281 & 0.00590 \\
\hline 010-029 & 1.00132 & 0.00007 & 1.0000 & 0.0028 & 1.00132 & 0.00280 & 0.00594 \\
\hline 010-030 & 0.99911 & 0.00010 & 1.0000 & 0.0028 & 0.99911 & 0.00280 & 0.00599 \\
\hline 017-001 & 0.99976 & 0.00010 & 1.0000 & 0.0031 & 0.99976 & 0.00310 & 0.00560 \\
\hline 017-002 & 0.99940 & 0.00010 & 1.0000 & 0.0031 & 0.99940 & 0.00310 & 0.00561 \\
\hline 017-003 & 0.99819 & 0.00010 & 1.0000 & 0.0031 & 0.99819 & 0.00310 & 0.00558 \\
\hline 017-004 & 0.99741 & 0.00010 & 1.0000 & 0.0031 & 0.99741 & 0.00309 & 0.00527 \\
\hline 017-005 & 0.99906 & 0.00010 & 1.0000 & 0.0031 & 0.99906 & 0.00310 & 0.00536 \\
\hline 017-006 & 0.99911 & 0.00010 & 1.0000 & 0.0031 & 0.99911 & 0.00310 & 0.00540 \\
\hline 017-007 & 0.99868 & 0.00010 & 1.0000 & 0.0031 & 0.99868 & 0.00310 & 0.00541 \\
\hline 017-008 & 0.99697 & 0.00007 & 1.0000 & 0.0031 & 0.99697 & 0.00309 & 0.00548 \\
\hline 017-009 & 0.99631 & 0.00010 & 1.0000 & 0.0031 & 0.99631 & 0.00309 & 0.00562 \\
\hline 017-010 & 0.99755 & 0.00007 & 1.0000 & 0.0031 & 0.99755 & 0.00309 & 0.00543 \\
\hline 017-011 & 0.99800 & 0.00009 & 1.0000 & 0.0031 & 0.99800 & 0.00310 & 0.00545 \\
\hline 017-012 & 0.99769 & 0.00009 & 1.0000 & 0.0031 & 0.99769 & 0.00309 & 0.00547 \\
\hline 017-013 & 0.99796 & 0.00010 & 1.0000 & 0.0031 & 0.99796 & 0.00310 & 0.00549 \\
\hline 017-014 & 0.99799 & 0.00010 & 1.0000 & 0.0031 & 0.99799 & 0.00310 & 0.00552 \\
\hline 017-015 & 0.99668 & 0.00008 & 1.0000 & 0.0028 & 0.99668 & 0.00279 & 0.00559 \\
\hline 017-016 & 0.99756 & 0.00008 & 1.0000 & 0.0028 & 0.99756 & 0.00279 & 0.00561 \\
\hline 017-017 & 0.99871 & 0.00008 & 1.0000 & 0.0028 & 0.99871 & 0.00280 & 0.00560 \\
\hline 017-018 & 0.99751 & 0.00007 & 1.0000 & 0.0028 & 0.99751 & 0.00279 & 0.00561 \\
\hline 017-019 & 0.99783 & 0.00007 & 1.0000 & 0.0028 & 0.99783 & 0.00279 & 0.00561 \\
\hline 017-020 & 0.99654 & 0.00007 & 1.0000 & 0.0028 & 0.99654 & 0.00279 & 0.00563 \\
\hline $017-021$ & 0.99654 & 0.00006 & 1.0000 & 0.0028 & 0.99654 & 0.00279 & 0.00566 \\
\hline 017-022 & 0.99556 & 0.00007 & 1.0000 & 0.0028 & 0.99556 & 0.00279 & 0.00576 \\
\hline 017-023 & 0.99741 & 0.00008 & 1.0000 & 0.0028 & 0.99741 & 0.00279 & 0.00569 \\
\hline $017-024$ & 0.99813 & 0.00008 & 1.0000 & 0.0028 & 0.99813 & 0.00280 & 0.00571 \\
\hline $017-025$ & 0.99637 & 0.00009 & 1.0000 & 0.0028 & 0.99637 & 0.00279 & 0.00565 \\
\hline $017-026$ & 0.99496 & 0.00009 & 1.0000 & 0.0028 & 0.99496 & 0.00279 & 0.00530 \\
\hline $017-027$ & 0.99698 & 0.00008 & 1.0000 & 0.0028 & 0.99698 & 0.00279 & 0.00540 \\
\hline 017-028 & 0.99762 & 0.00008 & 1.0000 & 0.0028 & 0.99762 & 0.00279 & 0.00543 \\
\hline 017-029 & 0.99757 & 0.00007 & 1.0000 & 0.0028 & 0.99757 & 0.00279 & 0.00546 \\
\hline $042-001$ & 0.99706 & 0.00160 & 1.0000 & 0.0016 & 0.99706 & 0.00160 & 0.00556 \\
\hline
\end{tabular}


Table A.7. Detailed multigroup results for KENO V.a LCT systems (continued)

\begin{tabular}{cccccccc}
\hline Case & $\boldsymbol{k}_{\text {eff }}$ & $\boldsymbol{\sigma}$ & $\begin{array}{c}\text { Expected } \\
\boldsymbol{k}_{\text {eff }}\end{array}$ & $\begin{array}{c}\text { Experimental } \\
\text { uncertainty }\end{array}$ & $\mathbf{C} / \mathbf{E}$ & $\begin{array}{c}\text { C/E } \\
\text { uncertainty }\end{array}$ & $\begin{array}{c}\text { Cross-section } \\
\text { uncertainty }\end{array}$ \\
\hline $042-002$ & 0.99677 & 0.00160 & 1.0000 & 0.0016 & 0.99677 & 0.00160 & 0.00544 \\
$042-003$ & 0.99794 & 0.00160 & 1.0000 & 0.0016 & 0.99794 & 0.00160 & 0.00539 \\
$042-004$ & 0.99852 & 0.00170 & 1.0000 & 0.0017 & 0.99852 & 0.00170 & 0.00540 \\
$042-005$ & 0.99840 & 0.00330 & 1.0000 & 0.0033 & 0.99840 & 0.00330 & 0.00540 \\
$042-006$ & 0.99830 & 0.00160 & 1.0000 & 0.0016 & 0.99830 & 0.00160 & 0.00552 \\
$042-007$ & 0.99634 & 0.00180 & 1.0000 & 0.0018 & 0.99634 & 0.00180 & 0.00545 \\
$050-001$ & 0.99737 & 0.00100 & 1.0004 & 0.0010 & 0.99737 & 0.00100 & 0.00668 \\
$050-002$ & 0.99685 & 0.00100 & 1.0004 & 0.0010 & 0.99685 & 0.00100 & 0.00660 \\
$050-003$ & 0.99768 & 0.00100 & 1.0004 & 0.0010 & 0.99768 & 0.00100 & 0.00647 \\
$050-004$ & 0.99689 & 0.00100 & 1.0004 & 0.0010 & 0.99689 & 0.00100 & 0.00636 \\
$050-005$ & 0.99843 & 0.00100 & 1.0004 & 0.0010 & 0.99843 & 0.00100 & 0.00625 \\
$050-006$ & 0.99848 & 0.00100 & 1.0004 & 0.0010 & 0.99848 & 0.00100 & 0.00621 \\
$050-007$ & 0.99849 & 0.00100 & 1.0004 & 0.0010 & 0.99849 & 0.00100 & 0.00614 \\
$050-008$ & 0.99524 & 0.00100 & 1.0004 & 0.0010 & 0.99524 & 0.00100 & 0.00651 \\
$050-009$ & 0.99587 & 0.00100 & 1.0004 & 0.0010 & 0.99587 & 0.00100 & 0.00642 \\
$050-010$ & 0.99575 & 0.00100 & 1.0004 & 0.0010 & 0.99575 & 0.00100 & 0.00641 \\
$050-011$ & 0.99633 & 0.00100 & 1.0004 & 0.0010 & 0.99633 & 0.00100 & 0.00643 \\
$050-012$ & 0.99733 & 0.00100 & 1.0004 & 0.0010 & 0.99733 & 0.00100 & 0.00632 \\
$050-013$ & 0.99754 & 0.00100 & 1.0004 & 0.0010 & 0.99754 & 0.00100 & 0.00631 \\
$050-014$ & 0.99676 & 0.00100 & 1.0004 & 0.0010 & 0.99676 & 0.00100 & 0.00620 \\
$050-015$ & 0.99768 & 0.00100 & 1.0004 & 0.0010 & 0.99768 & 0.00100 & 0.00617 \\
$050-016$ & 0.99876 & 0.00100 & 1.0004 & 0.0010 & 0.99876 & 0.00100 & 0.00624 \\
$050-017$ & 0.99860 & 0.00100 & 1.0004 & 0.0010 & 0.99860 & 0.00100 & 0.00621 \\
$050-018$ & 0.99845 & 0.00100 & 1.0004 & 0.0010 & 0.99845 & 0.00100 & 0.00623 \\
\hline
\end{tabular}

Table A.8. Detailed continuous energy results for KENO V.a LCT systems

\begin{tabular}{ccccccc}
\hline Case & $\boldsymbol{k}_{\text {eff }}$ & $\boldsymbol{\sigma}$ & $\begin{array}{c}\text { Expected } \\
\boldsymbol{k}_{\text {eff }}\end{array}$ & $\begin{array}{c}\text { Experimental } \\
\text { uncertainty }\end{array}$ & $\mathbf{C} / \mathbf{E}$ & $\begin{array}{c}\mathbf{C} / \mathbf{E} \\
\text { uncertainty }\end{array}$ \\
\hline $001-001$ & 0.99993 & 0.00048 & 0.9998 & 0.0031 & 1.00013 & 0.00314 \\
$001-002$ & 0.99793 & 0.00049 & 0.9998 & 0.0031 & 0.99813 & 0.00313 \\
$001-003$ & 0.99887 & 0.00044 & 0.9998 & 0.0031 & 0.99907 & 0.00313 \\
$001-004$ & 0.99903 & 0.00049 & 0.9998 & 0.0031 & 0.99923 & 0.00314 \\
$001-005$ & 0.99689 & 0.00049 & 0.9998 & 0.0031 & 0.99709 & 0.00313 \\
$001-006$ & 0.99906 & 0.00048 & 0.9998 & 0.0031 & 0.99926 & 0.00314 \\
$001-007$ & 0.99808 & 0.00046 & 0.9998 & 0.0031 & 0.99828 & 0.00313 \\
$001-008$ & 0.99710 & 0.00048 & 0.9998 & 0.0031 & 0.99730 & 0.00313 \\
$002-001$ & 0.99825 & 0.00011 & 0.9997 & 0.0020 & 0.99855 & 0.00200 \\
$002-002$ & 0.99983 & 0.00010 & 0.9997 & 0.0020 & 1.00013 & 0.00200 \\
$002-003$ & 0.99921 & 0.00012 & 0.9997 & 0.0020 & 0.99951 & 0.00200 \\
$002-004$ & 0.99887 & 0.00011 & 0.9997 & 0.0020 & 0.99917 & 0.00200 \\
$002-005$ & 0.99734 & 0.00012 & 0.9997 & 0.0020 & 0.99764 & 0.00200 \\
$010-001$ & 1.00436 & 0.00009 & 1.0000 & 0.0021 & 1.00436 & 0.00211 \\
$010-002$ & 1.00471 & 0.00010 & 1.0000 & 0.0021 & 1.00471 & 0.00211 \\
$010-003$ & 1.00388 & 0.00010 & 1.0000 & 0.0021 & 1.00388 & 0.00211 \\
$010-004$ & 0.99680 & 0.00009 & 1.0000 & 0.0021 & 0.99680 & 0.00210 \\
$010-005$ & 0.99927 & 0.00010 & 1.0000 & 0.0021 & 0.99927 & 0.00210 \\
$010-006$ & 1.00014 & 0.00010 & 1.0000 & 0.0021 & 1.00014 & 0.00210 \\
$010-007$ & 1.00114 & 0.00010 & 1.0000 & 0.0021 & 1.00114 & 0.00210 \\
$010-008$ & 0.99790 & 0.00010 & 1.0000 & 0.0021 & 0.99790 & 0.00210 \\
$010-009$ & 0.99920 & 0.00010 & 1.0000 & 0.0021 & 0.99920 & 0.00210 \\
$010-010$ & 0.99957 & 0.00010 & 1.0000 & 0.0021 & 0.99957 & 0.00210 \\
$010-011$ & 1.00013 & 0.00010 & 1.0000 & 0.0021 & 1.00013 & 0.00210 \\
& & & & & &
\end{tabular}


Table A.8. Detailed continuous energy results for KENO V.a LCT systems (continued)

\begin{tabular}{|c|c|c|c|c|c|c|}
\hline Case & $\boldsymbol{k}_{e f f}$ & $\boldsymbol{\sigma}$ & $\begin{array}{c}\text { Expected } \\
\boldsymbol{k}_{\text {eff }} \\
\end{array}$ & $\begin{array}{c}\text { Experimental } \\
\text { uncertainty }\end{array}$ & $\mathbf{C} / \mathbf{E}$ & $\begin{array}{c}\mathrm{C} / \mathrm{E} \\
\text { uncertainty }\end{array}$ \\
\hline 010-012 & 0.99981 & 0.00010 & 1.0000 & 0.0021 & 0.99981 & 0.00210 \\
\hline $010-013$ & 0.99775 & 0.00010 & 1.0000 & 0.0021 & 0.99775 & 0.00210 \\
\hline 010-014 & 1.00135 & 0.00010 & 1.0000 & 0.0028 & 1.00135 & 0.00281 \\
\hline 010-015 & 0.99865 & 0.00010 & 1.0000 & 0.0028 & 0.99865 & 0.00280 \\
\hline 010-016 & 1.00256 & 0.00009 & 1.0000 & 0.0028 & 1.00256 & 0.00281 \\
\hline $010-017$ & 1.00217 & 0.00010 & 1.0000 & 0.0028 & 1.00217 & 0.00281 \\
\hline 010-018 & 1.00233 & 0.00010 & 1.0000 & 0.0028 & 1.00233 & 0.00281 \\
\hline 010-019 & 1.00200 & 0.00010 & 1.0000 & 0.0028 & 1.00200 & 0.00281 \\
\hline 010-020 & 1.00345 & 0.00010 & 1.0000 & 0.0028 & 1.00345 & 0.00281 \\
\hline 010-021 & 1.00354 & 0.00009 & 1.0000 & 0.0028 & 1.00354 & 0.00281 \\
\hline 010-022 & 1.00310 & 0.00009 & 1.0000 & 0.0028 & 1.00310 & 0.00281 \\
\hline $010-023$ & 1.00178 & 0.00007 & 1.0000 & 0.0028 & 1.00178 & 0.00281 \\
\hline $010-024$ & 0.99972 & 0.00010 & 1.0000 & 0.0028 & 0.99972 & 0.00280 \\
\hline $010-025$ & 1.00114 & 0.00009 & 1.0000 & 0.0028 & 1.00114 & 0.00280 \\
\hline $010-026$ & 1.00174 & 0.00010 & 1.0000 & 0.0028 & 1.00174 & 0.00281 \\
\hline $010-027$ & 1.00190 & 0.00010 & 1.0000 & 0.0028 & 1.00190 & 0.00281 \\
\hline 010-028 & 1.00235 & 0.00010 & 1.0000 & 0.0028 & 1.00235 & 0.00281 \\
\hline 010-029 & 1.00252 & 0.00007 & 1.0000 & 0.0028 & 1.00252 & 0.00281 \\
\hline $010-030$ & 1.00061 & 0.00009 & 1.0000 & 0.0028 & 1.00061 & 0.00280 \\
\hline 017-001 & 1.00092 & 0.00010 & 1.0000 & 0.0031 & 1.00092 & 0.00310 \\
\hline 017-002 & 1.00078 & 0.00009 & 1.0000 & 0.0031 & 1.00078 & 0.00310 \\
\hline $017-003$ & 0.99944 & 0.00010 & 1.0000 & 0.0031 & 0.99944 & 0.00310 \\
\hline 017-004 & 0.99804 & 0.00009 & 1.0000 & 0.0031 & 0.99804 & 0.00310 \\
\hline 017-005 & 0.99957 & 0.00010 & 1.0000 & 0.0031 & 0.99957 & 0.00310 \\
\hline 017-006 & 0.99987 & 0.00010 & 1.0000 & 0.0031 & 0.99987 & 0.00310 \\
\hline 017-007 & 0.99970 & 0.00010 & 1.0000 & 0.0031 & 0.99970 & 0.00310 \\
\hline 017-008 & 0.99826 & 0.00007 & 1.0000 & 0.0031 & 0.99826 & 0.00310 \\
\hline 017-009 & 0.99758 & 0.00010 & 1.0000 & 0.0031 & 0.99758 & 0.00309 \\
\hline 017-010 & 0.99777 & 0.00007 & 1.0000 & 0.0031 & 0.99777 & 0.00309 \\
\hline 017-011 & 0.99797 & 0.00010 & 1.0000 & 0.0031 & 0.99797 & 0.00310 \\
\hline 017-012 & 0.99829 & 0.00010 & 1.0000 & 0.0031 & 0.99829 & 0.00310 \\
\hline $017-013$ & 0.99872 & 0.00009 & 1.0000 & 0.0031 & 0.99872 & 0.00310 \\
\hline 017-014 & 0.99912 & 0.00010 & 1.0000 & 0.0031 & 0.99912 & 0.00310 \\
\hline 017-015 & 0.99655 & 0.00008 & 1.0000 & 0.0028 & 0.99655 & 0.00279 \\
\hline 017-016 & 0.99790 & 0.00007 & 1.0000 & 0.0028 & 0.99790 & 0.00279 \\
\hline 017-017 & 0.99938 & 0.00007 & 1.0000 & 0.0028 & 0.99938 & 0.00280 \\
\hline 017-018 & 0.99816 & 0.00008 & 1.0000 & 0.0028 & 0.99816 & 0.00280 \\
\hline 017-019 & 0.99867 & 0.00008 & 1.0000 & 0.0028 & 0.99867 & 0.00280 \\
\hline 017-020 & 0.99774 & 0.00007 & 1.0000 & 0.0028 & 0.99774 & 0.00279 \\
\hline 017-021 & 0.99794 & 0.00005 & 1.0000 & 0.0028 & 0.99794 & 0.00279 \\
\hline 017-022 & 0.99726 & 0.00009 & 1.0000 & 0.0028 & 0.99726 & 0.00279 \\
\hline $017-023$ & 0.99921 & 0.00008 & 1.0000 & 0.0028 & 0.99921 & 0.00280 \\
\hline 017-024 & 0.99979 & 0.00009 & 1.0000 & 0.0028 & 0.99979 & 0.00280 \\
\hline $017-025$ & 0.99808 & 0.00009 & 1.0000 & 0.0028 & 0.99808 & 0.00280 \\
\hline $017-026$ & 0.99582 & 0.00009 & 1.0000 & 0.0028 & 0.99582 & 0.00279 \\
\hline $017-027$ & 0.99799 & 0.00009 & 1.0000 & 0.0028 & 0.99799 & 0.00280 \\
\hline 017-028 & 0.99876 & 0.00008 & 1.0000 & 0.0028 & 0.99876 & 0.00280 \\
\hline 017-029 & 0.99891 & 0.00009 & 1.0000 & 0.0028 & 0.99891 & 0.00280 \\
\hline $042-001$ & 0.99775 & 0.00009 & 1.0000 & 0.0016 & 0.99775 & 0.00160 \\
\hline $042-002$ & 0.99751 & 0.00010 & 1.0000 & 0.0016 & 0.99751 & 0.00160 \\
\hline $042-003$ & 0.99826 & 0.00009 & 1.0000 & 0.0016 & 0.99826 & 0.00160 \\
\hline $042-004$ & 0.99891 & 0.00010 & 1.0000 & 0.0017 & 0.99891 & 0.00170 \\
\hline $042-005$ & 0.99887 & 0.00009 & 1.0000 & 0.0033 & 0.99887 & 0.00330 \\
\hline $042-006$ & 0.99871 & 0.00009 & 1.0000 & 0.0016 & 0.99871 & 0.00160 \\
\hline
\end{tabular}


Table A.8. Detailed continuous energy results for KENO V.a LCT systems (continued)

\begin{tabular}{ccccccc}
\hline Case & $\boldsymbol{k}_{\text {eff }}$ & $\boldsymbol{\sigma}$ & $\begin{array}{c}\text { Expected } \\
\boldsymbol{k}_{\text {eff }}\end{array}$ & $\begin{array}{c}\text { Experimental } \\
\text { uncertainty }\end{array}$ & $\mathbf{C} / \mathbf{E}$ & $\begin{array}{c}\mathbf{C} / \mathbf{E} \\
\text { uncertainty }\end{array}$ \\
\hline $042-007$ & 0.99680 & 0.00009 & 1.0000 & 0.0018 & 0.99680 & 0.00180 \\
$050-001$ & 0.99891 & 0.00010 & 1.0004 & 0.0010 & 0.99851 & 0.00100 \\
$050-002$ & 0.99872 & 0.00010 & 1.0004 & 0.0010 & 0.99832 & 0.00100 \\
$050-003$ & 0.99961 & 0.00010 & 1.0004 & 0.0010 & 0.99921 & 0.00100 \\
$050-004$ & 0.99904 & 0.00010 & 1.0004 & 0.0010 & 0.99864 & 0.00100 \\
$050-005$ & 1.00043 & 0.00010 & 1.0004 & 0.0010 & 1.00003 & 0.00100 \\
$050-006$ & 1.00036 & 0.00010 & 1.0004 & 0.0010 & 0.99996 & 0.00100 \\
$050-007$ & 1.00051 & 0.00010 & 1.0004 & 0.0010 & 1.00011 & 0.00100 \\
$050-008$ & 0.99717 & 0.00010 & 1.0004 & 0.0010 & 0.99677 & 0.00100 \\
$050-009$ & 0.99799 & 0.00010 & 1.0004 & 0.0010 & 0.99759 & 0.00100 \\
$050-010$ & 0.99763 & 0.00010 & 1.0004 & 0.0010 & 0.99723 & 0.00100 \\
$050-011$ & 0.99830 & 0.00010 & 1.0004 & 0.0010 & 0.99790 & 0.00100 \\
$050-012$ & 0.99934 & 0.00010 & 1.0004 & 0.0010 & 0.99894 & 0.00100 \\
$050-013$ & 0.99948 & 0.00010 & 1.0004 & 0.0010 & 0.99908 & 0.00100 \\
$050-014$ & 0.99921 & 0.00010 & 1.0004 & 0.0010 & 0.99881 & 0.00100 \\
$050-015$ & 0.99987 & 0.00010 & 1.0004 & 0.0010 & 0.99947 & 0.00100 \\
$050-016$ & 1.00081 & 0.00010 & 1.0004 & 0.0010 & 1.00041 & 0.00100 \\
$050-017$ & 1.00077 & 0.00010 & 1.0004 & 0.0010 & 1.00037 & 0.00100 \\
$050-018$ & 1.00066 & 0.00010 & 1.0004 & 0.0010 & 1.00026 & 0.00100 \\
\hline
\end{tabular}

Table A.9. Detailed multigroup results for KENO V.a LST systems

\begin{tabular}{cccccccc}
\hline Case & $\boldsymbol{k}_{\text {eff }}$ & $\boldsymbol{\sigma}$ & $\begin{array}{c}\text { Expected } \\
\boldsymbol{k}_{\text {eff }}\end{array}$ & $\begin{array}{c}\text { Experimental } \\
\text { uncertainty }\end{array}$ & $\mathbf{C} / \mathbf{E}$ & $\begin{array}{c}\mathbf{C} / \mathbf{E} \\
\text { uncertainty }\end{array}$ & $\begin{array}{c}\text { Cross section } \\
\text { uncertainty }\end{array}$ \\
\hline $002-001$ & 1.00015 & 0.00010 & 1.0038 & 0.0040 & 0.99636 & 0.00397 & 0.00536 \\
$002-002$ & 0.99605 & 0.00010 & 1.0024 & 0.0037 & 0.99367 & 0.00367 & 0.00563 \\
$002-003$ & 1.00098 & 0.00010 & 1.0024 & 0.0044 & 0.99858 & 0.00438 & 0.00552 \\
$003-001$ & 0.99666 & 0.00010 & 0.9997 & 0.0039 & 0.99696 & 0.00389 & 0.00618 \\
$003-002$ & 0.99548 & 0.00010 & 0.9993 & 0.0042 & 0.99617 & 0.00419 & 0.00595 \\
$003-003$ & 0.99965 & 0.00010 & 0.9995 & 0.0042 & 1.00015 & 0.00420 & 0.00588 \\
$003-004$ & 0.99325 & 0.00009 & 0.9995 & 0.0042 & 0.99374 & 0.00418 & 0.00585 \\
$003-005$ & 0.99758 & 0.00010 & 0.9997 & 0.0048 & 0.99788 & 0.00479 & 0.00531 \\
$003-006$ & 0.99813 & 0.00010 & 0.9999 & 0.0049 & 0.99823 & 0.00489 & 0.00524 \\
$003-007$ & 0.99653 & 0.00010 & 0.9994 & 0.0049 & 0.99712 & 0.00489 & 0.00518 \\
$003-008$ & 1.00020 & 0.00010 & 0.9993 & 0.0052 & 1.00090 & 0.00521 & 0.00493 \\
$003-009$ & 0.99738 & 0.00010 & 0.9996 & 0.0052 & 0.99777 & 0.00519 & 0.00491 \\
$004-001$ & 0.99997 & 0.00039 & 0.9994 & 0.0008 & 1.00057 & 0.00089 & 0.00603 \\
$004-002$ & 1.00163 & 0.00049 & 0.9999 & 0.0009 & 1.00173 & 0.00103 & 0.00590 \\
$004-003$ & 0.99864 & 0.00044 & 0.9999 & 0.0009 & 0.99874 & 0.00100 & 0.00577 \\
$004-004$ & 1.00151 & 0.00038 & 0.9999 & 0.0010 & 1.00161 & 0.00107 & 0.00564 \\
$004-005$ & 1.00300 & 0.00042 & 0.9999 & 0.0010 & 1.00310 & 0.00109 & 0.00554 \\
$004-006$ & 1.00075 & 0.00042 & 0.9994 & 0.0011 & 1.00135 & 0.00118 & 0.00546 \\
$004-007$ & 1.00049 & 0.00045 & 0.9996 & 0.0011 & 1.00089 & 0.00119 & 0.00538 \\
\hline
\end{tabular}


Table A.10. Detailed continuous energy results for KENO V.a LST systems

\begin{tabular}{ccccccc}
\hline Case & $\boldsymbol{k}_{\text {eff }}$ & $\boldsymbol{\sigma}$ & $\begin{array}{c}\text { Expected } \\
\boldsymbol{k}_{\text {eff }}\end{array}$ & $\begin{array}{c}\text { Experimental } \\
\text { uncertainty }\end{array}$ & $\boldsymbol{C} / \mathbf{E}$ & $\begin{array}{c}\text { C/E } \\
\text { uncertainty }\end{array}$ \\
\hline $002-001$ & 0.99943 & 0.00010 & 1.0038 & 0.0040 & 0.99564 & 0.00397 \\
$002-002$ & 0.99521 & 0.00010 & 1.0024 & 0.0037 & 0.99282 & 0.00367 \\
$002-003$ & 1.00017 & 0.00010 & 1.0024 & 0.0044 & 0.99777 & 0.00438 \\
$003-001$ & 0.99613 & 0.00010 & 0.9997 & 0.0039 & 0.99643 & 0.00389 \\
$003-002$ & 0.99526 & 0.00010 & 0.9993 & 0.0042 & 0.99596 & 0.00419 \\
$003-003$ & 0.99952 & 0.00010 & 0.9995 & 0.0042 & 1.00002 & 0.00420 \\
$003-004$ & 0.99322 & 0.00010 & 0.9995 & 0.0042 & 0.99372 & 0.00418 \\
$003-005$ & 0.99763 & 0.00010 & 0.9997 & 0.0048 & 0.99792 & 0.00479 \\
$003-006$ & 0.99814 & 0.00010 & 0.9999 & 0.0049 & 0.99824 & 0.00489 \\
$003-007$ & 0.99643 & 0.00010 & 0.9994 & 0.0049 & 0.99703 & 0.00489 \\
$003-008$ & 1.00027 & 0.00009 & 0.9993 & 0.0052 & 1.00097 & 0.00521 \\
$003-009$ & 0.99736 & 0.00010 & 0.9996 & 0.0052 & 0.99776 & 0.00519 \\
$004-001$ & 1.00036 & 0.00047 & 0.9994 & 0.0008 & 1.00096 & 0.00093 \\
$004-002$ & 1.00019 & 0.00048 & 0.9999 & 0.0009 & 1.00029 & 0.00102 \\
$004-003$ & 0.99881 & 0.00049 & 0.9999 & 0.0009 & 0.99891 & 0.00102 \\
$004-004$ & 1.00178 & 0.00041 & 0.9999 & 0.0010 & 1.00188 & 0.00108 \\
$004-005$ & 1.00120 & 0.00043 & 0.9999 & 0.0010 & 1.00130 & 0.00109 \\
$004-006$ & 1.00059 & 0.00044 & 0.9994 & 0.0011 & 1.00119 & 0.00119 \\
$004-007$ & 1.00079 & 0.00044 & 0.9996 & 0.0011 & 1.00119 & 0.00119 \\
\hline
\end{tabular}

Table A.11. Detailed multigroup results for KENO V.a MCT systems

\begin{tabular}{cccccccc}
\hline Case & $\boldsymbol{k}_{\text {eff }}$ & $\boldsymbol{\sigma}$ & $\begin{array}{c}\text { Expected } \\
\boldsymbol{k}_{\text {eff }}\end{array}$ & $\begin{array}{c}\text { Experimental } \\
\text { uncertainty }\end{array}$ & $\boldsymbol{C} / \mathbf{E}$ & $\begin{array}{c}\text { C/E } \\
\text { uncertainty }\end{array}$ & $\begin{array}{c}\text { Cross-section } \\
\text { uncertainty }\end{array}$ \\
\hline $001-001$ & 1.00057 & 0.00010 & 1.0000 & 0.0025 & 1.00057 & 0.00250 & 0.01159 \\
$001-002$ & 0.99975 & 0.00010 & 1.0000 & 0.0026 & 0.99975 & 0.00260 & 0.01248 \\
$001-003$ & 0.99841 & 0.00010 & 1.0000 & 0.0032 & 0.99841 & 0.00320 & 0.01274 \\
$001-004$ & 1.00046 & 0.00010 & 1.0000 & 0.0039 & 1.00046 & 0.00390 & 0.01278 \\
$002-001 \mathrm{~S}$ & 1.00102 & 0.00010 & 1.0024 & 0.0060 & 0.99862 & 0.00598 & 0.01017 \\
$002-002 \mathrm{~S}$ & 1.00142 & 0.00010 & 1.0009 & 0.0047 & 1.00052 & 0.00470 & 0.00986 \\
$002-003 \mathrm{~S}$ & 1.00216 & 0.00010 & 1.0042 & 0.0031 & 0.99796 & 0.00308 & 0.01075 \\
$002-004 \mathrm{~S}$ & 1.00518 & 0.00010 & 1.0024 & 0.0024 & 1.00278 & 0.00240 & 0.00986 \\
$002-005 \mathrm{~S}$ & 1.00431 & 0.00010 & 1.0038 & 0.0025 & 1.00051 & 0.00249 & 0.01077 \\
$002-006 \mathrm{~S}$ & 1.00557 & 0.00010 & 1.0029 & 0.0027 & 1.00266 & 0.00270 & 0.00995 \\
$004-001$ & 0.99511 & 0.00010 & 1.0000 & 0.0046 & 0.99511 & 0.00458 & 0.01004 \\
$004-002$ & 0.99619 & 0.00010 & 1.0000 & 0.0046 & 0.99619 & 0.00458 & 0.01006 \\
$004-003$ & 0.99645 & 0.00010 & 1.0000 & 0.0046 & 0.99645 & 0.00458 & 0.01007 \\
$004-004$ & 0.99579 & 0.00010 & 1.0000 & 0.0039 & 0.99579 & 0.00388 & 0.01006 \\
$004-005$ & 0.99678 & 0.00010 & 1.0000 & 0.0039 & 0.99678 & 0.00389 & 0.01008 \\
$004-006$ & 0.99744 & 0.00010 & 1.0000 & 0.0039 & 0.99744 & 0.00389 & 0.01012 \\
$004-007$ & 0.99682 & 0.00010 & 1.0000 & 0.0040 & 0.99682 & 0.00399 & 0.01001 \\
$004-008$ & 0.99760 & 0.00010 & 1.0000 & 0.0040 & 0.99760 & 0.00399 & 0.01004 \\
$004-009$ & 0.99797 & 0.00010 & 1.0000 & 0.0040 & 0.99797 & 0.00399 & 0.01006 \\
$004-010$ & 0.99766 & 0.00010 & 1.0000 & 0.0051 & 0.99766 & 0.00509 & 0.00990 \\
$004-011$ & 0.99792 & 0.00010 & 1.0000 & 0.0051 & 0.99792 & 0.00509 & 0.00993 \\
\hline
\end{tabular}


Table A.12. Detailed continuous energy results for KENO V.a MCT systems

\begin{tabular}{ccccccc}
\hline Case & $\boldsymbol{k}_{\text {eff }}$ & $\boldsymbol{\sigma}$ & $\begin{array}{c}\text { Expected } \\
\boldsymbol{k}_{\text {eff }}\end{array}$ & $\begin{array}{c}\text { Experimental } \\
\text { uncertainty }\end{array}$ & $\begin{array}{c}\text { C/E } \\
\text { uncertainty }\end{array}$ & $\begin{array}{c}\text { C } \\
001-001\end{array}$ \\
0.99470 & 0.00010 & 1.0000 & 0.0025 & 0.99470 & 0.00249 \\
$001-002$ & 0.99564 & 0.00010 & 1.0000 & 0.0026 & 0.99564 & 0.00259 \\
$001-003$ & 0.99584 & 0.00010 & 1.0000 & 0.0032 & 0.99584 & 0.00319 \\
$001-004$ & 0.99905 & 0.00010 & 1.0000 & 0.0039 & 0.99905 & 0.00390 \\
$002-001 \mathrm{~S}$ & 0.99883 & 0.00010 & 1.0024 & 0.0060 & 0.99644 & 0.00597 \\
$002-002 \mathrm{~S}$ & 0.99953 & 0.00010 & 1.0009 & 0.0047 & 0.99863 & 0.00469 \\
$002-003 \mathrm{~S}$ & 1.00115 & 0.00010 & 1.0042 & 0.0031 & 0.99696 & 0.00308 \\
$002-004 \mathrm{~S}$ & 1.00551 & 0.00010 & 1.0024 & 0.0024 & 1.00311 & 0.00240 \\
$002-005 \mathrm{~S}$ & 1.00353 & 0.00010 & 1.0038 & 0.0025 & 0.99973 & 0.00249 \\
$002-006 \mathrm{~S}$ & 1.00565 & 0.00010 & 1.0029 & 0.0027 & 1.00274 & 0.00270 \\
$004-001$ & 0.99231 & 0.00010 & 1.0000 & 0.0046 & 0.99231 & 0.00457 \\
$004-002$ & 0.99325 & 0.00010 & 1.0000 & 0.0046 & 0.99325 & 0.00457 \\
$004-003$ & 0.99358 & 0.00010 & 1.0000 & 0.0046 & 0.99358 & 0.00457 \\
$004-004$ & 0.99351 & 0.00010 & 1.0000 & 0.0039 & 0.99351 & 0.00388 \\
$004-005$ & 0.99472 & 0.00010 & 1.0000 & 0.0039 & 0.99472 & 0.00388 \\
$004-006$ & 0.99510 & 0.00010 & 1.0000 & 0.0039 & 0.99510 & 0.00388 \\
$004-007$ & 0.99547 & 0.00010 & 1.0000 & 0.0040 & 0.99547 & 0.00398 \\
$004-008$ & 0.99618 & 0.00010 & 1.0000 & 0.0040 & 0.99618 & 0.00399 \\
$004-009$ & 0.99665 & 0.00010 & 1.0000 & 0.0040 & 0.99665 & 0.00399 \\
$004-010$ & 0.99674 & 0.00010 & 1.0000 & 0.0051 & 0.99674 & 0.00508 \\
$004-011$ & 0.99705 & 0.00010 & 1.0000 & 0.0051 & 0.99705 & 0.00509 \\
\hline
\end{tabular}

Table A.13. Detailed multigroup results for KENO V.a PMF systems

\begin{tabular}{cccccccc}
\hline Case & $\boldsymbol{k}_{\text {eff }}$ & $\boldsymbol{\sigma}$ & $\begin{array}{c}\text { Expected } \\
\boldsymbol{k}_{\text {eff }}\end{array}$ & $\begin{array}{c}\text { Experimental } \\
\text { uncertainty }\end{array}$ & $\boldsymbol{C} / \mathbf{E}$ & $\begin{array}{c}\text { C/E } \\
\text { uncertainty }\end{array}$ & $\begin{array}{c}\text { Cross-section } \\
\text { uncertainty }\end{array}$ \\
\hline $001-001$ & 1.00007 & 0.00010 & 1.0000 & 0.0020 & 1.00007 & 0.00200 & 0.01391 \\
$002-001$ & 1.00078 & 0.00010 & 1.0000 & 0.0020 & 1.00078 & 0.00200 & 0.01218 \\
$005-001$ & 1.00619 & 0.00010 & 1.0000 & 0.0013 & 1.00619 & 0.00131 & 0.01974 \\
$006-001$ & 1.00254 & 0.00010 & 1.0000 & 0.0030 & 1.00254 & 0.00301 & 0.01245 \\
$008-001$ & 0.99773 & 0.00010 & 1.0000 & 0.0006 & 0.99773 & 0.00061 & 0.01302 \\
$010-001$ & 1.00084 & 0.00010 & 1.0000 & 0.0018 & 1.00084 & 0.00180 & 0.01390 \\
$018-001$ & 0.99513 & 0.00010 & 1.0000 & 0.0030 & 0.99513 & 0.00299 & 0.01321 \\
$022-001$ & 0.99857 & 0.00010 & 1.0000 & 0.0023 & 0.99857 & 0.00230 & 0.01417 \\
$023-001$ & 0.99967 & 0.00010 & 1.0000 & 0.0022 & 0.99967 & 0.00220 & 0.01367 \\
$024-001$ & 1.00201 & 0.00010 & 1.0000 & 0.0022 & 1.00201 & 0.00221 & 0.01361 \\
\hline
\end{tabular}


Table A.14. Detailed continuous energy results for KENO V.a PMF systems

\begin{tabular}{ccccccc}
\hline Case & $\boldsymbol{k}_{\text {eff }}$ & $\boldsymbol{\sigma}$ & $\begin{array}{c}\text { Expected } \\
\boldsymbol{k}_{\text {eff }}\end{array}$ & $\begin{array}{c}\text { Experimental } \\
\text { uncertainty }\end{array}$ & $\boldsymbol{C} / \mathbf{E}$ & $\begin{array}{c}\mathbf{C} / \mathbf{E} \\
\text { uncertainty }\end{array}$ \\
\hline $001-001$ & 0.99964 & 0.00010 & 1.0000 & 0.0020 & 0.99964 & 0.00200 \\
$002-001$ & 0.99963 & 0.00010 & 1.0000 & 0.0020 & 0.99963 & 0.00200 \\
$005-001$ & 1.00919 & 0.00010 & 1.0000 & 0.0013 & 1.00919 & 0.00132 \\
$006-001$ & 1.00127 & 0.00010 & 1.0000 & 0.0030 & 1.00127 & 0.00301 \\
$008-001$ & 0.99837 & 0.00010 & 1.0000 & 0.0006 & 0.99837 & 0.00061 \\
$010-001$ & 0.99950 & 0.00010 & 1.0000 & 0.0018 & 0.99950 & 0.00180 \\
$018-001$ & 0.99459 & 0.00010 & 1.0000 & 0.0030 & 0.99459 & 0.00299 \\
$022-001$ & 0.99811 & 0.00010 & 1.0000 & 0.0023 & 0.99811 & 0.00230 \\
$023-001$ & 0.99954 & 0.00010 & 1.0000 & 0.0022 & 0.99954 & 0.00220 \\
$024-001$ & 1.00149 & 0.00010 & 1.0000 & 0.0022 & 1.00149 & 0.00221 \\
\hline
\end{tabular}

Table A.15. Detailed multigroup results for KENO V.a PST systems

\begin{tabular}{|c|c|c|c|c|c|c|c|}
\hline Case & $\boldsymbol{k}_{\text {eff }}$ & $\sigma$ & $\begin{array}{c}\text { Expected } \\
\boldsymbol{k}_{\text {eff }} \\
\end{array}$ & $\begin{array}{c}\text { Experimental } \\
\text { uncertainty }\end{array}$ & $\mathbf{C} / \mathbf{E}$ & $\begin{array}{c}\mathrm{C} / \mathrm{E} \\
\text { uncertainty }\end{array}$ & $\begin{array}{c}\text { Cross-section } \\
\text { uncertainty }\end{array}$ \\
\hline $001-001$ & 1.00628 & 0.00010 & 1.0000 & 0.0050 & 1.00628 & 0.00503 & 0.01475 \\
\hline 001-002 & 1.00853 & 0.00010 & 1.0000 & 0.0050 & 1.00853 & 0.00504 & 0.01472 \\
\hline 001-003 & 1.01125 & 0.00009 & 1.0000 & 0.0050 & 1.01125 & 0.00506 & 0.01464 \\
\hline 001-004 & 1.00566 & 0.00010 & 1.0000 & 0.0050 & 1.00566 & 0.00503 & 0.01461 \\
\hline $001-005$ & 1.00968 & 0.00010 & 1.0000 & 0.0050 & 1.00968 & 0.00505 & 0.01459 \\
\hline 001-006 & 1.01133 & 0.00010 & 1.0000 & 0.0050 & 1.01133 & 0.00506 & 0.01420 \\
\hline $002-001$ & 1.00471 & 0.00010 & 1.0000 & 0.0047 & 1.00471 & 0.00472 & 0.01479 \\
\hline $002-002$ & 1.00569 & 0.00010 & 1.0000 & 0.0047 & 1.00569 & 0.00473 & 0.01479 \\
\hline $002-003$ & 1.00466 & 0.00010 & 1.0000 & 0.0047 & 1.00466 & 0.00472 & 0.01481 \\
\hline $002-004$ & 1.00762 & 0.00010 & 1.0000 & 0.0047 & 1.00762 & 0.00474 & 0.01479 \\
\hline $002-005$ & 1.01062 & 0.00010 & 1.0000 & 0.0047 & 1.01062 & 0.00475 & 0.01478 \\
\hline $002-006$ & 1.00641 & 0.00010 & 1.0000 & 0.0047 & 1.00641 & 0.00473 & 0.01480 \\
\hline $002-007$ & 1.00875 & 0.00009 & 1.0000 & 0.0047 & 1.00875 & 0.00474 & 0.01478 \\
\hline 003-001 & 1.00326 & 0.00010 & 1.0000 & 0.0047 & 1.00326 & 0.00472 & 0.01464 \\
\hline 003-002 & 1.00297 & 0.00010 & 1.0000 & 0.0047 & 1.00297 & 0.00471 & 0.01465 \\
\hline 003-003 & 1.00574 & 0.00010 & 1.0000 & 0.0047 & 1.00574 & 0.00473 & 0.01463 \\
\hline 003-004 & 1.00513 & 0.00010 & 1.0000 & 0.0047 & 1.00513 & 0.00473 & 0.01463 \\
\hline 003-005 & 1.00627 & 0.00010 & 1.0000 & 0.0047 & 1.00627 & 0.00473 & 0.01464 \\
\hline 003-006 & 1.00662 & 0.00010 & 1.0000 & 0.0047 & 1.00662 & 0.00473 & 0.01466 \\
\hline 003-007 & 1.00749 & 0.00010 & 1.0000 & 0.0047 & 1.00749 & 0.00474 & 0.01462 \\
\hline 003-008 & 1.00622 & 0.00010 & 1.0000 & 0.0047 & 1.00622 & 0.00473 & 0.01463 \\
\hline 004-001 & 1.00435 & 0.00010 & 1.0000 & 0.0047 & 1.00435 & 0.00472 & 0.01450 \\
\hline 004-002 & 0.99923 & 0.00010 & 1.0000 & 0.0047 & 0.99923 & 0.00470 & 0.01450 \\
\hline 004-003 & 1.00144 & 0.00010 & 1.0000 & 0.0047 & 1.00144 & 0.00471 & 0.01449 \\
\hline 004-004 & 0.99932 & 0.00010 & 1.0000 & 0.0047 & 0.99932 & 0.00470 & 0.01453 \\
\hline 004-005 & 1.00032 & 0.00010 & 1.0000 & 0.0047 & 1.00032 & 0.00470 & 0.01448 \\
\hline 004-006 & 1.00233 & 0.00010 & 1.0000 & 0.0047 & 1.00233 & 0.00471 & 0.01446 \\
\hline 004-007 & 1.00636 & 0.00010 & 1.0000 & 0.0047 & 1.00636 & 0.00473 & 0.01445 \\
\hline 004-008 & 1.00190 & 0.00010 & 1.0000 & 0.0047 & 1.00190 & 0.00471 & 0.01448 \\
\hline 004-009 & 1.00127 & 0.00010 & 1.0000 & 0.0047 & 1.00127 & 0.00471 & 0.01449 \\
\hline 004-010 & 1.00279 & 0.00010 & 1.0000 & 0.0047 & 1.00279 & 0.00471 & 0.01452 \\
\hline 004-011 & 1.00145 & 0.00010 & 1.0000 & 0.0047 & 1.00145 & 0.00471 & 0.01458 \\
\hline 004-012 & 1.00374 & 0.00010 & 1.0000 & 0.0047 & 1.00374 & 0.00472 & 0.01446 \\
\hline 004-013 & 1.00106 & 0.00010 & 1.0000 & 0.0047 & 1.00106 & 0.00471 & 0.01446 \\
\hline $005-001$ & 1.00306 & 0.00010 & 1.0000 & 0.0047 & 1.00306 & 0.00472 & 0.01444 \\
\hline $005-002$ & 1.00348 & 0.00010 & 1.0000 & 0.0047 & 1.00348 & 0.00472 & 0.01445 \\
\hline
\end{tabular}


Table A.15. Detailed multigroup results for KENO V.a PST systems (continued)

\begin{tabular}{|c|c|c|c|c|c|c|c|}
\hline Case & $\boldsymbol{k}_{e f f}$ & $\sigma$ & $\begin{array}{c}\text { Expected } \\
\boldsymbol{k}_{\text {eff }}\end{array}$ & $\begin{array}{c}\text { Experimental } \\
\text { uncertainty }\end{array}$ & $\mathbf{C} / \mathbf{E}$ & $\begin{array}{c}\mathrm{C} / \mathrm{E} \\
\text { uncertainty }\end{array}$ & $\begin{array}{c}\text { Cross-section } \\
\text { uncertainty }\end{array}$ \\
\hline 005-003 & 1.00407 & 0.00010 & 1.0000 & 0.0047 & 1.00407 & 0.00472 & 0.01446 \\
\hline 005-004 & 1.00577 & 0.00010 & 1.0000 & 0.0047 & 1.00577 & 0.00473 & 0.01446 \\
\hline 005-005 & 1.00703 & 0.00010 & 1.0000 & 0.0047 & 1.00703 & 0.00473 & 0.01448 \\
\hline 005-006 & 1.00659 & 0.00010 & 1.0000 & 0.0047 & 1.00659 & 0.00473 & 0.01450 \\
\hline 005-007 & 1.00514 & 0.00010 & 1.0000 & 0.0047 & 1.00514 & 0.00473 & 0.01454 \\
\hline 005-008 & 1.00023 & 0.00010 & 1.0000 & 0.0047 & 1.00023 & 0.00470 & 0.01445 \\
\hline 005-009 & 1.00295 & 0.00010 & 1.0000 & 0.0047 & 1.00295 & 0.00471 & 0.01445 \\
\hline 006-001 & 1.00148 & 0.00010 & 1.0000 & 0.0035 & 1.00148 & 0.00351 & 0.01430 \\
\hline 006-002 & 1.00251 & 0.00010 & 1.0000 & 0.0035 & 1.00251 & 0.00351 & 0.01431 \\
\hline 006-003 & 1.00221 & 0.00010 & 1.0000 & 0.0035 & 1.00221 & 0.00351 & 0.01433 \\
\hline 007-001 & 1.01156 & 0.00010 & 1.0000 & 0.0047 & 1.01156 & 0.00476 & 0.01433 \\
\hline 007-002 & 1.00589 & 0.00010 & 1.0000 & 0.0047 & 1.00589 & 0.00473 & 0.01440 \\
\hline 007-003 & 1.01098 & 0.00010 & 1.0000 & 0.0047 & 1.01098 & 0.00475 & 0.01471 \\
\hline 007-004 & 1.00471 & 0.00010 & 1.0000 & 0.0047 & 1.00471 & 0.00472 & 0.01474 \\
\hline 007-005 & 1.00665 & 0.00010 & 1.0000 & 0.0047 & 1.00665 & 0.00473 & 0.01473 \\
\hline 007-006 & 1.00035 & 0.00010 & 1.0000 & 0.0047 & 1.00035 & 0.00470 & 0.01477 \\
\hline 007-007 & 0.99883 & 0.00010 & 1.0000 & 0.0047 & 0.99883 & 0.00470 & 0.01477 \\
\hline 007-008 & 1.00234 & 0.00010 & 1.0000 & 0.0047 & 1.00234 & 0.00471 & 0.01476 \\
\hline 011-001 & 1.01077 & 0.00010 & 1.0000 & 0.0052 & 1.01077 & 0.00526 & 0.01475 \\
\hline 011-002 & 1.01556 & 0.00010 & 1.0000 & 0.0052 & 1.01556 & 0.00528 & 0.01474 \\
\hline 011-003 & 1.01737 & 0.00010 & 1.0000 & 0.0052 & 1.01737 & 0.00529 & 0.01473 \\
\hline 011-004 & 1.01019 & 0.00010 & 1.0000 & 0.0052 & 1.01019 & 0.00525 & 0.01479 \\
\hline 011-005 & 1.00733 & 0.00010 & 1.0000 & 0.0052 & 1.00733 & 0.00524 & 0.01485 \\
\hline 011-006 & 0.99495 & 0.00010 & 1.0000 & 0.0052 & 0.99495 & 0.00517 & 0.01438 \\
\hline 011-007 & 1.00122 & 0.00010 & 1.0000 & 0.0052 & 1.00122 & 0.00521 & 0.01437 \\
\hline 011-008 & 0.99759 & 0.00010 & 1.0000 & 0.0052 & 0.99759 & 0.00519 & 0.01438 \\
\hline 011-009 & 0.99429 & 0.00010 & 1.0000 & 0.0052 & 0.99429 & 0.00517 & 0.01442 \\
\hline 011-010 & 1.00423 & 0.00010 & 1.0000 & 0.0052 & 1.00423 & 0.00522 & 0.01436 \\
\hline 011-011 & 1.00089 & 0.00010 & 1.0000 & 0.0052 & 1.00089 & 0.00521 & 0.01446 \\
\hline 011-012 & 1.00028 & 0.00010 & 1.0000 & 0.0052 & 1.00028 & 0.00520 & 0.01440 \\
\hline 020-001 & 1.00451 & 0.00010 & 1.0000 & 0.0059 & 1.00451 & 0.00593 & 0.01446 \\
\hline 020-002 & 1.00698 & 0.00010 & 1.0000 & 0.0059 & 1.00698 & 0.00594 & 0.01443 \\
\hline $020-003$ & 1.00143 & 0.00010 & 1.0000 & 0.0059 & 1.00143 & 0.00591 & 0.01444 \\
\hline 020-004 & 1.00531 & 0.00010 & 1.0000 & 0.0059 & 1.00531 & 0.00593 & 0.01451 \\
\hline 020-005 & 1.00562 & 0.00010 & 1.0000 & 0.0059 & 1.00562 & 0.00593 & 0.01451 \\
\hline 020-006 & 0.99932 & 0.00010 & 1.0000 & 0.0059 & 0.99932 & 0.00590 & 0.01446 \\
\hline 020-007 & 1.00504 & 0.00010 & 1.0000 & 0.0059 & 1.00504 & 0.00593 & 0.01468 \\
\hline 020-008 & 0.99633 & 0.00010 & 1.0000 & 0.0059 & 0.99633 & 0.00588 & 0.01467 \\
\hline 020-009 & 1.00527 & 0.00010 & 1.0000 & 0.0059 & 1.00527 & 0.00593 & 0.01444 \\
\hline 020-010 & 1.00206 & 0.00010 & 1.0000 & 0.0059 & 1.00206 & 0.00591 & 0.01442 \\
\hline 020-011 & 1.00361 & 0.00010 & 1.0000 & 0.0059 & 1.00361 & 0.00592 & 0.01452 \\
\hline 020-012 & 1.00484 & 0.00010 & 1.0000 & 0.0059 & 1.00484 & 0.00593 & 0.01452 \\
\hline 020-013 & 0.99415 & 0.00010 & 1.0000 & 0.0059 & 0.99415 & 0.00587 & 0.01470 \\
\hline 020-014 & 0.99797 & 0.00010 & 1.0000 & 0.0059 & 0.99797 & 0.00589 & 0.01472 \\
\hline 020-015 & 1.00460 & 0.00010 & 1.0000 & 0.0059 & 1.00460 & 0.00593 & 0.01441 \\
\hline
\end{tabular}


Table A.16. Detailed continuous energy results for KENO V.a PST systems

\begin{tabular}{|c|c|c|c|c|c|c|}
\hline Case & $\boldsymbol{k}_{e f f}$ & $\sigma$ & $\begin{array}{c}\text { Expected } \\
k_{\text {eff }} \\
\end{array}$ & $\begin{array}{c}\text { Experimental } \\
\text { uncertainty }\end{array}$ & $\mathbf{C} / \mathbf{E}$ & $\begin{array}{c}\mathrm{C} / \mathrm{E} \\
\text { uncertainty }\end{array}$ \\
\hline 001-001 & 1.00170 & 0.00010 & 1.0000 & 0.0050 & 1.00170 & 0.00501 \\
\hline 001-002 & 1.00279 & 0.00010 & 1.0000 & 0.0050 & 1.00279 & 0.00501 \\
\hline 001-003 & 1.00482 & 0.00010 & 1.0000 & 0.0050 & 1.00482 & 0.00503 \\
\hline 001-004 & 0.99901 & 0.00010 & 1.0000 & 0.0050 & 0.99901 & 0.00500 \\
\hline 001-005 & 1.00287 & 0.00010 & 1.0000 & 0.0050 & 1.00287 & 0.00502 \\
\hline 001-006 & 1.00264 & 0.00010 & 1.0000 & 0.0050 & 1.00264 & 0.00501 \\
\hline 002-001 & 1.00203 & 0.00010 & 1.0000 & 0.0047 & 1.00203 & 0.00471 \\
\hline 002-002 & 1.00309 & 0.00010 & 1.0000 & 0.0047 & 1.00309 & 0.00472 \\
\hline $002-003$ & 1.00173 & 0.00010 & 1.0000 & 0.0047 & 1.00173 & 0.00471 \\
\hline 002-004 & 1.00444 & 0.00010 & 1.0000 & 0.0047 & 1.00444 & 0.00472 \\
\hline $002-005$ & 1.00713 & 0.00010 & 1.0000 & 0.0047 & 1.00713 & 0.00473 \\
\hline $002-006$ & 1.00254 & 0.00010 & 1.0000 & 0.0047 & 1.00254 & 0.00471 \\
\hline $002-007$ & 1.00468 & 0.00010 & 1.0000 & 0.0047 & 1.00468 & 0.00472 \\
\hline 003-001 & 1.00216 & 0.00010 & 1.0000 & 0.0047 & 1.00216 & 0.00471 \\
\hline 003-002 & 1.00188 & 0.00010 & 1.0000 & 0.0047 & 1.00188 & 0.00471 \\
\hline 003-003 & 1.00376 & 0.00010 & 1.0000 & 0.0047 & 1.00376 & 0.00472 \\
\hline 003-004 & 1.00326 & 0.00010 & 1.0000 & 0.0047 & 1.00326 & 0.00472 \\
\hline 003-005 & 1.00405 & 0.00010 & 1.0000 & 0.0047 & 1.00405 & 0.00472 \\
\hline 003-006 & 1.00424 & 0.00010 & 1.0000 & 0.0047 & 1.00424 & 0.00472 \\
\hline 003-007 & 1.00582 & 0.00010 & 1.0000 & 0.0047 & 1.00582 & 0.00473 \\
\hline 003-008 & 1.00472 & 0.00010 & 1.0000 & 0.0047 & 1.00472 & 0.00472 \\
\hline 004-001 & 1.00400 & 0.00010 & 1.0000 & 0.0047 & 1.00400 & 0.00472 \\
\hline 004-002 & 0.99897 & 0.00010 & 1.0000 & 0.0047 & 0.99897 & 0.00470 \\
\hline 004-003 & 1.00110 & 0.00010 & 1.0000 & 0.0047 & 1.00110 & 0.00471 \\
\hline 004-004 & 0.99893 & 0.00010 & 1.0000 & 0.0047 & 0.99893 & 0.00470 \\
\hline 004-005 & 0.99959 & 0.00010 & 1.0000 & 0.0047 & 0.99959 & 0.00470 \\
\hline 004-006 & 1.00099 & 0.00010 & 1.0000 & 0.0047 & 1.00099 & 0.00471 \\
\hline 004-007 & 1.00484 & 0.00010 & 1.0000 & 0.0047 & 1.00484 & 0.00472 \\
\hline 004-008 & 1.00069 & 0.00010 & 1.0000 & 0.0047 & 1.00069 & 0.00470 \\
\hline 004-009 & 0.99966 & 0.00010 & 1.0000 & 0.0047 & 0.99966 & 0.00470 \\
\hline 004-010 & 1.00095 & 0.00010 & 1.0000 & 0.0047 & 1.00095 & 0.00471 \\
\hline 004-011 & 0.99906 & 0.00010 & 1.0000 & 0.0047 & 0.99906 & 0.00470 \\
\hline 004-012 & 1.00235 & 0.00010 & 1.0000 & 0.0047 & 1.00235 & 0.00471 \\
\hline 004-013 & 0.99945 & 0.00010 & 1.0000 & 0.0047 & 0.99945 & 0.00470 \\
\hline 005-001 & 1.00155 & 0.00010 & 1.0000 & 0.0047 & 1.00155 & 0.00471 \\
\hline 005-002 & 1.00170 & 0.00010 & 1.0000 & 0.0047 & 1.00170 & 0.00471 \\
\hline 005-003 & 1.00234 & 0.00010 & 1.0000 & 0.0047 & 1.00234 & 0.00471 \\
\hline 005-004 & 1.00382 & 0.00010 & 1.0000 & 0.0047 & 1.00382 & 0.00472 \\
\hline $005-005$ & 1.00484 & 0.00010 & 1.0000 & 0.0047 & 1.00484 & 0.00472 \\
\hline 005-006 & 1.00395 & 0.00010 & 1.0000 & 0.0047 & 1.00395 & 0.00472 \\
\hline $005-007$ & 1.00229 & 0.00010 & 1.0000 & 0.0047 & 1.00229 & 0.00471 \\
\hline 005-008 & 0.99828 & 0.00010 & 1.0000 & 0.0047 & 0.99828 & 0.00469 \\
\hline 005-009 & 1.00071 & 0.00010 & 1.0000 & 0.0047 & 1.00071 & 0.00470 \\
\hline 006-001 & 1.00008 & 0.00010 & 1.0000 & 0.0035 & 1.00008 & 0.00350 \\
\hline 006-002 & 1.00143 & 0.00010 & 1.0000 & 0.0035 & 1.00143 & 0.00351 \\
\hline 006-003 & 1.00093 & 0.00010 & 1.0000 & 0.0035 & 1.00093 & 0.00350 \\
\hline 007-001 & 1.00336 & 0.00010 & 1.0000 & 0.0047 & 1.00336 & 0.00472 \\
\hline 007-002 & 0.99802 & 0.00010 & 1.0000 & 0.0047 & 0.99802 & 0.00469 \\
\hline $007-003$ & 1.00516 & 0.00010 & 1.0000 & 0.0047 & 1.00516 & 0.00473 \\
\hline 007-004 & 0.99910 & 0.00010 & 1.0000 & 0.0047 & 0.99910 & 0.00470 \\
\hline 007-005 & 1.00121 & 0.00010 & 1.0000 & 0.0047 & 1.00121 & 0.00471 \\
\hline 007-006 & 0.99462 & 0.00010 & 1.0000 & 0.0047 & 0.99462 & 0.00468 \\
\hline
\end{tabular}


Table A.16. Detailed continuous energy results for KENO V.a PST systems (continued)

\begin{tabular}{ccccccc}
\hline Case & $\boldsymbol{k}_{\text {eff }}$ & $\boldsymbol{\sigma}$ & $\begin{array}{c}\text { Expected } \\
\boldsymbol{k}_{\text {eff }}\end{array}$ & $\begin{array}{c}\text { Experimental } \\
\text { uncertainty }\end{array}$ & $\mathbf{C} / \mathbf{E}$ & $\begin{array}{c}\mathbf{C} / \mathbf{E} \\
\text { uncertainty }\end{array}$ \\
\hline $007-007$ & 0.99325 & 0.00010 & 1.0000 & 0.0047 & 0.99325 & 0.00467 \\
$007-008$ & 0.99718 & 0.00010 & 1.0000 & 0.0047 & 0.99718 & 0.00469 \\
$011-001$ & 1.00823 & 0.00010 & 1.0000 & 0.0052 & 1.00823 & 0.00524 \\
$011-002$ & 1.01295 & 0.00010 & 1.0000 & 0.0052 & 1.01295 & 0.00527 \\
$011-003$ & 1.01479 & 0.00010 & 1.0000 & 0.0052 & 1.01479 & 0.00528 \\
$011-004$ & 1.00733 & 0.00010 & 1.0000 & 0.0052 & 1.00733 & 0.00524 \\
$011-005$ & 1.00401 & 0.00010 & 1.0000 & 0.0052 & 1.00401 & 0.00522 \\
$011-006$ & 0.99376 & 0.00010 & 1.0000 & 0.0052 & 0.99376 & 0.00517 \\
$011-007$ & 0.99975 & 0.00010 & 1.0000 & 0.0052 & 0.99975 & 0.00520 \\
$011-008$ & 0.99616 & 0.00010 & 1.0000 & 0.0052 & 0.99616 & 0.00518 \\
$011-009$ & 0.99271 & 0.00010 & 1.0000 & 0.0052 & 0.99271 & 0.00516 \\
$011-010$ & 1.00273 & 0.00010 & 1.0000 & 0.0052 & 1.00273 & 0.00522 \\
$011-011$ & 0.99899 & 0.00010 & 1.0000 & 0.0052 & 0.99899 & 0.00520 \\
$011-012$ & 0.99893 & 0.00010 & 1.0000 & 0.0052 & 0.99893 & 0.00520 \\
$020-001$ & 1.00189 & 0.00010 & 1.0000 & 0.0059 & 1.00189 & 0.00591 \\
$020-002$ & 1.00444 & 0.00010 & 1.0000 & 0.0059 & 1.00444 & 0.00593 \\
$020-003$ & 0.99955 & 0.00010 & 1.0000 & 0.0059 & 0.99955 & 0.00590 \\
$020-004$ & 1.00175 & 0.00010 & 1.0000 & 0.0059 & 1.00175 & 0.00591 \\
$020-005$ & 1.00223 & 0.00010 & 1.0000 & 0.0059 & 1.00223 & 0.00591 \\
$020-006$ & 0.99695 & 0.00010 & 1.0000 & 0.0059 & 0.99695 & 0.00588 \\
$020-007$ & 1.00012 & 0.00010 & 1.0000 & 0.0059 & 1.00012 & 0.00590 \\
$020-008$ & 0.99313 & 0.00010 & 1.0000 & 0.0059 & 0.99313 & 0.00586 \\
$020-009$ & 1.00252 & 0.00010 & 1.0000 & 0.0059 & 1.00252 & 0.00592 \\
$020-010$ & 0.99986 & 0.00010 & 1.0000 & 0.0059 & 0.99986 & 0.00590 \\
$020-011$ & 1.00010 & 0.00010 & 1.0000 & 0.0059 & 1.00010 & 0.00590 \\
$020-012$ & 1.00119 & 0.00010 & 1.0000 & 0.0059 & 1.00119 & 0.00591 \\
$020-013$ & 0.99113 & 0.00010 & 1.0000 & 0.0059 & 0.99113 & 0.00585 \\
$020-014$ & 0.99335 & 0.00010 & 1.0000 & 0.0059 & 0.99335 & 0.00586 \\
$020-015$ & 1.00256 & 0.00010 & 1.0000 & 0.0059 & 1.00256 & 0.00592 \\
\hline & & & & & &
\end{tabular}





\section{APPENDIX B: DETAILED RESULTS FOR KENO-VI}

All uncertainties reported in this appendix are at the one sigma level. The Monte Carlo and experimental uncertainty values are absolute uncertainties and are reported in $\Delta k_{\text {eff }}$ units. The cross-section uncertainty values are relative uncertainties and are reported in $\Delta k_{\text {eff }} / k_{\text {eff }}$ units.

Table B.1. Detailed multigroup results for KENO-VI HMF systems

\begin{tabular}{cccccccc}
\hline Case & $\boldsymbol{k}_{\text {eff }}$ & $\boldsymbol{\sigma}$ & $\begin{array}{c}\text { Expected } \\
\boldsymbol{k}_{\text {eff }}\end{array}$ & $\begin{array}{c}\text { Experimental } \\
\text { uncertainty }\end{array}$ & $\mathbf{C / E}$ & $\begin{array}{c}\mathbf{C} / \mathbf{E} \\
\text { uncertainty }\end{array}$ & $\begin{array}{c}\text { Cross-section } \\
\text { uncertainty }\end{array}$ \\
\hline $005-001$ & 0.99696 & 0.00010 & 1.0000 & 0.0036 & 0.99696 & 0.00359 & 0.01579 \\
$005-002$ & 0.99668 & 0.00010 & 1.0007 & 0.0036 & 0.99598 & 0.00358 & 0.01723 \\
$005-003$ & 0.99717 & 0.00010 & 0.9996 & 0.0036 & 0.99757 & 0.00359 & 0.01709 \\
$005-004$ & 0.99043 & 0.00010 & 0.9989 & 0.0036 & 0.99152 & 0.00357 & 0.01675 \\
$005-005$ & 0.99886 & 0.00010 & 0.9980 & 0.0036 & 1.00086 & 0.00361 & 0.01583 \\
$005-006$ & 0.99800 & 0.00010 & 0.9987 & 0.0036 & 0.99930 & 0.00360 & 0.01563 \\
$008-001$ & 0.99660 & 0.00010 & 0.9989 & 0.0016 & 0.99770 & 0.00160 & 0.01066 \\
$009-001$ & 0.99521 & 0.00010 & 0.9992 & 0.0015 & 0.99601 & 0.00150 & 0.01227 \\
$009-002$ & 0.99535 & 0.00010 & 0.9992 & 0.0015 & 0.99615 & 0.00150 & 0.01184 \\
$010-001$ & 0.99735 & 0.00010 & 0.9992 & 0.0015 & 0.99815 & 0.00150 & 0.01201 \\
$010-002$ & 0.99737 & 0.00010 & 0.9992 & 0.0015 & 0.99817 & 0.00150 & 0.01182 \\
$011-001$ & 0.99575 & 0.00010 & 0.9989 & 0.0015 & 0.99684 & 0.00150 & 0.01054 \\
$013-001$ & 0.99737 & 0.00010 & 0.9990 & 0.0015 & 0.99837 & 0.00150 & 0.01114 \\
$024-001$ & 0.99769 & 0.00005 & 0.9990 & 0.0015 & 0.99869 & 0.00150 & 0.01087 \\
$080-001$ & 1.00796 & 0.00010 & 1.0000 & 0.0012 & 1.00796 & 0.00121 & 0.01169 \\
\hline
\end{tabular}

Table B.2. Detailed continuous energy results for KENO-VI HMF systems

\begin{tabular}{ccccccc}
\hline Case & $\boldsymbol{k}_{\text {eff }}$ & $\boldsymbol{\sigma}$ & $\begin{array}{c}\text { Expected } \\
\boldsymbol{k}_{\text {eff }}\end{array}$ & $\begin{array}{c}\text { Experimental } \\
\text { uncertainty }\end{array}$ & $\mathbf{C} / \mathbf{E}$ & $\begin{array}{c}\mathbf{C} / \mathbf{E} \\
\text { uncertainty }\end{array}$ \\
\hline $005-001$ & 0.99601 & 0.00010 & 1.0000 & 0.0036 & 0.99601 & 0.00359 \\
$005-002$ & 0.99460 & 0.00010 & 1.0007 & 0.0036 & 0.99391 & 0.00358 \\
$005-003$ & 0.99468 & 0.00010 & 0.9996 & 0.0036 & 0.99508 & 0.00359 \\
$005-004$ & 0.98798 & 0.00010 & 0.9989 & 0.0036 & 0.98906 & 0.00357 \\
$005-005$ & 0.99544 & 0.00010 & 0.9980 & 0.0036 & 0.99744 & 0.00360 \\
$005-006$ & 0.99539 & 0.00010 & 0.9987 & 0.0036 & 0.99668 & 0.00359 \\
$008-001$ & 0.99577 & 0.00010 & 0.9989 & 0.0016 & 0.99687 & 0.00160 \\
$009-001$ & 0.99414 & 0.00010 & 0.9992 & 0.0015 & 0.99494 & 0.00150 \\
$009-002$ & 0.99473 & 0.00010 & 0.9992 & 0.0015 & 0.99553 & 0.00150 \\
$010-001$ & 0.99641 & 0.00010 & 0.9992 & 0.0015 & 0.99721 & 0.00150 \\
$010-002$ & 0.99674 & 0.00010 & 0.9992 & 0.0015 & 0.99754 & 0.00150 \\
$011-001$ & 0.99457 & 0.00010 & 0.9989 & 0.0015 & 0.99566 & 0.00150 \\
$013-001$ & 0.99591 & 0.00010 & 0.9990 & 0.0015 & 0.99691 & 0.00150 \\
$024-001$ & 0.99650 & 0.00005 & 0.9990 & 0.0015 & 0.99749 & 0.00150 \\
$080-001$ & 1.00925 & 0.00010 & 1.0000 & 0.0012 & 1.00925 & 0.00122 \\
\hline
\end{tabular}

Table B.3. Detailed multigroup results for KENO-VI IMF systems

\begin{tabular}{cccccccc}
\hline Case & $\boldsymbol{k}_{\text {eff }}$ & $\boldsymbol{\sigma}$ & $\begin{array}{c}\text { Expected } \\
\boldsymbol{k}_{\text {eff }}\end{array}$ & $\begin{array}{c}\text { Experimental } \\
\text { uncertainty }\end{array}$ & $\mathbf{C} / \mathbf{E}$ & $\begin{array}{c}\mathbf{C} / \mathbf{E} \\
\text { uncertainty }\end{array}$ & $\begin{array}{c}\text { Cross-section } \\
\text { uncertainty }\end{array}$ \\
\hline $019-001$ & 1.00876 & 0.00010 & 1.0008 & 0.0035 & 1.00795 & 0.00353 & 0.01231 \\
$019-002$ & 1.00805 & 0.00010 & 1.0007 & 0.0042 & 1.00734 & 0.00423 & 0.01207 \\
\hline
\end{tabular}


Table B.4. Detailed continuous energy results for KENO-VI IMF systems

\begin{tabular}{ccccccc}
\hline Case & $\boldsymbol{k}_{\text {eff }}$ & $\boldsymbol{\sigma}$ & $\begin{array}{c}\text { Expected } \\
\boldsymbol{k}_{\text {eff }}\end{array}$ & $\begin{array}{c}\text { Experimental } \\
\text { uncertainty }\end{array}$ & $\boldsymbol{C} / \mathbf{E}$ & $\begin{array}{c}\mathbf{C} / \mathbf{E} \\
\text { uncertainty }\end{array}$ \\
\hline $019-001$ & 1.00615 & 0.00010 & 1.0008 & 0.0035 & 1.00534 & 0.00352 \\
$019-002$ & 1.00604 & 0.00010 & 1.0007 & 0.0042 & 1.00534 & 0.00422 \\
\hline
\end{tabular}

Table B.5. Detailed multigroup results for KENO-VI MCT systems

\begin{tabular}{|c|c|c|c|c|c|c|c|}
\hline Case & $\boldsymbol{k}_{\text {eff }}$ & $\sigma$ & $\begin{array}{c}\text { Expected } \\
k_{\text {eff }} \\
\end{array}$ & $\begin{array}{c}\text { Experimental } \\
\text { uncertainty }\end{array}$ & $\mathbf{C} / \mathbf{E}$ & $\begin{array}{c}\mathrm{C} / \mathrm{E} \\
\text { uncertainty }\end{array}$ & $\begin{array}{c}\text { Cross-section } \\
\text { uncertainty }\end{array}$ \\
\hline $008-001$ & 0.99735 & 0.00007 & 0.9997 & 0.0032 & 0.99765 & 0.00319 & 0.00936 \\
\hline 008-002 & 0.99863 & 0.00010 & 1.0008 & 0.0030 & 0.99783 & 0.00299 & 0.00966 \\
\hline 008-003 & 0.99837 & 0.00009 & 1.0023 & 0.0038 & 0.99608 & 0.00378 & 0.00968 \\
\hline 008-004 & 1.00178 & 0.00010 & 1.0015 & 0.0047 & 1.00027 & 0.00470 & 0.00962 \\
\hline 008-005 & 1.00222 & 0.00010 & 1.0022 & 0.0056 & 1.00002 & 0.00559 & 0.00947 \\
\hline 008-006 & 1.00164 & 0.00010 & 1.0028 & 0.0065 & 0.99884 & 0.00648 & 0.00940 \\
\hline 008-007 & 0.99666 & 0.00010 & 1.0023 & 0.0039 & 0.99437 & 0.00387 & 0.00968 \\
\hline 008-008 & 0.99692 & 0.00009 & 1.0023 & 0.0039 & 0.99463 & 0.00387 & 0.00966 \\
\hline 008-009 & 0.99706 & 0.00009 & 1.0023 & 0.0039 & 0.99477 & 0.00387 & 0.00966 \\
\hline 008-010 & 0.99642 & 0.00010 & 1.0023 & 0.0039 & 0.99414 & 0.00387 & 0.00965 \\
\hline 008-011 & 0.99583 & 0.00010 & 1.0023 & 0.0039 & 0.99355 & 0.00387 & 0.00965 \\
\hline 008-012 & 0.99529 & 0.00010 & 1.0023 & 0.0039 & 0.99301 & 0.00387 & 0.00964 \\
\hline 008-013 & 0.99637 & 0.00010 & 1.0023 & 0.0039 & 0.99408 & 0.00387 & 0.00967 \\
\hline 008-014 & 0.99605 & 0.00009 & 1.0023 & 0.0039 & 0.99377 & 0.00387 & 0.00965 \\
\hline 008-015 & 0.99594 & 0.00009 & 1.0023 & 0.0039 & 0.99366 & 0.00387 & 0.00965 \\
\hline 008-016 & 0.99487 & 0.00010 & 1.0023 & 0.0039 & 0.99259 & 0.00386 & 0.00964 \\
\hline 008-017 & 0.99551 & 0.00010 & 1.0023 & 0.0041 & 0.99323 & 0.00406 & 0.00963 \\
\hline 008-018 & 0.99503 & 0.00010 & 1.0023 & 0.0041 & 0.99275 & 0.00406 & 0.00963 \\
\hline 008-019 & 0.99538 & 0.00010 & 1.0023 & 0.0041 & 0.99310 & 0.00406 & 0.00962 \\
\hline 008-020 & 0.99518 & 0.00010 & 1.0023 & 0.0041 & 0.99290 & 0.00406 & 0.00962 \\
\hline 008-021 & 0.99481 & 0.00010 & 1.0023 & 0.0041 & 0.99253 & 0.00406 & 0.00962 \\
\hline 008-022 & 0.99539 & 0.00010 & 1.0023 & 0.0041 & 0.99310 & 0.00406 & 0.00962 \\
\hline $008-023$ & 0.99492 & 0.00010 & 1.0023 & 0.0041 & 0.99264 & 0.00406 & 0.00963 \\
\hline $008-024$ & 0.99565 & 0.00010 & 1.0023 & 0.0041 & 0.99336 & 0.00406 & 0.00963 \\
\hline $008-025$ & 0.99521 & 0.00010 & 1.0023 & 0.0041 & 0.99292 & 0.00406 & 0.00963 \\
\hline $008-026$ & 0.99493 & 0.00010 & 1.0023 & 0.0041 & 0.99265 & 0.00406 & 0.00962 \\
\hline $008-027$ & 0.99485 & 0.00010 & 1.0023 & 0.0040 & 0.99256 & 0.00396 & 0.00963 \\
\hline 008-028 & 0.99523 & 0.00008 & 1.0023 & 0.0040 & 0.99295 & 0.00396 & 0.00962 \\
\hline
\end{tabular}


Table B.6. Detailed continuous energy results for KENO-VI MCT systems

\begin{tabular}{ccccccc}
\hline Case & $\boldsymbol{k}_{\text {eff }}$ & $\boldsymbol{\sigma}$ & $\begin{array}{c}\text { Expected } \\
\boldsymbol{k}_{\text {eff }}\end{array}$ & $\begin{array}{c}\text { Experimental } \\
\text { uncertainty }\end{array}$ & $\mathbf{C} / \mathbf{E}$ & $\mathbf{C} / \mathbf{E}$ Unc. \\
\hline $008-001$ & 0.99328 & 0.00007 & 0.9997 & 0.0032 & 0.99358 & 0.00318 \\
$008-002$ & 0.99574 & 0.00010 & 1.0008 & 0.0030 & 0.99495 & 0.00298 \\
$008-003$ & 0.99664 & 0.00010 & 1.0023 & 0.0038 & 0.99435 & 0.00377 \\
$008-004$ & 0.99968 & 0.00010 & 1.0015 & 0.0047 & 0.99818 & 0.00469 \\
$008-005$ & 1.00081 & 0.00010 & 1.0022 & 0.0056 & 0.99862 & 0.00558 \\
$008-006$ & 1.00031 & 0.00010 & 1.0028 & 0.0065 & 0.99752 & 0.00647 \\
$008-007$ & 0.99456 & 0.00010 & 1.0023 & 0.0039 & 0.99227 & 0.00386 \\
$008-008$ & 0.99476 & 0.00010 & 1.0023 & 0.0039 & 0.99248 & 0.00386 \\
$008-009$ & 0.99458 & 0.00010 & 1.0023 & 0.0039 & 0.99230 & 0.00386 \\
$008-010$ & 0.99394 & 0.00010 & 1.0023 & 0.0039 & 0.99166 & 0.00386 \\
$008-011$ & 0.99354 & 0.00010 & 1.0023 & 0.0039 & 0.99126 & 0.00386 \\
$008-012$ & 0.99291 & 0.00010 & 1.0023 & 0.0039 & 0.99063 & 0.00386 \\
$008-013$ & 0.99410 & 0.00010 & 1.0023 & 0.0039 & 0.99182 & 0.00386 \\
$008-014$ & 0.99419 & 0.00010 & 1.0023 & 0.0039 & 0.99190 & 0.00386 \\
$008-015$ & 0.99376 & 0.00010 & 1.0023 & 0.0039 & 0.99148 & 0.00386 \\
$008-016$ & 0.99298 & 0.00010 & 1.0023 & 0.0039 & 0.99070 & 0.00386 \\
$008-017$ & 0.99330 & 0.00010 & 1.0023 & 0.0041 & 0.99102 & 0.00406 \\
$008-018$ & 0.99279 & 0.00010 & 1.0023 & 0.0041 & 0.99051 & 0.00405 \\
$008-019$ & 0.99298 & 0.00010 & 1.0023 & 0.0041 & 0.99070 & 0.00405 \\
$008-020$ & 0.99270 & 0.00009 & 1.0023 & 0.0041 & 0.99042 & 0.00405 \\
$008-021$ & 0.99249 & 0.00010 & 1.0023 & 0.0041 & 0.99021 & 0.00405 \\
$008-022$ & 0.99303 & 0.00009 & 1.0023 & 0.0041 & 0.99075 & 0.00405 \\
$008-023$ & 0.99256 & 0.00010 & 1.0023 & 0.0041 & 0.99028 & 0.00405 \\
$008-024$ & 0.99309 & 0.00010 & 1.0023 & 0.0041 & 0.99081 & 0.00405 \\
$008-025$ & 0.99274 & 0.00010 & 1.0023 & 0.0041 & 0.99047 & 0.00405 \\
$008-026$ & 0.99258 & 0.00010 & 1.0023 & 0.0041 & 0.99030 & 0.00405 \\
$008-027$ & 0.99274 & 0.00010 & 1.0023 & 0.0040 & 0.99046 & 0.00395 \\
$008-028$ & 0.99280 & 0.00010 & 1.0023 & 0.0040 & 0.99052 & 0.00395 \\
\hline
\end{tabular}

